\title{
Nanomaterials-patterned flexible electrodes for wearable health monitoring: a review
}

\author{
Md Mehdi Hasan ${ }^{1,2}$ and Md Milon Hossain ${ }^{1,3, *}$ (1) \\ ${ }^{1}$ Department of Textile Engineering, Khulna University of Engineering \& Technology, Khulna 9203, Bangladesh \\ ${ }^{2}$ UNAM - National Nanotechnology Research Center and, Institute of Materials Science and Nanotechnology, Bilkent University, \\ Ankara 06800, Turkey \\ ${ }^{3}$ Department of Textile Engineering, Chemistry and Science, North Carolina State University, Raleigh 27606, USA
}

Received: 7 January 2021

Accepted: 8 June 2021

Published online:

28 June 2021

(C) The Author(s), under exclusive licence to Springer Science+Business Media, LLC, part of Springer Nature 2021

\begin{abstract}
Electrodes fabricated on a flexible substrate are a revolutionary development in wearable health monitoring due to their lightweight, breathability, comfort, and flexibility to conform to the curvilinear body shape. Different metallic thin-film and plastic-based substrates lack comfort for long-term monitoring applications. However, the insulating nature of different polymer, fiber, and textile substrates requires the deposition of conductive materials to render interactive functionality to substrates. Besides, the high porosity and flexibility of fiber and textile substrates pose a great challenge for the homogenous deposition of active materials. Printing is an excellent process to produce a flexible conductive textile electrode for wearable health monitoring applications due to its low cost and scalability. This article critically reviews the current state of the art of different textile architectures as a substrate for the deposition of conductive nanomaterials. Furthermore, recent progress in various printing processes of nanomaterials, challenges of printing nanomaterials on textiles, and their health monitoring applications are described systematically.
\end{abstract}

Handling Editor: Maude Jimenez.

Address correspondence to E-mail: mhossai5@ncsu.edu 


\section{GRAPHICAL ABSTRACT}

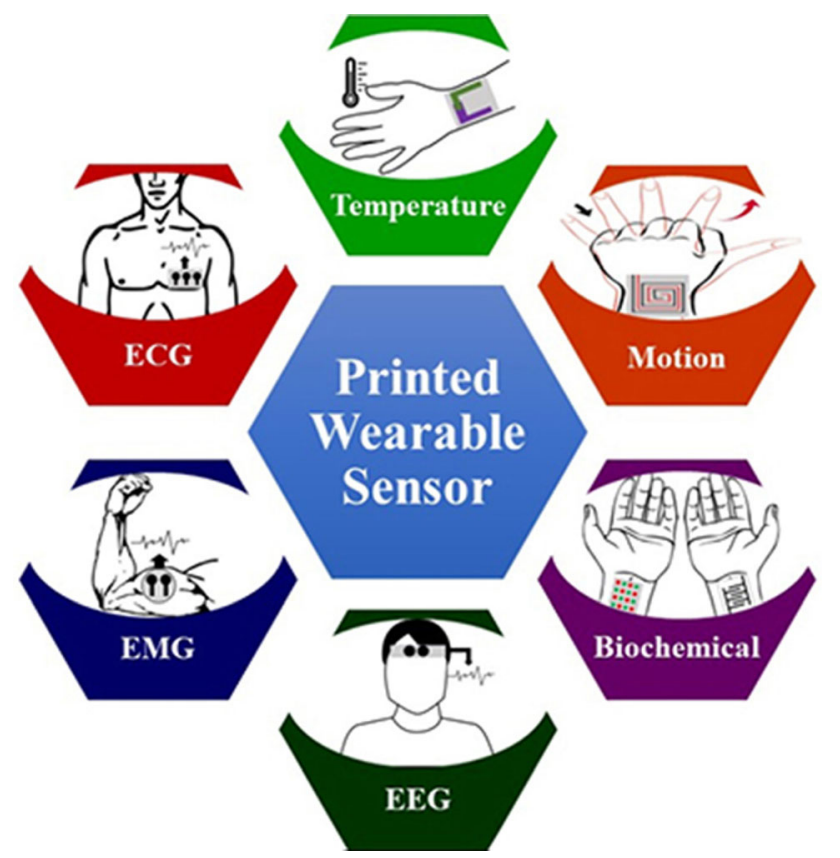

\section{Introduction}

Wearable electronics are receiving tremendous attention from consumers and are expected to redefine human-computer interactions. Different flexible substrates have been explored to fabricate wearable devices for body conformable electronics. Among different flexible substrates, textiles offer high surface area [1], porosity [2], air and moisture permeability $[3,4]$, and maintain the microclimate of skin to ensure comfort [5] compared to flexible plastic substrates [6] for developing truly wearable electronics [7-9]. Electrodes based on textiles are currently ubiquitous for monitoring physiological and environmental phenomena, and human-computer interactions [10-13], personal thermal management [14-17], antennas for tracking and communicating [18-21], energy harvesting [22-25], and storing devices [26-29]. Fibershaped energy storage [30-33] and harvester $[22,34,35]$ devices provide opportunities to fabricate self-powered wearable devices [36-38] eliminating the need for an external power source. Fiber electrodes have demonstrated sensitivity toward physical changes [12], chemical compounds in the body fluids [39-42], and biopotential signals [43-48], which provide opportunities for real-time health monitoring, diagnosis, and therapeutics [49-53]. The integration of functional materials with fibers/textiles materials is an indispensable requirement to transform insulating substrates into conductive textiles and realize the potential of textile substrates for wearable applications. Interdisciplinary efforts for the advancement of textiles technology, nanotechnology, material science, and miniaturization of electronics are facilitating the development of textile electrodes for wearable health monitoring. Widely explored materials include metallic nanoparticles [5, 40], intrinsically conductive polymer (ICP) [52, 54], and carbonaceous materials, e.g., carbon nanotube (CNT) [55], graphene [56], carbon black (CB) [57], activated carbon [58], to impart electrical conductivity in textiles. Recent research approaches involve preparing a suspension of these materials to form conductive inks, printing paste, and applied to the textile substrates using different processes [54, 59-65]. 
Coating [54], physical and chemical vapor deposition [59], electroless deposition [5, 60], wet spinning [61, 62], biscrolling [63], printing [64, 65] have been extensively studied to develop conductive textiles. In recent years, printing technology has gained a lot of interest in scientific communities due to its ease of processing and high scalability, and excellent design freedom of depositing materials on-demand with precise control while maintaining the breathability and flexibility of textiles. Highly localized deposition of active materials provides opportunities for integrating multiple devices with different functionality and low material wastage. However, this technique also poses some challenges and the ink system often requires to be specially formulated [66] for the rough and porous textile surface. Therefore, it is of the utmost importance to obtain proper insights on different printing technologies, their challenges, and the potential for the development of next-generation wearable electronics. Wearable sensor to monitor different physiological information and placement of the sensor in different body parts is illustrated in Fig. 1.

This paper comprehensively reviews the development of printed textile electrodes with a specific focus on wearable health monitoring applications. The first section discussed different textile architectures used as a substrate for electrode fabrication. Unlike nanomanufacturing, the printing process is very suitable for bulk-scale and roll-roll manufacturing of flexible electronic devices for large-area applications. Therefore, in the following section, different printing technologies like screen printing, gravure printing, flexographic printing, inkjet printing, and 3D printing used for electroactive materials printing on textile substrates various have been elaborately discussed. The printing resolution and throughput of different printing processes and compatibility of printing techniques have been summarized for providing the reader a better understanding of printed textile electrodes. Finally, the application of printed textile electrodes for wearable health monitoring and sensing mechanisms is presented which includes the non-invasive acquisition of biopotential signals and chemical sensing of biomarkers. The challenges of the printing process on the textile substrates and an outlook were also outlined before concluding the review.

\section{Flexible architectures for printed electrode fabrication}

There are a variety of materials available for flexible electrode fabrication which not only show variation in chemical constituent but also physical and surface characteristics. Porous textile as a substrate is popular due to its excellent flexibility, breathability, and comfort. The textile substrates manufacturing process starts with the processing of fibers, which are long flexible forms of polymeric materials with a large length-to-diameter ratio [67] and broadly categorized as natural and synthetic fibers. These fibers are onedimensional in shape and have poor mechanical strength to be used as a free-standing substrate. Natural fibers contain different functional groups in their chemical structures based on the origin, and
Figure 1 a Printed physiological parameter monitoring sensor. $\mathbf{b}$ An overview of different applications of wearable flexible sensors worn on various body parts.

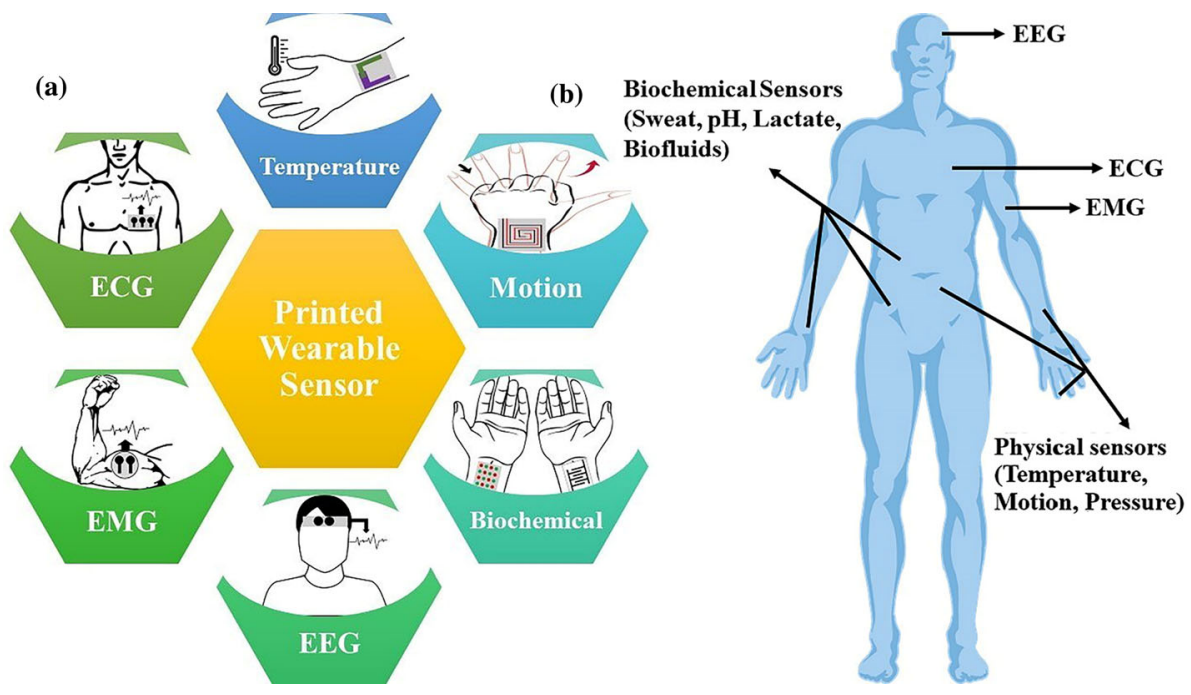


demonstrated affinity to different chemicals. Therefore, it is required to select appropriate conductive materials to impart conductivity to natural fibers. Natural fibers are derived from plants, animals, and minerals, and exist as staple fibers unlike continuous filaments of synthetic fiber (except silk). The properties of these fibers are largely dependent on the staple length, chemical architecture, properties of constituent polymers, and the geometry and morphology of the fibers [67, 68]. In contrast, synthetic fibers commonly known as filament are engineered for specific applications and the chemical structure and reactivity of synthetic filament can be tailored as desired. The wide availability of cheap synthetic polymers revolutionized filament production and dominating the fiber market [69]. Popular techniques to produce filaments are wet spinning, melt spinning, and solution spinning, and are in a continuous form which can be cut into shorter staple sizes if required [68]. By combining thousands of fibers and filaments, continuous yarn is produced, and yarns possess sufficient strength to be used as connectors or electrodes for wearable electronic applications [70]. However, irrespective of fiber types, the flexibility of the textile yarn has made them unique as this property allows the yarns to interlace, form loops, and bonded with adhesive to form a two-dimensional planar structure, termed as fabric. Different textile architectures used for the printing of conductive materials are presented in Fig. 2.

While one-dimensional fibers and yarns are suitable as interconnects, two-dimensional fabric structures are extensively used for large-area applications. It is important to note that all printing techniques do not comply with one-dimensional textile structures. For example, screen and inkjet printing is well studied and popular printing process but only implementable on two-dimensional fabrics due to the large

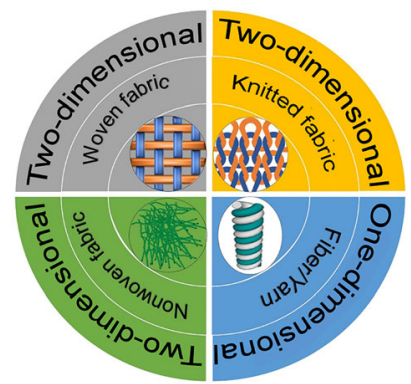

Figure 2 Illustration of different types of textile structures used for electrode fabrication according to the structural dimension. printing head. Although 3D printed fibers and textile structures [71] are receiving growing interest, those are still at the early phase of development and do not often resemble textile properties. Among the planar fabric structures, nonwoven might be isotropic compared to the woven and knit fabric which is highly anisotropic [72]. The isotropic characteristics of nonwoven fabric depend on the fabrication process, and the fiber orientations are highly controlled. Nonwoven fabrics are manufactured by chemical, mechanical, or thermal bonding of short fibers with adhesives and are classified into dry-laid, wet-laid, and spunmelt nonwovens [72], and nonwoven facilitates the addition of conductive polymers during the fabrication process, unlike woven and knit structures. Overall, nonwoven fabrics have better control of surface texture, porosity, and thickness. The nonwoven fabric has a comparatively smoother surface than woven and knit fabrics; however, poor draping, flexibility, and breathability limit the applications of nonwoven fabric for long-term and continuous health monitoring applications [72]. In contrast, both woven and knit fabrics have several derivatives that cause variation in their surface and physical properties $[73,74]$. Though the high elasticity and porosity of knit fabrics have made them more comfortable and desirable for wearable applications, they are more susceptible to dimensional stability and very challenging for inkjet printing due to their porous structure. The intermittent contact between yarns in knitted fabric leads to higher contact resistance making it more complicated to fabricate electrodes with good electrical conductivity. However, providing sufficient electrical conductivity in knitted fabric might be beneficial for highly stretchable strain and pressure sensing for wearable applications [75-77]. Compared to knit fabric, woven fabric shows better dimensional stability and less elasticity providing a relatively robust surface for printing. The resolution of the printed pattern depends on yarn characteristics and fabric structure, and it is difficult to control the surface properties of both woven and knitted fabrics. Compared to flat thinfilm substrates, different challenges are required to overcome for electrode fabrication on textile substrates. Conductive print pastes/inks are easily penetrated in the fiber interstices of planar fabric making it difficult to control the conductive pattern. To solve this issue, high surface energy interface layers are printed first before printing conductive layers [78, 79]. Both natural and synthetic fiber-based substrates and 
their blend have been widely utilized as substrates for printing electrode [80-82]. Although earlier electrodes used to be printed on nonwoven fabrics, later woven fabrics and recently knitted fabrics are used as a substrate for wearable electrode fabrication [80, 83, 84]. The conductivity of printed traces on textile substrates depends on fiber diameter, porosity, surface energy, and tightness factor [80] and is often tailored as required for desired applications.

Several factors require to be carefully considered for the fabrication of wearable fabric devices. Textiles, one of the integral components of human life, have to undergo extreme bending, stretching, and abrasion. Proper morphological and structural designing of the textile devices can ensure required intimate contact with the body and mechanical stability [85-87]. The high-performance sensors are characterized by low response and recovery time. Highly sensitive sensors translate external stress or strain to corresponding electrical signals depending on the transduction mechanism [85, 88]. Some applications require the sensors to have the self-healing ability to reconstruct the conduction network as soon as the external stimuli are removed to ensure accurate signal acquisition, especially when the device is subjected to repeated stress or strain [89-91]. Linearity in signal response is another crucial criterion, i.e., nonlinear response and drifts in response may present additional complexities in the calibration process [92]. Electrochemical sensors require careful biomarker collection as analytes to avoid noisy signals [93, 94]. The sensors may demonstrate an inaccurate response depending on the presence of analytes from the older sample on the electrode area. Proper microfluidics design and possible self-cleaning ability may ensure the reusability of the sensor for analysis [95, 96]. As the fabric devices remain close to the skin, biocompatibility is a necessary parameter to be considered for avoiding skin irritation or injury [97]. To minimize the rigid and bulky components from the devices, the self-powering capability is widely explored. Current research trends include triboelectric nanogenerator (TENG) [98], thermoelectric generator (TEG) [99], bacterial fuel cell [100, 101], photovoltaics [102] textiles to power fabric devices; however, the low energy consumption of the devices is important to fabricate self-powered devices. Research on these parameters may ensure improved performance of the flexible fabric devices compatible with the available rigid consumer products.

\section{Nanomaterials for conductive ink formulation}

The performance of the flexible electrodes depends on the choice of materials for active electrode fabrication. The material should impart high electrical conductivity while maintaining the flexibility and the mechanical properties of the substrate. Moreover, the conductive layer should have environmental stability as well as the ability to sustain external adverse phenomenon, e.g., washing, abrasion, sweating, and continuous mechanical deformations. The nanomaterials used for conductive electrode fabrication can be broadly classified into three classes: (i) metallic nanomaterials [103], (ii) carbon-based nanomaterials [104], and (iii) conductive polymers [105]. Furthermore, flexible electronics have been experiencing a surge in the usage of a new class of materials, i.e., transition metal carbides and nitrides (MXene) in recent years for superior conductivity, dispersibility, and environmental stability [106].

Metal has been widely explored for flexible textile electrode fabrication for the last two decades [107]. Conductive metal nanomaterials are the low-dimensional nanostructures in zero-dimensional (0D) nanoparticles (NPs) or one-dimensional (1D) nanowires (NWs) forms of bulk metals. Popular metalbased functional includes the application of copper $(\mathrm{Cu})$, gold $(\mathrm{Au})$, silver $(\mathrm{Ag})$. Among these, silverbased nanomaterials (Ag NPs and Ag NWs) are the most attractive option [12]. Although gold nanoparticles (Au NPs) have comparable conductivity to silver nanomaterials and resistant to corrosion or oxidation, the cost related to its rarity, and requirement of high temperature and high vacuum for effective deposition have always been driving factors for choosing Ag NPs and Ag NWs over Au NPs. Silver-based nanomaterials have the highest conductivity among the metals, low oxidation rate, and the advantage of easy deposition in the liquid phase has made these materials more attractive to researchers [9, 108, 109]. Copper nanoparticles $(\mathrm{Cu}$ NPs) have shown great promise in recent years as a preferable functional material due to comparable performance to silver nanomaterials in terms of conductivity, low cost, and stability in the presence of oxygen and moisture has made it effective in corrosive conditions $[110,111]$. However, the thermodynamic instability of $\mathrm{Cu}$ NPs poses a challenge due to the formation of a surface oxide layer during 
synthesis in the atmospheric condition [112]. In fact, the stability of metal-based conductive nanomaterials is one of the challenges yet to overcome. Moreover, the surface deposition of metallic nanomaterials requires sintering process. The sintering process is the removal of liquid phase carrier solution to produce a continuous thin film on the substrate [113]. Moreover, nanomaterials often cause problem during inkjet printing by the formation of the coffee ring effect, which is the aggregation of nanomaterials along the edges of a circular droplet [114].

Carbon-based nanomaterials involve all the realms of nanomaterial dimensions, i.e., zero-dimensional carbon quantum dots (CQDs), one-dimensional carbon nanotubes (CNTs), and two-dimensional graphene. Carbonaceous nanomaterials are popular due to the superior mechanical properties, higher electrical and thermal conductivity, and environmental stability [115]. Graphene and CNTs are widely explored for printable functional ink formulation. Graphene is the single layer of carbon atoms in the two-dimensional planar structure. It has demonstrated superior electrical and mechanical properties is thus considered one of the most promising materials in flexible electronics [116]. However, the absence of functional groups makes the dispersion preparation of graphene difficult and oxygen-containing graphene oxide (GO) is used for liquid phase ink preparation [117, 118]. The dispersibility is achieved at the cost of conductivity, i.e., GO is not electrically conductive and cannot be used for conductive electrode fabrication. The GO requires the reduction process to form reduced graphene oxide (rGO), and the performance of the conductive electrodes depends on the extent of the reduction of GO [119]. Carbon nanotube is the cylindrical or tubular form of the single or multi-layer concentric carbon atom or graphene sheets, named single-walled (SWCNT) and multi-walled (MWCNT) carbon nanotube, respectively [120]. Chirality along the graphene sheets dictates the properties, i.e., semiconducting or metallic properties of the CNTs [121]. The conductivity of the CNTs is comparable to the metal; however, the defects produced during the synthesis increase the resistivity of the CNTs [122]. The CNTs show good adhesion to the textile materials [123]. Nevertheless, CNTs pose several challenges during the printing process. Large aspect ratio and van der Waals force drive the formation of large bundles of CNTs that causes clogging in the printer nozzle [124]. This also deteriorates the conductivity as utilization of defect-free separated CNTs is the dominating factors for preserving the CNTs properties [125]. Other carbon-based nanomaterials include carbon black (CB) and activated carbon (AC) which are not widely explored as CNTs and graphene for conductive application [126, 127].

Intrinsically conductive polymers (CPs) are organic materials that exhibit the electrical properties of metals while maintaining the physical and mechanical properties of the polymers [128]. The key factor is the delocalized $\pi$-electron or the conjugation which provides the pathway for the charge transportation along the polymer chain [129]. Widely used CPs include polypyrrole (PPy), polyaniline (PANI), poly(3,4-ethylene dioxythiophene) (PEDOT), polyacetylene, polythiophene for better electrical, mechanical and optical properties, elasticity, solution processability, flexibility along being lightweight [130]. Among these, PEDOT is widely used for printed textile electrode fabrication. PEDOT has high electrical conductivity and stability in the moist atmosphere, and air at high temperatures. PEDOT is generally doped with polyanion, e.g., poly-styrenesulfonate (PSS), to form PEDOT:PSS and becomes water dispersible with good film-forming properties. PEDOT:PSS has a core-shell structure where hydrophobic PEDOT in the core remains surrounded by the hydrophilic PSS [129]. This phenomenon leads to the reduction in the conductivity as PSS hinders the carrier transport along the backbone of the polymer chain and thus requires the removal of excess PSS [131, 132]. Conductive polymers are exciting materials for maintaining the performance of stretchable electrodes due to the inherent elasticity.

\section{Flexible electrode fabrication by various printing processes}

Printing has been widely used as a versatile method to introduce design and color to textile fabrics from ancient times [133]. In recent years, this technique has gained popularity with increased demand in flexible electronic applications. The facility of transferring ink in a highly localized fashion with low chemical consumption, i.e., efficient operation as well as compatibility with a wide range of substrate materials, was the key driver for adopting printing techniques for wearable applications [66]. Conductive inks were first 
applied to polymer substrates and the trend soon followed in the development of e-textile applications due to flexibility and comfortability. Various materials including inorganic metallic nanoparticles $(\mathrm{Ag}$, $\mathrm{Cu}, \mathrm{Ni}, \mathrm{Au}, \mathrm{Al}$ ) and organic carbon-based nanomaterials (carbon black, rGO, graphene, CNT) as well as conductive polymers have been studied to produce conductive inks [134-137]. The inks are formulated by incorporating functional materials into the ink system with additives and binders and dispersed or dissolved in the organic or aqueous solvent [138-140]. Among those, metallic ink based on silver (Ag) has been extensively studied and implemented due to its high room temperature conductivity [141]. In the case of textiles, most of the studies focused on silver $(\mathrm{Ag})$, graphene $(\mathrm{GO}, \mathrm{rGO}), \mathrm{CNT}$, and poly $(3,4-$ ethylene dioxythiophene) polystyrene sulfonate (PEDOT:PSS)-based conductive inks for fabricating electrodes [79, 80, 142-147].

Different printing techniques have been successfully used for printing conductive inks/pastes for a long time, and the most popular printing processes are illustrated in Fig. 3. Contact pattering and noncontact or nozzle-based patterning are the two mechanisms used by the printing techniques $[148,149]$. The contact technique uses a printing plate in direct contact with the substrate, and external pressure is applied which promotes adhesion and penetration of conductive ink into textiles. This technique includes screen printing [146, 150], gravure printing [151, 152], flexographic printing [153], and soft lithography [154]. On the other hand, only the ink comes in contact with the substrate in the noncontact printing process, and thus, this process requires careful controlling of parameters during ink formation for the homogenous spreading of the ink. This technique includes direct inkjet printing [79, 142, 154-157], write printing [158], and aerosol jet printing [159]. Both of these processes have their own merits and limitations. Therefore, it is necessary to optimize the printing parameters and the appropriate printing process is adopted according to the user requirements. Contact printing techniques facilitate large-area printing, whereas nozzle-based systems ensure higher resolution of printing and versatility of materials [141]. Among these printing processes, screen printing is widely used due to the simple setup and roll-roll manufacturing. However, screenprinted pattern resolution is limited as high-resolution images require a small feature size which is driven by mesh count per unit area. Smaller openings disrupt ink penetration through mesh to the substrate and result in non-uniform pattern [160]. Details of screen printing process are discussed in the next section. However, the use of inkjet printing is surging due to the fine details printing and greater flexibility of ink printed on textiles. The inkjet printed pattern is stabilized by high temperature curing [133]. Therefore, selection of substrates, inks, temperature, pressure, etc. is critical to fabricate electrodes and interconnects without affecting the textiles during curing process. Although printing even pattern on textile is difficult than thin film substrates, ink penetration through micro-capillaries results in better anchoring than films [44]. The popular printing techniques used for electrode fabrication are discussed in details in the following sections.

\section{Screen printing}

Screen printing is the most used and well-understood printing technique which is simultaneously used in textile industries to produce the patterned design as well as in the electronic industries to fabricate printed circuit board (PCB) [141]. Screen-printed electrodes have been used in various applications, but this review is limited to the printed electrodes fabricated on textile substrates for wearable health monitoring applications. The screen printing method consists of a substrate, screen or mesh, squeeze, and press bed for transferring print paste to the substrates. Inks are pressed through the stencil screen made of thin, delicate, and fine porous fabric or metal wire net using the squeeze [161]. This technique requires an additional screen preparation step, which is done by closing the pores of the mesh except for the area of the desired pattern through which the inks are transferred [138]. The mesh not only replicates the desired pattern on the substrate but also controls the resolution, size, and deposition thickness. The number of threads per unit area, thread dimension, and applied pressure determine the amount of deposited ink on the substrate [138, 140, 162]. The printed patterns are cured $[163,164]$ to remove the solvent and allow the inks bonded/attached to the substrate properly to provide better functionality. The conductivity of the pattern depends on the active agent as well as the printed structures [141]. Although flatbed screen printing is easy and requires inexpensive equipment, limited resolution and slow 
Figure 3 Illustration of popular printing techniques and their components.

a Screen printing - the squeeze spreads the print paste uniformly and transfers to the substrate through the screen/ mesh. b Gravure printing - ink is transferred to the substrate using a roller with an engraved pattern. c Inkjet printing - ink is deposited on the substrate to form a $2 \mathrm{D}$ pattern using a computer-assisted printer. d $3 \mathrm{D}$ printing - $3 \mathrm{D}$ structure is printed on the substrate using a computer-assisted system.

Here, (a), (b) represent contact printing and (c), (d) represent non-contact printing. e Tradeoff between printing throughput and resolution for several different printing techniques that have been proposed for printed electronics. (a)

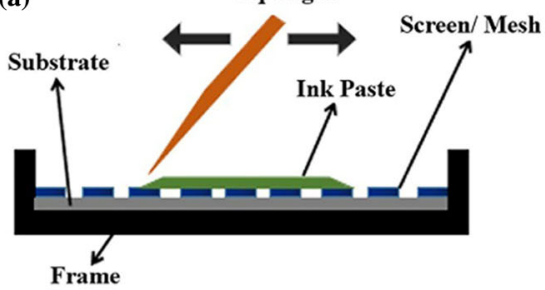

(b)

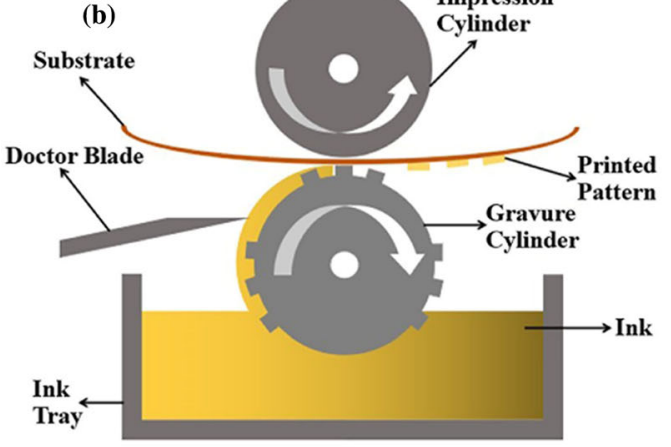

(c)

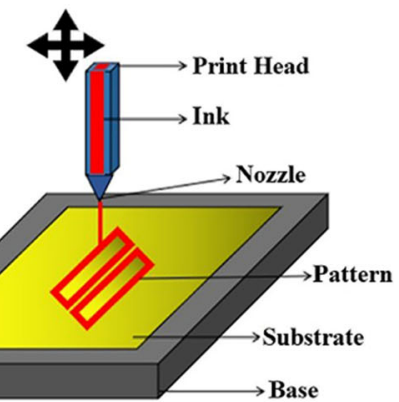

(d)

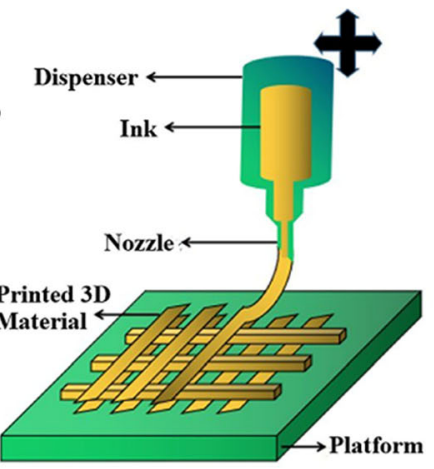

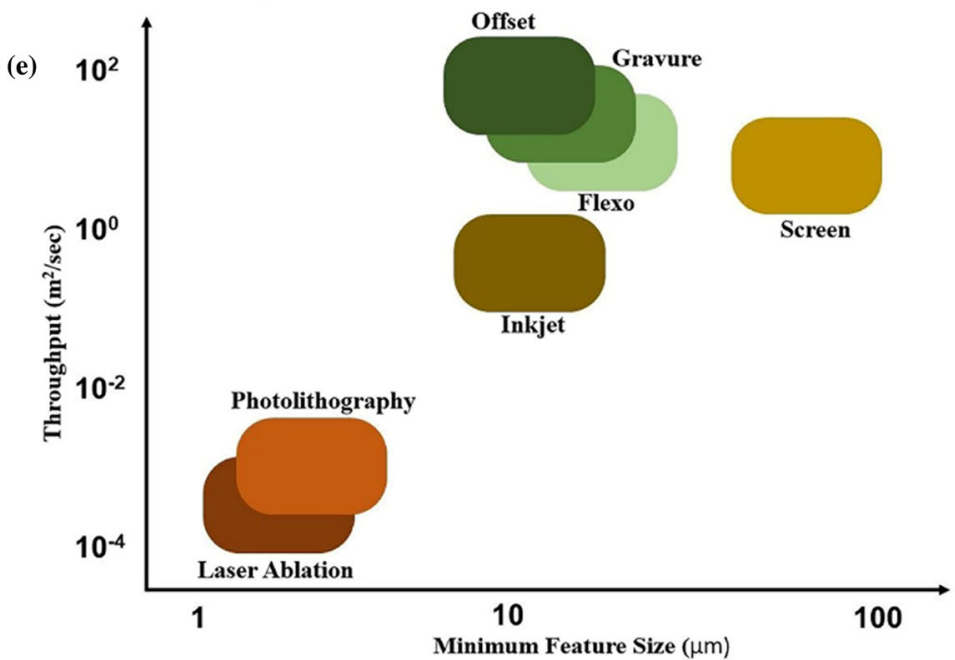

process limit its applications [150]. The issues of flatbed screen printing could be mitigated by the rotary screen printing method. However, rotary screen printing is a comparatively complicated process, costly, and difficult to maintain [165]. The rotary screen-printing method requires ink to be of high viscosity, and low viscosity ink may cause bleeding and unwanted spreading of inks [148]. In contrast, rotary screen printing can produce a pattern with high electrical conductivity. Therefore, it is essential to define the user requirements of electrode materials and optimize the printing process accordingly to obtain better performance. Different modifications and improvements have been carried out in the screen printing process for specific applications.

Screen printing is the most popular method for fabricating textile electrodes for health-care applications, and silver-based ink has been dominating as a functional material. Paul and co-workers screen printed silver paste for various applications, and they printed the polyurethane interface layer first to obtain the desired pattern [64, 167]. Improper adhesion or heterogeneous deposition of conductive ink on textile substrates leads to variation in conductivity. Health monitoring data obtained from such an electrode are unreliable and inconsistent. Gomes et al. studied the resistance variation in silver composite (PE 825) and 
silver conductive ink (PE 828) applied by the screenprinting technique on four different textile substrates such as $100 \%$ cotton, $50 \% / 50 \%$ cotton/polyester, $100 \%$ polyester, and $100 \%$ polyamide [109]. The results showed PE 825 ink forms thick films on the textile substrate resulting in lower flexibility of the produced electrode. However, the conductivity of PE 825 conductive ink printed electrode was superior compared to PE 828. The wash durability of the printed electrode was also evaluated after placing the electrode in plastic wash ball. After 8 washing cycles, sample without encapsulation showed crack in conductive layer and lost conductivity (Fig. 4e-f). Wash durability of electrode materials is crucial for longterm monitoring applications, and the electrodes are required to maintain the functionality against significant number of washing cycles. Compared to regular textiles, wearable electrodes are expected to maintain its electrical functionality up to 25 washing cycles. Different conductive materials have been explored and evaluated to improve their wash durability.

In a series of works, Achilli and co-workers have been trying to fabricate the standard electrode intended for ECG and EMG application by screen printing PEDOT:PSS on cotton fabric. They demonstrated PEDOT:PSS coated cotton has low sheet resistance and achieved wash stability up to 20 cycles maintaining acceptable performance [168-170]. Low contact impedance between skin and electrode is vital for acquiring excellent biopotential signals. Different approaches and modifications have been carried out to improve obtained signal quality. Adding dimethyl sulfoxide (DMSO) and fluorosurfactant in PEDOT:PSS solution demonstrated improved electrical conductivity and wetting properties enabling facile deposition on various substrates [171]. Takamatsu et al. (2015) printed PEDOT:PSS electrode inspired from the Japanese Kimono dyeing process (Fig. 4a-d), using polydimethylsiloxane (PDMS) as a stencil unlike rice paste used in the original process. Hydrophobic PDMS assisted to confine PEDOT:PSS aqueous ink as the desired pattern and recorded sheet resistance of knitted polyester fabric were as low as $230 \Omega$ [166]. The conductivity of electrodes could be tuned by increasing the deposition of conductive inks while sacrificing flexibility. As mentioned earlier, the flexibility of electrodes is an indispensable requirement for wearable health monitoring applications. Therefore, the electrical conductivity of printed electrodes is often traded off by flexibility. Additionally, wearable electrodes undergo different bending forces by the movement of the wearer and electrodes must withstand this bending force for long-term monitoring. Xu et al. (2019) screen-printed graphene/carboxymethyl cellulose (CMC) ink on cotton fabric which reached low resistance of $42.2 \Omega$ and showed outstanding bending stability. The resistance of the graphene/CMC printed electrodes increased only $4.5 \%$ after 1000 bending cycles [146]. The bending resistance of the printed electrodes is further improved by using stretchable electrodes. Knitted fabric has excellent stretchability due to the intermeshing of loops which can extend significantly under tension. However, the porous structure of knit fabric makes the printing process challenging and requires a better understanding of ink chemistry to create a conductive pathway in the knitted fabric. The electrical property of the stretchable textile substrates directly depends on ink permeation into the substrate. The permeation and immobilization of ink into the textile create an intrinsically conductive stretchable path inside the fiber bundles without affecting the structure of the knit fabric and thus can utilize the benefit of stretchable ink as well as the extensibility of knit textile [172].

The screen printing process has greater freedom of designing electrodes in bulk scale. However, the printing parameters have a greater impact on the electrodes and require optimization for better performance. A small amount of ink is transferred by each cycle during screen printing, and inks are mostly deposited on the surface rather than interstice of fabric. The coating of only the top layer of textiles maintains a continuous pattern showing good electrical conductivity. Ink formulation and rheology not only ensure homogeneous deposition but also assist in avoiding common screen printing defects such as thickness variations and pattern bridging. A better understanding of substrate materials and the curing process of the ink is essential to realize high-performance electrodes. Any process parameters of screen printing must not affect the substrate for the reliable functionality and stability of the electrodes.

\section{Gravure printing}

Gravure printing is a promising contact technique that transfers functional inks directly through the physical contact of the engraved structures of the 

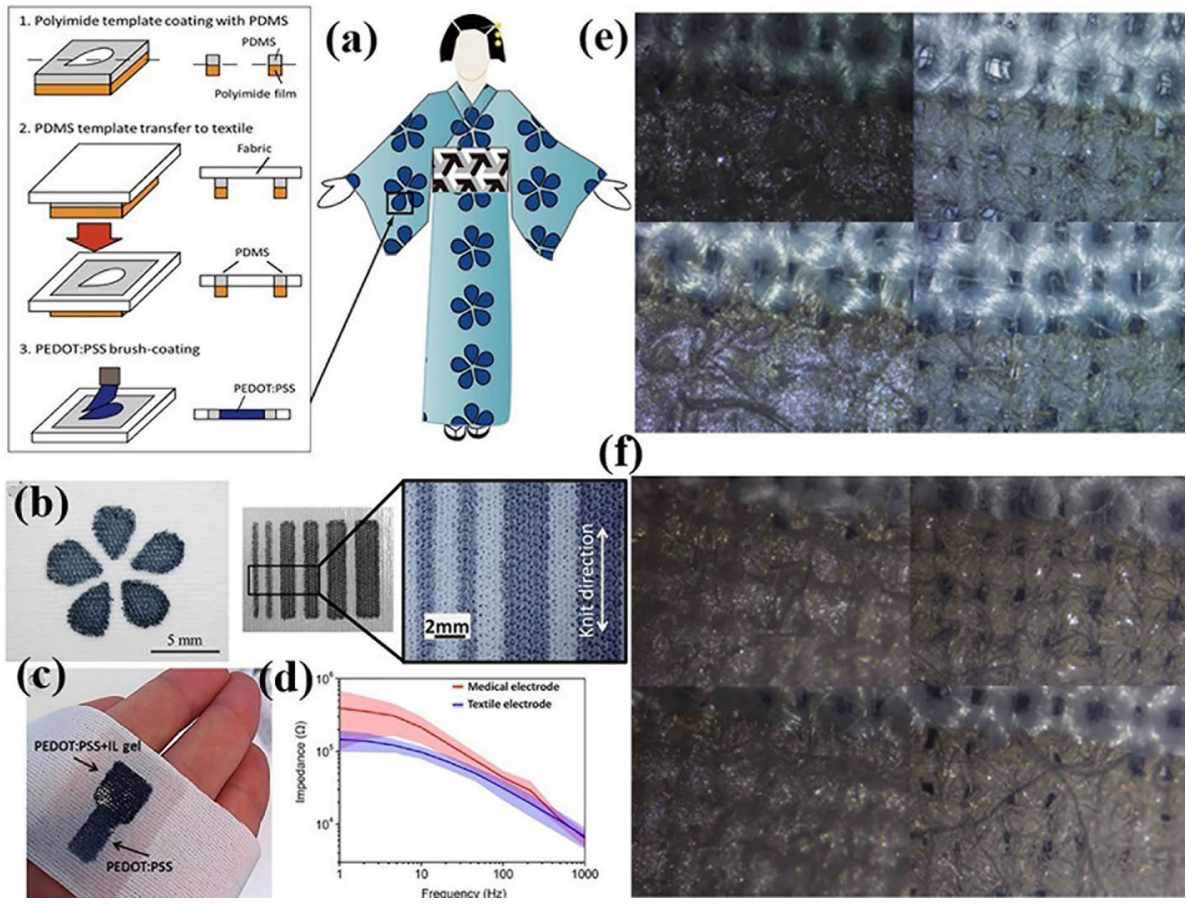

(f)

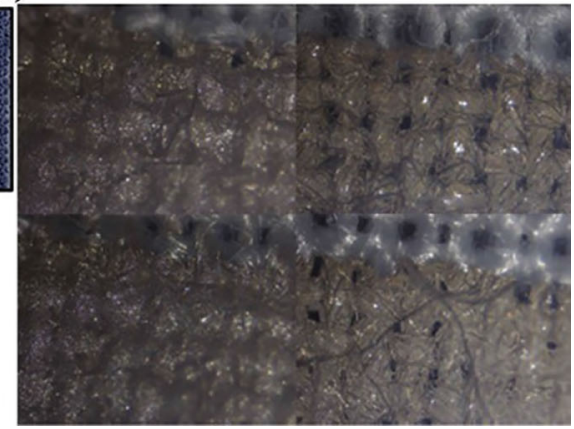

Figure 4 a Process flow of pattering conductive ink on textiles, inspired by Japanese Kimono dyeing method. $\mathbf{b}$ Various PEDOT:PSS conductive patterns formed using Kimono process. c Screen-printed electrode on the textile wristband with ionic liquid (IL) gel. d Impedance spectra of a textile and medical electrode. ([a-d] reproduced from ref. [166], Copyright (C) 2015

substrates [138, 140, 173, 174]. It offers a smooth layer of the high-resolution pattern at roll-roll manufacturing speed and with low viscosity inks. However, the setup is complex and costly, and thus, it is only suitable for large-scale production, unlike the screen printing process for prototype development. The gravure setup consists of a printing roller which is a Cu-plated cylinder with micron-sized cells engraved on the surface where the cylinder stores ink. A flexible doctor blade usually made of metal removes excess ink from the surface, and the ink is transferred to the substrate in the nip between the printing roller and the impression roller [175, 176]. The depth and width of microcell range from $10-30 \mu \mathrm{m}$ and 3-5 $\mu \mathrm{m}$, respectively [141], and 30-70\% ink is transferred during every printing cycle. The rest of the ink, which remains in the cells, gets refilled in the next cycle [177]. Efficient ink transfer and print quality in this technique depend on the ink properties, i.e., solvent and viscosity, feature dimensions on the cylinder and cell spacing, the applied pressure, and the substrate [151, 152, 178]. However, a jagged line is observed while printing a straight line pattern as the straight-
The Author. Published by Springer Nature) e Microscopic image of different conductive silver composite ink screen printed on fabric before washing and $\mathbf{f}$ after 10 washes. ([e $-\mathbf{f}]$ reproduced with permission from ref. [109], Copyright (C) 2020, Society of Dyers and Colourists).

line pattern is created from separated microcells. This is a major obstacle to obtain high-resolution electrodes using gravure printing [150].

Recently, gravure offset printing has been introduced to avoid damage to the substrate due to high shear pressure. This technique utilizes an intermediate roller with an elastic blanket to finally print the pattern on the substrate [179]. Nomura et al. (2018) used screen offset printing, which closely resembles gravure offset printing, to fabricate a silver ink-based blood leakage sensor [143]. Using this method, the ink was first printed on a blanket and a fine pattern was transferred to the cotton fabric without causing bleeding of ink as the blanket absorbed the solvent. The viscosity of the ink increased due to the absorption, preventing blurring, and printed highresolution patterns.

Flexographic printing or simply flexo is a continuous roll-roll manufacturing process similar to gravure printing [141]. The printing process uses a flexible relief plate, an anilox roller with engraved microcavities/cells, and a printing plate called a flexo plate/ relief plate. Unlike the gravure printing 
process, where a gravure cylinder with an engraved cell directly transfers ink to the substrate, ink is first transferred to a relief plate in flexographic printing with raised images from anilox cells. The doctor blade removes the excess ink from the cylinder. The printing plate rotates in contact with the substrate and transfers the desired pattern [133, 180]. The fundamental difference between gravure and flexo printing is an anilox roller responsible for metering ink volume rather than producing patterns. For this reason, gravure printing is called a direct process where flexo printing is attributed as an indirect process. Reliable transfer of ink and producing a highquality pattern is possible with low contact pressure between the printing plate and the substrate [141]. Ink properties, pressure, drying time, and substrate type influence print quality. Spikes and gridlines appear after printing, which is a major challenge to overcome for flexographic printing [176]. Often patterns with excess ink occur due to compression between flexo plate and substrate which leads to poor image stability and resolution [148]. This method is widely used in the printed electronics industry using thin-film substrates [181-184]. Flexographic printing for the fabrication of the textile electrode is yet to be explored.

\section{Inkjet printing}

Inkjet printing is a solution-based functional material patterning technique that deposits nanomaterials in colloidal dispersion form on the substrate [185-187]. This technique is still in the early stage of development with growing interest among the scientific community due to its advantages of rapid and accurate deposition of a wide range of functional materials, compatibility with various substrates, lowtemperature operation, low material wastage, and easy deposition over a large area [187]. The system consists of the ink reservoir and print head with nozzle, and the process starts with digital design preparation which forms patterns on substrates in three core steps: generation of droplets, spreading of ink, and drying. It can be utilized for pressure-sensitive and non-planar substrates, thanks to its noncontact maskless approach [188]. The ink droplets can be deposited in two available modes of operation, i.e., continuous inkjet (CIJ) and drop-on-demand (DoD) $[186,189,190]$. In the CIJ system, pressurized ink is continuously ejected through the nozzle which breaks up into uniform drops using surface tension, and the deflection of the droplets is controlled electrically using discharge electrodes. On the other hand, the DoD system works by depositing a single drop at a time upon activation. DoD utilizes the generation of the pressure pulse in a fluid-filled cavity behind the nozzle to eject the functional ink droplet and is characterized by a small droplet diameter, high accuracy, and better quality of the printed pattern. CIJ method is widely used in the manufacturing industries, whereas the DoD system dominates the novel material printing process [190]. Recently developed double-shot inkjet printing process [191] and reactive inkjet printing process $[192,193]$ utilize two nozzles for functionality. The double shot technique deposits two types of ink at the same place, whereas the reactive inkjet printing process combines materials deposition and chemical reaction. For the inkjet printing technique, some parameters should be carefully considered to control the quality of the printed pattern. For example, the nozzle must be at an optimum distance from the substrate to avoid satellite droplet formation and to ensure accurate pattern printing [22, 23]. Additionally, inter-droplet distance should be optimum to circumvent discontinuous patterns and agglomeration of particles caused by the distance variations [194]. The coffee ring effect [186, 195] is a common phenomenon that occurs due to differential evaporation across the droplet, and different strategies $[196,197]$ have been proposed to overcome the coffee ring effect. However, the ink system imposes several restrictions such as cost and requirement of hightemperature curing requires careful engineering of ink to utilize this technique for printing on textile substrates [198-200]. Recently emerged 2D materialsbased ink demonstrated excellent compatibility of printing on various textile substrates using the inkjet process [201-203].

Inkjet printing received significant attention in the past decade to produce flexible and wearable electrodes. A wide variety of materials have been inkjet printed on the textile substrate for various wearable applications. Tao et al. (2015) printed bioactive silk ink on gloves by inkjet printing process for biochemical sensing applications. The ink supports the addition of other functional materials, i.e., dopants and bioactive compounds while maintaining compatibility with the inkjet process and a novel "silk ink" formulation can be produced. The ink was 
prepared in an aqueous system without any additives or surfactants and eliminates the requirement of organic and inorganic solvents [204]. Karim and coworkers inkjet-printed graphene-based ink on cotton fabric after surface treatment with hydroxyl functional polystyrene emulsion polymer (Fig. 5a, 5b). The pre-treatment ensured continuous regular print on the rough surface of cotton fabric. The sheet resistance of the fabric decreased by three orders of magnitude. The nanoparticle pre-treatment on the fabric worked as a receptor layer for water-based rGO ink and contributed to reducing sheet resistance [79]. To utilize the excellent electrical conductivity of silver-based ink, a composite ink of silver-graphene was prepared by the same research group and inkjet printed on cotton fabric. (Fig. 5c) The sheet resistance decreased to $2.11 \Omega$ due to the synergistic effect of composite ink [142]. However, using additivities to ensure stable inkjet printing has a detrimental impact on electrical conductivity. Shahariar et al. (2019) demonstrated a novel and conformal inkjet printing of reactive silver ink on polyethylene terephthalate (PET) fabric without an interface layer (Fig. 5d) and achieved low sheet resistance of $0.2 \pm 0.025 \Omega$ and $0.9 \pm 0.02 \Omega$ for woven and knit structures, respectively [80]. The in situ heat curing further decreased the sheet resistance by two orders of magnitudes. The ink showed a tendency of staying at the junction rather than spreading when the ink droplet size is larger than the fiber diameter. However, after heat curing, the ink formed a mesh-like structure and a continuous conductive line was produced. Unlike silver nanoparticle-based ink, this particle-free reactive silver ink does not clog the nozzle of the printer which is a major problem of the inkjet printing process. Moreover, ink printed on knit fabric showed no
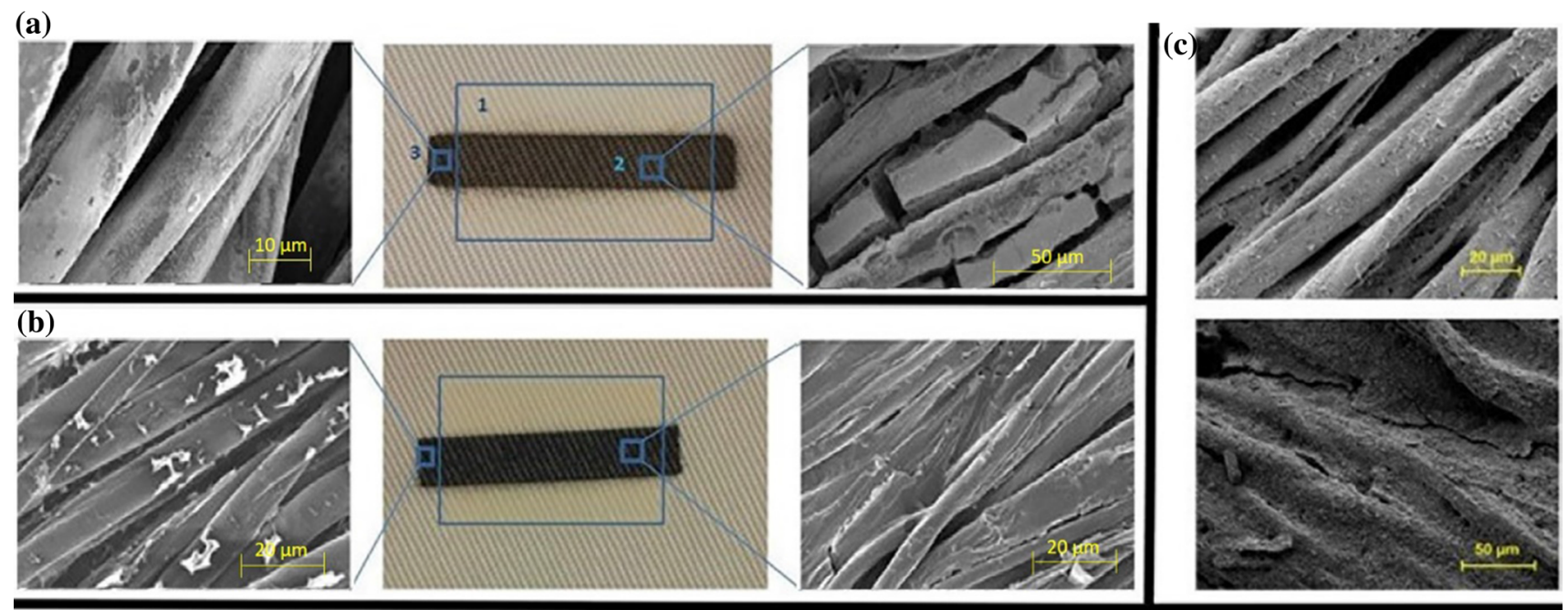

(d)
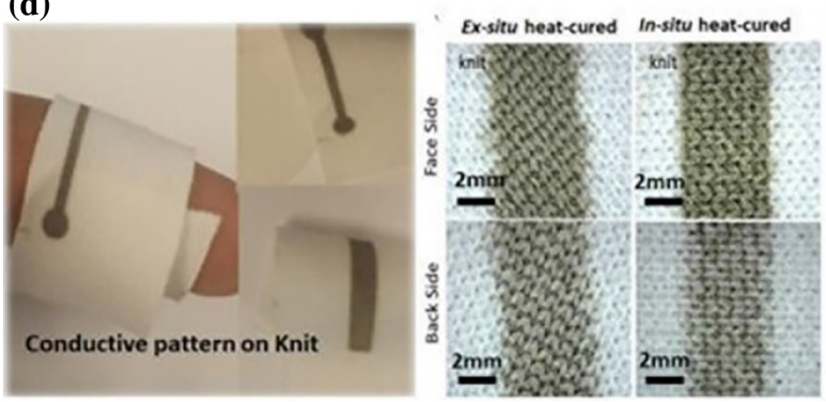

Figure 5 a SEM images of inkjet-printed silver ink onto untreated (left) and nanoparticles printed (right) cotton fabric. b SEM images of inkjet-printed rGO ink onto untreated (left) and NP1 nanoparticles printed (right) cotton fabric. ([a-b] reproduced from ref. [79], Copyright (C) 2017 The Author. Published by The Royal Society of Chemistry) c SEM images of inkjet-printed graphene-silver composite ink onto untreated (top) and

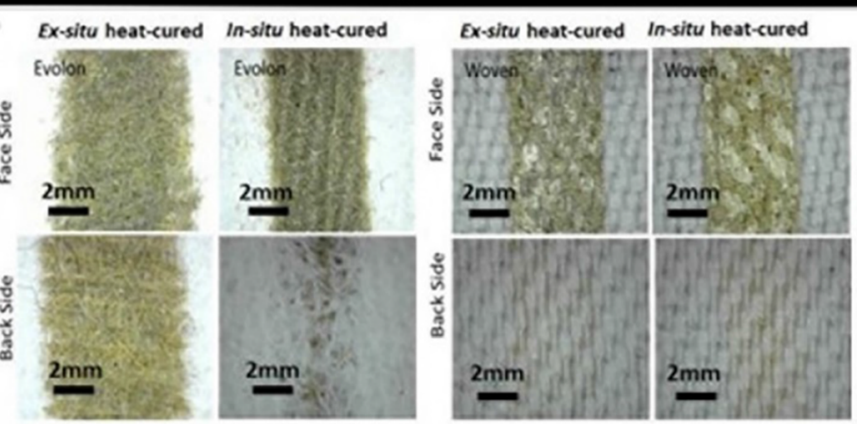

nanoparticles printed (bottom) cotton fabric. (Reproduced from ref. [142], Copyright (C) 2015 The Author. Published by Springer Nature) d Left to right: Reactive inkjet-printed silver pattern on textile, Ex-situ, and In-situ heat-cured patterns on knit PET, Evolon, and woven PET fabric. (Reproduced with permission from ref. [80], Copyright (C) 2019, American Chemical Society). 
significant increase in resistance even after 10,000 bending cycles [80]. The feasibility of the process while maintaining inherent stretchability, breathability, and comfort was also studied [145]. Li et al. (2018) demonstrated an interesting approach by combining inkjet printing of silver ink with Kirigami patterning to tackle the issue of mechanical dissimilarities between the textile substrate and the ink [83]. This Kirigami-inspired textile electrode was formed by printing ink on PET woven fabric followed by laser cutting of Kirigami pattern and led to a softer mechanical response by decreasing elastic modulus and enhancing stretchability. By aligning mechanical compliance between the conductive component and wearable platform while preventing crack formation during stretching, the textile patch showed superior electromechanical performance. Furthermore, the electromechanical property can be customized by changing the patterned cut-out ratio. Low-temperature inkjet printing is required for textile substrates with low glass transition temperatures to maintain the structural rigidity of the substrate. Therefore, water-soluble silver ink was prepared by the modified Tollens' process, which ensured inkjet printability of the textile surface with simultaneous sintering at low temperatures around $90{ }^{\circ} \mathrm{C}$. The ink was printed on the interface layer containing acrylic copolymer-based resin [205]. Inkjet-printed silver ink demonstrated better sensor rigidity against bending compared to the lithography process [206]. La et al. (2018) inkjet-printed silver powder-based fluoroelastomer nanocomposite ink on polyurethane (PU) nanotextile substrates. By controlling the permeation of ink, a cladding layer was formed which improved the mechanical and electrical properties of the electrode. This process eliminates the need for pre-treatment as well as high-temperature post-treatment which is necessary for printing silver inks and thus saves time by printing in a single step [207].

Compared to the widely used screen printing process, inkjet printing can generate high-resolution printing and require low viscous ink. Inkjet printing with low viscosity ink provides better control on localized printing and easier to retain inherent characteristics of printed textiles. Though particle-free ink could evade the nozzle clogging issues, it restricts the applicability and versatility of inkjet printing on different textile substrates. Unlike particle-free ink, cheaper and wider particle-based inks are available which can be used with various textile materials.
However, ink chemistry for different substrates required to be optimized for better performance and thus limits the choice of the textile substrates. Additionally, inkjet printing is less suitable for bulk-scale printing compared to the screen printing process. Different printing processes discussed above print various substrates in two dimensions, and mostly the top layer of the substrate is printed. This limits the fabrication of complex and multilayer electrodes and is difficult to control the permeation of inks inside the multilayer substrates.

\section{D printing}

$3 \mathrm{D}$ printing is an emerging additive manufacturing process that builds up structure in a layer-by-layer deposition of material directly from the computerbased model. The core strength of 3D printing is the ability to produce any geometry which enables fabricating complex structures while controlling dimensions of the feature precisely [208, 209]. Moreover, most of the materials in the electronics industry, i.e., metal, polymers, carbon materials, and their hybrid forms, can be used to build up structures [210]. Different types of 3D printing technologies are available in practice and can be classified into seven broad groups [211], e.g., (i) material extrusion [212], (ii) vat polymerization [213], (iii) power bed fusion [214], (iv) material jetting [215], (v) binder jetting [216], (vi) direct energy deposition [217], and (vii) sheet lamination [218]. These techniques have gained extensive attention in recent years to fabricate microfluidic devices [219], sensors [220], energy storage [221] and showed immense potential in the health-care industry [222, 223]. Though the 3D printing technique has been utilized for some fashion products, limited research has been reported for developing functional textiles [224-226]. Recently, a $3 \mathrm{D}$ printing approach to produce fiber and freestanding structure [227, 228], and direct ink writing [229-233] on the textile substrate to impart functionality have been explored. Cao et al. (2019) developed MXene/cellulose nanofibril hybrid ink-based 3D printed fiber and fabric (Fig. 6a-f) like structures [227]. The 3D printed structures demonstrated the capabilities of sensing human movement when encapsulated on an elastic silicone matrix. The method resembles the wet spinning method and involves solvent exchange. Zhao et al. 2018 reported $3 \mathrm{D}$ printed supercapacitor assembly by printing 
vanadium oxide and nitride with single-walled CNT as the positive and negative electrode and twisting them together [228]. A 3rd fiber using rGO worked as a self-powered temperature sensing device when added to the supercapacitor assembly.

Flexible thermoplastic polyurethane was 3D printed on PEDOT:PSS coated textile for electroluminescence application [229]. Shahariar et al. 2020 directwrite printed silver micro flakes-based ink (Fig. 6g) for the formation of the embedded wire-like composite structure. The conductive network was well maintained even after extreme mechanical deformation of 1000 cycles and 25 washing cycles [230]. This may become crucial in developing stretchable sensing textiles without compromising the integrity of interconnects and electrodes. The screen printable ink can be printed onto textiles without any pre-treatment process using the direct-write technique by manipulating ink rheology. Ink penetration can be controlled by changing fluid pressure and tuning the rheology of ink materials [232]. In recent years, several other 3D printing techniques are explored for direct 3D printing of polymers and nanocomposites on textile substrates [71]. Fused deposition modeling (FDM) is a material extrusion-based additive manufacturing method [234]. The method involves layerby-layer deposition of thermoplastic polymer filaments to form a three-dimensional structure. The printer uses a heated nozzle for the melting process, and the desired pattern is produced upon solidification [235-237]. Another common bottom-up 3D printing method is stereolithography, which utilizes the vat photopolymerization technique [238]. The process uses photopolymers, a type of liquid resin that solidifies (cured) when irradiated with ultraviolet (UV) light [239]. The light source initiates a chain reaction by free radicals or reactive species to convert multifunctional photosensitive polymer to crosslinked polymer, and the monomers often require the addition of low molecular weight organic initiator molecule to start the reaction [240]. The process is performed in a vat with a submerged platform which moves and selectively exposes photopolymers to light and transforms the molecular raw material into the macromolecular structure [241-243]. Though the $3 \mathrm{D}$ printing process demonstrated the substantial potential of developing functional electrodes, there are a lot of challenges that need to be solved such as i) limited material choice for 3D printing, ii) poor flexibility of the 3D printed electrodes, iii) lack of comfort for wearability, iv) very slow fabrication process and unsuitable for bulk production compared to its counterpart, v) limited design flexibility vi) low resolution of printing, vii) poor aesthetic compared to traditional textile structures.

\section{Wearable health monitoring applications of printed electrodes}

Electrically conductive textiles have been strongly linked to wearable health-care applications and recently showed significant improvement with the rise of human-machine interactions [244, 245] and the Internet of Things (IoT) [246]. This interconnected system has allowed remote monitoring and easier interaction. Textile substrates are an integral part of
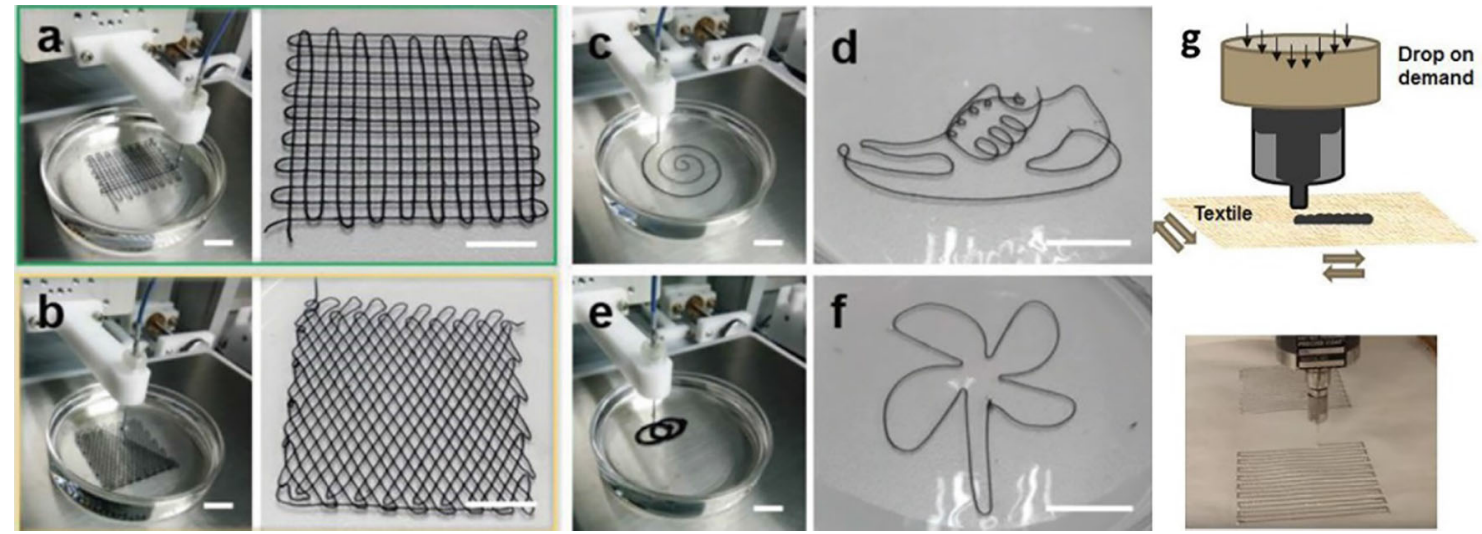

Figure 6 a - f Optical images of $3 \mathrm{D}$ printed $\mathrm{TOCNF} / \mathrm{Ti}_{3} \mathrm{C}_{2}$ fabric of different structures. ( Reproduced with permission from ref. [227], Copyright (C) 2019 WILEY-VCH Verlag GmbH \& Co.
KGaA, Weinheim) g Direct write printing of conductive ink onto textile fabric. (Reproduced with permission from ref. [230], Copyright (C) 2020, IOP Publishing). 
human beings and maintain conformal contact with the body, which is crucial for continuous monitoring of various health phenomena. Moreover, electrodes made of textiles are comfortable and can be invisibly integrated into clothing [247]. The integration of textile-based flexible biosensors may result in improved clinical diagnosis and better health-care management and assist physically challenged people to interact proactively $[245,248,249]$. The outstanding benefits of wearable health monitoring electrodes are the point of care testing and early detection of illness. Different health parameters of the human body can be detected by using a textile-based sensor and broadly categorized as physical sensing and chemical sensing. The principle of physical sensing is to detect changes in physical stimulus and turning those into signals for measuring and recording, which includes biopotential sensing, temperature monitoring, and human motion detection, etc. Chemical sensing involves the detection of biomolecules, which gives rise to the analytical signal with the aid of an analyte and includes saliva, sweat, $\mathrm{pH}$, lactate, and various other ions sensing [249]. In this section, the application of printing techniques to develop the textile electrode for biosensing and monitoring has been discussed.

\section{Biopotential monitoring}

Electrocardiogram (ECG), Electroencephalogram (EEG), Electromyogram (EMG), Electrooculogram (EOG) are the common biopotentials that operate on the principle of measuring the variation in electrical potential due to heart, brain, muscle, and ocular activity [250]. Wearable textile-based electrodes can be used to develop home-based or remote monitoring protocol with minimal interruption in normal life and can significantly reduce clinical visits and costs by continuously monitoring these biopotentials [44]. Signal acquisition and processing play a crucial role in the health-care system by providing information essential for the diagnosis and monitoring process. Table 1 summarizes various approaches demonstrated in the literature to monitor biopotential using printed textile electrodes.

Biopotential signals are generally acquired by physical sensors. Piezoresistive, piezoelectric, and capacitive transduction mechanisms are extensively used for data collection [106, 265]. Conductive networks developed by nanomaterials deposition on substrate get disrupted, i.e., the effective mass of charge carriers and distribution of active materials changes under stress and subsequently the resistance of piezoresistive sensors changes [266, 267]. Piezoelectric sensors convert mechanical energy to electrical signals via the reorientation of crystal structures. Positive and negative charge separation induced by internal polarization within materials causes the change in a potential difference proportional to the applied stress [268]. Capacitive sensors usually consist of two parallel electrodes placed closely with a dielectric layer in between. Upon deformation, the capacitance changes with the change in distance between electrodes and produces a corresponding signal [269].

\section{Electrocardiography (ECG)}

ECG is a biopotential signal acquisition system that measures the variation in heart potential by utilizing surface electrodes across the body [7]. It is a noninvasive skin surface measurement of the electrical changes arising from the heart muscle depolarizing during a heartbeat and can indicate abnormalities in heart rhythm [270]. Cardiovascular diseases are assessed through such abnormalities in rhythm. Some of these anomalies are not immediately fatal and can be detected over long-term monitoring and are characterized by sudden changes in the ECG signal which requires continuous data acquisition to detect the disease [271]. A portable device that enables continuous monitoring of the heart may play a critical role in the early detection of heart malfunction and initiate an emergency response when necessary [272]. A typical ECG beat mainly comprises a $\mathrm{P}$ wave, QRS complex, and $\mathrm{T}$ wave which can be used to diagnose various cardiac disorders. For example, missing P-waves, which correspond to atrial depolarization, indicate atrial fibrillation and can lead to stroke. Atrial diseases can be revealed by the morphology of the ST segment duration which corresponds to the period during which the ventricles remain in a depolarized state. Variation in RR intervals leads to sleep apnea and may be used as an indicator of arrhythmias. The abnormality of QT intervals is attributed to ventricular fibrillation and causes sudden cardiac arrest [7, 273, 274].

The most widely used ECG signal acquisition is represented by $\mathrm{Ag} / \mathrm{AgCl}$ gel electrode which has distinct advantages of reduced signal discrepancy 
Table 1 Printed textile-based electrodes for biopotential monitoring

\begin{tabular}{|c|c|c|c|c|c|c|c|}
\hline $\begin{array}{l}\text { Bio- } \\
\text { potential } \\
\text { Signal }\end{array}$ & $\begin{array}{l}\text { Cotton/polyester/ lycra } \\
\text { woven }\end{array}$ & $\begin{array}{l}\text { Screen/ } \\
\text { stencil }\end{array}$ & Functional ink material & $\begin{array}{l}\text { Wearable } \\
\text { structures }\end{array}$ & $\begin{array}{l}\text { Point of } \\
\text { operation }\end{array}$ & $\begin{array}{l}\text { Signal-to-noise } \\
\text { ratio }(\mathrm{SNR}) \mathrm{dB}\end{array}$ & Ref \\
\hline \multirow[t]{23}{*}{ ECG } & $\begin{array}{l}\text { Polyester/Nylon } \\
\text { segmented pie fiber } \\
\text { nonwoven }\end{array}$ & Screen & $\mathrm{Ag} / \mathrm{AgCl}$ & $\begin{array}{l}\text { Stretchable } \\
\text { belt }\end{array}$ & Chest & - & {$[84]$} \\
\hline & Fabric & Screen & Silver paste & Band-aid & Chest & - & [251] \\
\hline & $\begin{array}{l}\text { Cotton/Polyester/Lycra } \\
3 * 1 \text { twill woven }\end{array}$ & $\begin{array}{l}\text { Screen/ } \\
\text { Stencil }\end{array}$ & $\begin{array}{l}\text { Silver paste/ Conductive } \\
\text { rubber }\end{array}$ & Chestband & Chest & - & {$[252]$} \\
\hline & $\begin{array}{l}\text { Cotton/Polyester/ Lycra } \\
\text { woven }\end{array}$ & $\begin{array}{l}\text { Screen/ } \\
\text { Stencil }\end{array}$ & $\begin{array}{l}\text { Silver paste/ Conductive } \\
\text { rubber }\end{array}$ & Chestband & Chest & - & {$[64]$} \\
\hline & Polyester interlock knit & $\begin{array}{c}\text { Stencil/ } \\
\text { Brush } \\
\text { paint }\end{array}$ & PEDOT:PSS & Wristband & Arm & 16.3 & [166] \\
\hline & $\begin{array}{l}\text { Polypropylene } \\
\text { nonwoven }\end{array}$ & Screen & $\mathrm{Ag} / \mathrm{AgCl}$ & - & Chest & 28.68 (Dry) & [253] \\
\hline & & & & & & 26.70 (Wet) & \\
\hline & Cotton & Inkjet & rGO & - & Fingertip & 22.3 & [79] \\
\hline & Woven & $\begin{array}{l}\text { Screen/ } \\
\text { Stencil }\end{array}$ & $\begin{array}{l}\text { Silver paste/ Conductive } \\
\text { rubber }\end{array}$ & Body vest & $\begin{array}{l}\text { Frank } \\
\text { configuration }\end{array}$ & - & {$[254]$} \\
\hline & Knit & Screen & PEDOT:PSS & T-shirt & Chest & $\begin{array}{l}15.42 \text { (Dry) } \\
29.59 \text { (Wet) }\end{array}$ & [147] \\
\hline & Cotton & Screen & PEDOT:PSS & & & & [168] \\
\hline & Cotton Knit & Screen & PEDOT:PSS & & Forearms & 24.63 & [255] \\
\hline & Cotton/Lycra knit & & & & & 17.80 & \\
\hline & - & Screen & Silver & & & & [256] \\
\hline & - & Screen & PEDOT:PSS and Silver & Belt & Chest & 21 & [257] \\
\hline & Woven & Inkjet & Reactive silver & & Elbow & 18 & [83] \\
\hline & Woven and Knit & Brush & Silver & Cycling suit & Chest & - & [258] \\
\hline & Woven & Screen & MWCNT/PU & T-shirt & Chest & & [259] \\
\hline & Cotton & Screen & $\begin{array}{l}\text { Graphene/ Carboxymethl } \\
\text { cellulose (CMC) }\end{array}$ & & Wrist & & [146] \\
\hline & Cotton & Screen & $\begin{array}{l}\text { Graphene/ Ethyl cellulose } \\
\text { (EC) }\end{array}$ & & Wrist & & {$[260]$} \\
\hline & Woven cotton & Screen & PEDOT:PSS & & $\begin{array}{l}12 \text { lead } \\
\text { configuration }\end{array}$ & & [261] \\
\hline & Hosiery (Pantyhose) & Inkjet & PEDOT:PSS & Wrist & $\begin{array}{l}12.93 \\
13.75\end{array}$ & & {$[262]$} \\
\hline & Polyester-Spandex & $\begin{array}{l}\text { Direct } \\
\text { Ink } \\
\text { Write }\end{array}$ & Stretchable silver & Shirt & & & [232] \\
\hline \multirow[t]{4}{*}{ EMG } & $\begin{array}{l}\text { Cotton/Polyester/Lycra } \\
3 * 1 \text { twill woven }\end{array}$ & $\begin{array}{l}\text { Screen/ } \\
\text { Stencil }\end{array}$ & $\begin{array}{l}\text { Silver paste/ Conductive } \\
\text { rubber }\end{array}$ & Armband & Forearm & - & {$[252]$} \\
\hline & Polyurethane & Jet & $\begin{array}{l}\text { Silver powder-based } \\
\text { fluoro-elastomer } \\
\text { nanocomposite }\end{array}$ & & $\begin{array}{l}\text { Different body } \\
\text { parts }\end{array}$ & - & [207] \\
\hline & Cotton & Screen & PEDOT:PSS & & $\begin{array}{l}\text { Tibialis } \\
\text { anterior } \\
\text { muscle }\end{array}$ & & [169] \\
\hline & Nylon/PU tricot knit & Screen & Silver/ Fluoro- elastomer & $\begin{array}{l}\text { Compression } \\
\text { garment }\end{array}$ & Arm & & {$[172]$} \\
\hline
\end{tabular}


Table 1 continued

\begin{tabular}{|c|c|c|c|c|c|c|c|}
\hline $\begin{array}{l}\text { Bio- } \\
\text { potential } \\
\text { Signal }\end{array}$ & $\begin{array}{l}\text { Cotton/polyester/ lycra } \\
\text { woven }\end{array}$ & $\begin{array}{l}\text { Screen/ } \\
\text { stencil }\end{array}$ & Functional ink material & $\begin{array}{l}\text { Wearable } \\
\text { structures }\end{array}$ & $\begin{array}{l}\text { Point of } \\
\text { operation }\end{array}$ & $\begin{array}{l}\text { Signal-to-noise } \\
\text { ratio (SNR) } \mathrm{dB}\end{array}$ & Ref \\
\hline \multirow[t]{3}{*}{ EEG } & Woven & Screen & $\begin{array}{l}\text { Silver paste/ Conductive } \\
\text { rubber }\end{array}$ & Headband & Forehead & - & [263] \\
\hline & \multirow[t]{2}{*}{ Polyurethane } & Jet & $\begin{array}{l}\text { Silver powder-based } \\
\text { fluoro-elastomer } \\
\text { nanocomposite }\end{array}$ & & $\begin{array}{l}\text { Hairless region } \\
\text { behind the } \\
\text { ears }\end{array}$ & & [207] \\
\hline & & Screen & $\begin{array}{l}\text { Silver paste/ Conductive } \\
\text { rubber }\end{array}$ & Headband & Forehead & & [264] \\
\hline EOG & $\begin{array}{l}\text { Cotton/Polyester/Lycra } \\
3 * 1 \text { twill woven }\end{array}$ & $\begin{array}{l}\text { Screen/ } \\
\text { Stencil }\end{array}$ & $\begin{array}{l}\text { Silver paste/ Conductive } \\
\text { rubber }\end{array}$ & Headband & Forehead & - & {$[252]$} \\
\hline
\end{tabular}

caused by skin-electrode movement, inexpensive and acceptable comfortability for patients [275]. Ag/ $\mathrm{AgCl}$ wet electrodes have low skin-electrode impedance and thus produce an excellent signal. However, the gel used in the skin interface has several issues such as skin irritation, poor breathability, and unsuitable for long-term monitoring as the gel dried out [276-278]. Moreover, the presence of the adhesive layer limits the integration of these electrodes in clothing. Over the past few decades, different textile technologies have been explored to design and develop textile-based dry electrodes, which have been integrated into garments for ECG signal acquisition for long-term monitoring applications.

Hoi-Jun Yoo et al. (2010) developed a system consisting of a band-aid sensor and a vest for ECG monitoring. Band-aid is a wirelessly powered patch sensor to capture the ECG signal and the vest works as a base station that holds inductors. Both the inductors and electrodes were formed by screen printing of silver paste and consume only $12 \mu \mathrm{W}$ which is suitable for wearable monitoring applications and mitigates the inconvenience of restricted movements always evident for the gel electrode in clinical settings [251]. Paul et al. (2015) fabricated an active electrode on a woven textile for the first time using silver paste for transmission lines and conductive rubber as the electrode for wearable ECG. The electrode showed better performance than the conventional $\mathrm{Ag} / \mathrm{AgCl}$ electrode when the subject moves slowly. However, with the increased movement of the subject, motion artifact degrades the quality of the signal as the electrodes do not stay attached to the skin [64]. The same group then fabricated a body vest placing electrodes in 'frank configuration' to mitigate this issue and obtained a signal with minimal baseline drift [254]. PEDOT:PSS is beneficial for the transduction of ECG signals as PEDOT and PSS ensure electric and ionic conductivity, respectively. Sinha et al. (2017) integrated PEDOT:PSS screen-printed electrode which demonstrated the capability of real-time ECG signal recording. The electrode maintained good functionality after washing with detergent [147]. However, motion artifacts are the major challenge for dry electrodes that often interfere with the signal. A dry electrode was fabricated by inkjet printing of PEDOT:PSS on polyamide fabric pantyhose and the recorded signal demonstrated that the dry electrode is vulnerable to motion artifacts [262]. Therefore, different modification has been made to improve signal quality. Takamatsu et al. (2015) fabricated the ECG electrode in the form of a wristband being inspired by the Japanese kimono dyeing process and used ionic liquid (IL) gel to lower skin-electrode contact impedance. The PEDOT:PSS printed electrode showed long-term stability (Fig. 7c) and generated an accurate signal after continuous placement of electrodes on the chest for 3 days [166]. Kirigami patterned textile patch reported as less prone to motion artifacts due to the stretchability and showed stable ECG signal acquisition around complex curvilinear body surface like an elbow (Fig. 7a) by harnessing superior electromechanical properties induced by the exceptional structure [83]. In another study, Xu et al. developed a graphene-based screen- 
printed electrode with high bending (Fig. $7 \mathrm{~b}$ ) and wash stability by using either CMC or ethyl cellulose (EC) with graphene [146, 260]. The performance of the ECG signal of the graphene/EC ink electrode showed negligible change over 9 washing cycles and 2000 times bending cycles. Paiva et al. (2019) fabricated a cycling suit with a silver printed electrode for real-time ECG monitoring [258] and demonstrated that the electrode can successfully record ECG.

\section{Electromyography (EMG)}

Electromyography is a diagnostic system to estimate, record, and evaluate the electrical activity produced by skeletal muscles. Electrodes acquire a complex series of myoelectrical potential variations while placed on the skin surface due to voluntary or involuntary muscle contraction and relaxation cycles [279]. It is similar to the ECG signal, except that myoelectric signals are quite localized on the skin surface over the target muscle [7]. EMG plays a vital role to understand the muscle activity of the human body under different conditions [280]. There are two main methods for recording EMG: i) surface EMG (sEMG), which obtains signals in a non-invasive method from the surface of the skin, is preferred over ii) intramuscular EMG (iEMG) [44]. Interest in developing a textile-based EMG platform has increased to enable data acquisition in more realistic situations and for long-term monitoring. For

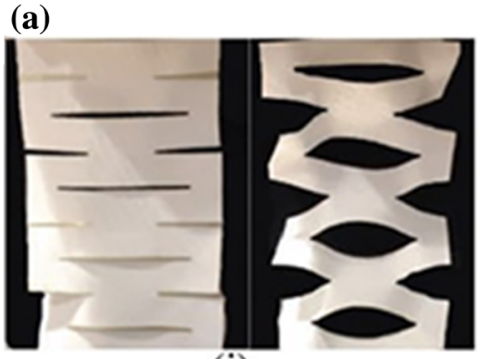

(b)

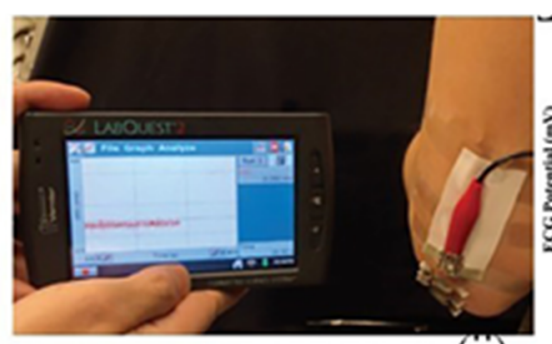

(ii)
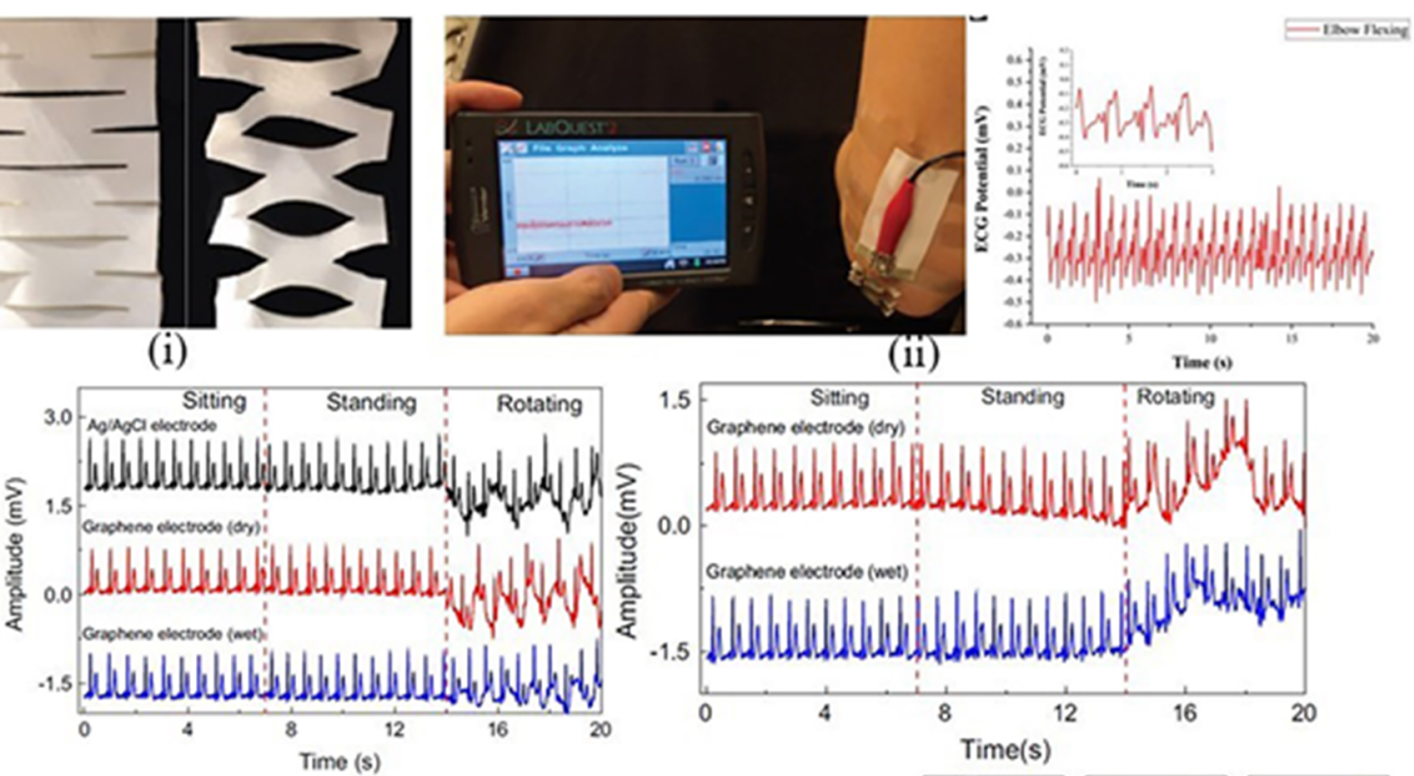

(c)
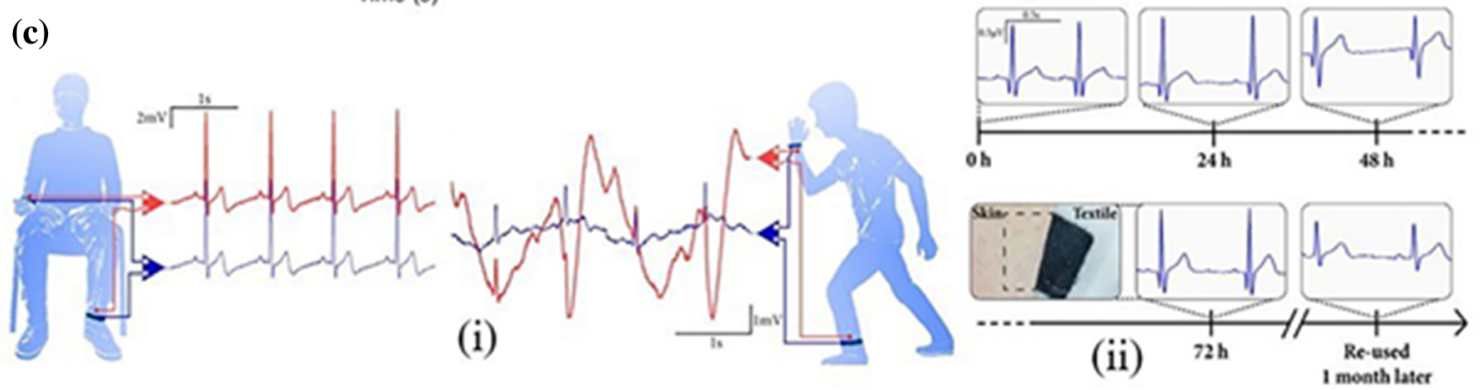

Figure 7 a Electrode with Kirigami cut (i) at rest and stretched, (ii) recorded ECG signal corresponding to elbow flexing, i.e., stretched condition. ( Reproduced with permission from ref. [83], Copyright (C) 2019 WILEY-VCH Verlag GmbH \& Co. KGaA, Weinheim) b Left: ECG signal obtained by $\mathrm{Ag} / \mathrm{AgCl}$ electrode and the graphene-coated dry and wet electrode at different conditions. Right: ECG signals from graphene-based fry and wet electrode after 1000 bending cycle. (Reproduced with permission from ref.
[146], Copyright (C) 2019 Springer Nature) c ECG recording using PEDOT:PSS textile electrode (i) when the subject is sitting and during movement. (ii) ECG signal evolution when kept in permanent contact with the skin over three days. The blue line represents the textile electrode and the red line represents the reference $\mathrm{Ag} / \mathrm{AgCl}$ electrode. (Reproduced from ref. [166], Copyright (C) 2015 The Author. Published by Springer Nature). 
example, recording the EMG of athletes during sports could prevent injury and assist in improving performance. The popular applications of textile electrodes to record EMG include prosthetics [281-283], and rehabilitation [284], muscle status monitoring [285-289], etc.

La et al. (2018) demonstrated two-layered e-textile patches that were inkjet printed using silver powderbased fluoroelastomer nanocomposite (Fig. 8a). Polyurethane (PU) nanotextile substrates were printed on both sides (an electrode on one side and serpentine traces on the other side) so that the sEMG signal is not affected by the transmission lines [230]. Paul et al. (2014) developed a headband to record EMG signals from facial muscles to be placed on the forehead. The electrode was attached to an elastic textile to ensure comfort and reduce motion artifact [167]. The same group fabricated an EMG armband, and connecting the armband with an accelerometer, a functional wearable mouse (Fig. 8b) was fabricated [252]. EMG electrode developed by Pani et al. (2019) via screen printing of PEDOT:PSS on cotton showed the capability of measuring the EMG signal of the tibialis anterior signal, which yielded an $R^{2}$ value higher than $97 \%$ when compared with conventional electrode [169]. Compared to the wet electrode, dry electrodes are prone to motion artifacts and different strategies have been adopted by the researcher to overcome motion artifacts. Dry electrodes placed tightly on the skin significantly improve the signal quality. Therefore, electrodes fabricated on the compression garment show less noise and drift while recording EMG signals [172].

\section{Electroencephalography (EEG)}

EEG is a cheap, non-invasive method to record physiological electric signals generated due to the neural activity of the brain [290-292]. This signal can indicate the consciousness and alertness of the subject, sleep quality, and clinical applications for the diagnosis and treatment of brain dysfunctions and the onset of neuropsychological diseases [293, 294]. EEG energy signal occurs due to five rhythms such as $\delta, \theta, \alpha, \beta, \gamma$ rhythm. $\delta$ rhythm is considered normal for younger patients and sometimes characterizes cerebral anomalies. $\theta$ often appears among children and younger adults, and $\alpha$ rhythm generates due to the closing and opening of eyes. $\beta$ rhythm appears when high mental activity occurs, and $\gamma$ rhythm can be detected when intense brain activity occurs [295]. A traditional EEG signal is detected using electrodes placed on the scalp. This poses a challenge for textile electrodes due to the presence of hair, and thus, textile EEG electrodes are generally placed on the forehead [263, 264] and often mounted behind the ears [207] on the hairless region.

Matiko et al. (2015) [264] and Wei et al. (2017) [263] both fabricated the active electrode in a similar fashion described by Paul et al. (2015) [64]. However, the electrode configuration of Matiko and co-workers was self-powered using wearable solar cells to power EMG (Fig. 9a). The work involved the fabrication of a

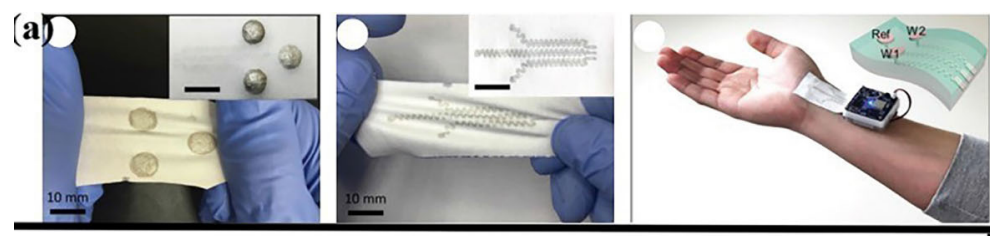

(b)

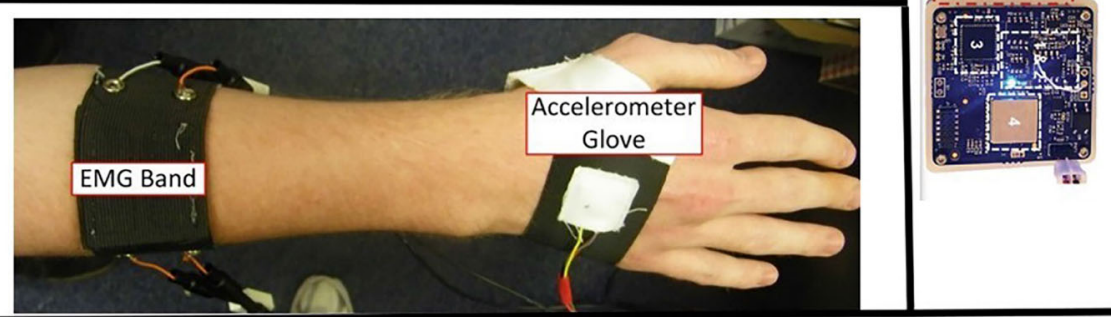

Figure 8 a Fully integrated sEMG sensor system with twolayered e-textile sensing electrodes for real-time monitoring of muscle activities. ( Reproduced with permission from ref. [207], Copyright (C) 2018 WILEY-VCH Verlag GmbH \& Co. KGaA,
Weinheim) b Wearable mouse using EMG armband and accelerometer. (Reproduced with permission from ref. [252], Copyright (C) 2013 Elsevier). 
headband with integrated flexible solar cells, energy storage, power management chip, and textile electrode [264]. On the other hand, Wei et al. (2017) developed a headband for detecting emotion and examined electrode locations for improved performance and achieved $91.75 \%$ subject-dependent accuracy and $64.73 \%$ independent accuracy when using Linear Discrimination Analysis (LDA) as the classification algorithm [263]. A two-layered e-textile patch developed by La et al. (2018) demonstrated less noise or smaller movement artifacts than commercial electrodes (Fig. 9b) due to stronger mechanical confirmation with the skin when tested simultaneously by placing the electrodes behind the ear [207].

Biopotential monitoring electrodes have been fabricated on different textile substrates and can generate a detectable signal. Textile-based dry electrodes are advantageous because they provide better comfort, flexibility, and breathability which are essential requirements for long-term monitoring. Though wet electrodes have superior functionality, dry electrodes are the viable option for long-term monitoring. The major problem of dry electrodes is the signal quality which is greatly affected by the motion artifacts. However, in the past decades, the signal quality has been improved significantly by using different conductive materials and design concepts. The noninvasive nature of dry electrodes is expected to be more user-friendly than wet electrodes. Textile-based dry electrodes are mostly tested in laboratory settings and the functionality might vary significantly when converted to a full-sized garment. In the coming years, dry electrodes might see a huge improvement in functionality and reliability which can be used for real-time diagnostics.

\section{Non-invasive biochemical sensing}

The flexible and wearable biosensor has gained substantial interest among the scientific community for the potential application of continuous, real-time monitoring of biomarkers via non-invasive methods [296]. Body fluids or biofluids such as sweat, saliva, blood, tears, etc. contain biomarkers, which can indicate the onset of diseases or conditions of health [297]. At present, biomarker analysis and diagnostic methods are mostly available as invasive methods based on standard laboratory settings. For remote monitoring of various biomarkers, flexible, wearable, and skin-based biochemical sensors have been developed [86]. The biochemical sensor system involves a chemical reaction utilizing ion or analyte [249]. Various manufacturing techniques have been
Figure 9 a Headband with solar panel, energy storage, power management chip, and active electrodes for EEG application. ( Reproduced with permission from ref. [264], Copyright (C) 2015 IOP Publishing) b Raw EEG data collected from behind the year using a commercial gel electrode and textile electrode simultaneously. The blue part represents the textile electrode and the red section represents a commercial electrode. (Reproduced with permission from ref. [207], Copyright (C) 2018 WILEY-VCH Verlag $\mathrm{GmbH} \& \mathrm{Co}$. KGaA, Weinheim).

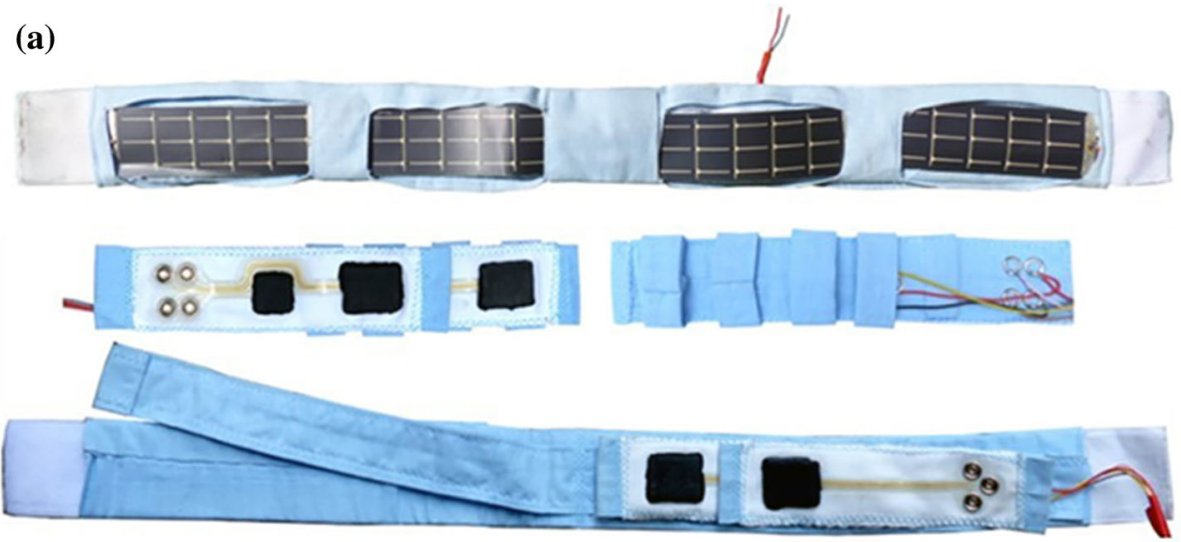

(b)

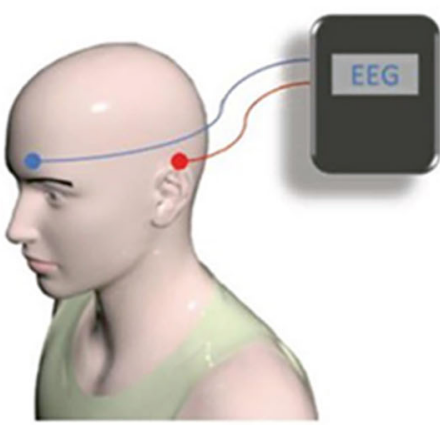


examined to fabricate a textile-based chemical sensor. However, the use of the printing process to sense and monitor biomarkers connected to health monitoring is not well explored yet. The developments are focused on optical and electrochemical sensing systems utilizing potentiometric, amperometric, voltammetric, colorimetric techniques. Optical sensors operate according to the principle of classical spectroscopy and can be detected by bare eyes or using image processing [298]. Electrochemical sensors have been widely used for a while and can be divided into distinct blocks according to the mode of operation, e.g., potentiometric, amperometric, conductometric. Potentiometric sensors provide information by analyzing the potential difference between the sensing and reference electrodes. Amperometric sensors work based on current-concentration relationships, whereas conductometric sensors provide data by analyzing the conductance of electrochemical cells $[299,300]$. Table 2 summarizes different textilebased biochemical sensors.

Skin being the most exposed organ of the human body, researchers have always exploited this benefit to fabricate biochemical sensors. Sweat is a slightly acidic ( $\mathrm{pH}$ 4.0-6.8) biological fluid readily available on the skin surface and composed of electrolytes (sodium $\mathrm{Na}+$, potassium $\mathrm{K}+$, ammonium), metabolites (lactate, glucose), proteins, and other molecules which may give an indication of electrolyte condition, stress, fatigue, mineral loss, metabolism, dehydration, and other physical conditions [302-307]. Thus, sweat can provide a valuable indication of health even before the condition deteriorate and extensive research has been done on developing a clinical-grade wearable sweat sensor. Coyle et al. (2009) presented a colorimetric optical sensor to monitor sweat activity in real-time and $\mathrm{pH}$-sensitive bromocresol purple dye was incorporated into a fabric fluidic system using tetraoctyl ammonium bromide [308]. The fabric fluidic channel was created by screen printing an acrylic hydrophobic paste on both sides of the fabric. A collection window was placed at one end of this channel where sweat enters from the skin, and at the opposite end of the channel, a super-absorbent (SAB) material was placed to increase the capillary flow through the fabric and store the collected sweat. The sensor was successfully used to measure the sweat $\mathrm{pH}$ and sweat rate during exercise providing valuable information regarding rehydration needs and can be useful for the treatment of hyperhidrosis.

Compared to biopotential monitoring, biochemical sensing requires the materials to be nontoxic and biocompatible. Biofluids encounter the electrodes directly, and therefore, the selection of appropriate electrode materials is crucial. Unlike electrodes for biopotential monitoring, biobased materials are the primary consideration for biochemical sensing. Omenetto et al. developed silk fibroin-based ink which can stabilize labile molecules and biofluids. Naturally derived biomaterial-based ink can utilize the benefit of using water as a solvent and can be processed at room temperature yielding stable bioactive ink. This ink was inkjet printed on gloves (Fig. 10a) which successfully detected E. Coli bacteria [204]. Later, they modified the ink to fabricate a screen-printed $\mathrm{T}$-shirt to monitor the $\mathrm{pH}$ of sweat (Fig. 10b). The discrete patterns printed on the T-shirt detected $\mathrm{pH}$ variations in real time. Five separate inks were used, among which three were $\mathrm{pH}$-sensitive, while the remaining acted as nonreactive controls and fiducial markers to correct for lighting artifacts during image processing [301]. However, multi-analyte sensing is very promising to obtain more insight into health conditions from the biofluids and can save time and cost for screening a patient. Promphet et al. (2019) developed a sweat sensor for the simultaneous detection of $\mathrm{pH}$ and lactate [309]. They deposited three layers of chitosan, sodium carboxymethyl cellulose, and indicator dye or lactate assay to fabricate the sensor. Screen printed $\mathrm{pH}$ indicator dye shifted color from red to blue as $\mathrm{pH}$ increased. In another study, Parrilla et al. (2016) fabricated a multi-ion potentiometric sensor to sense $\mathrm{Na}+, \mathrm{K}+$ ions simultaneously by analyzing sweat [310]. The work used multi-walled carbon nanotube (MWCNT) as sensing electrodes and $\mathrm{Ag} / \mathrm{AgCl}$ as a reference electrode. The stretch enduring ink along with the patterned serpentine electrode used in this sensor exhibited Nernstian behavior and showed negligible effect under extreme conditions of up to $100 \%$ stretching with repeated bending, crumbling, and washing. Lactate is another important biomarker and can be found in muscles, blood, sweat etc. Changes in lactate threshold level cause various health problems, and early detection of changes in lactate levels might improve the health-care management of critical patients. Venkataraman et al. (2016) developed an amperometric electrochemical lactate biosensor by 
Table 2 Printed textile-based biochemical sensing

\begin{tabular}{|c|c|c|c|c|c|c|c|}
\hline Analyte & Sample & $\begin{array}{l}\text { Textile } \\
\text { specification } \\
\text { and Role }\end{array}$ & $\begin{array}{l}\text { Printing } \\
\text { technique }\end{array}$ & Functional material & Sensor type & $\begin{array}{l}\text { Measurement } \\
\text { technique }\end{array}$ & Reference \\
\hline $\mathrm{pH}$ & Sweat & $\begin{array}{l}\text { Weft knit } \\
\text { polyester/lycra }\end{array}$ & Screen & $\begin{array}{c}\text { Acrylic hydrophobic } \\
\text { paste/pH-sensitive } \\
\text { bromocresol purple }\end{array}$ & Optical & Colorimetric & {$[308]$} \\
\hline $\mathrm{Na}+, \mathrm{K}+$ & Sweat & $\begin{array}{l}\text { Underwear/ } \\
\text { Watch Strap/ } \\
\text { Elastic band }\end{array}$ & Screen & $\begin{array}{l}\text { CNT (Sensing } \\
\text { electrode) and Ag/ } \\
\mathrm{AgCl} \text { (Reference } \\
\text { electrode) }\end{array}$ & Electrochemical & Potentiometric & {$[310]$} \\
\hline Lactate & Sweat & $\begin{array}{l}\text { Compression } \\
\text { garment }\end{array}$ & Screen & PEDOT:PSS/PVA & Electrochemical & Amperometric & [311] \\
\hline $\begin{array}{l}\text { Influenza A } \\
\text { virus }\end{array}$ & Biofluid & Cotton fabric & Screen & Silver/GO & Electrochemical & Potentiometric & [313] \\
\hline Lactate & $\begin{array}{l}\text { Lactate } \\
\text { oxidase }\end{array}$ & Cotton fabric & Hand & $\begin{array}{l}\text { Carbon graphite and } \\
\mathrm{Ag} / \mathrm{AgCl} \text { (Reference } \\
\text { electrode) }\end{array}$ & Electrochemical & Amperometric & {$[300]$} \\
\hline Blood leakage & Blood & Cotton fabric & $\begin{array}{r}\text { Screen- } \\
\text { offset }\end{array}$ & Silver & Electrochemical & Impedance & [143] \\
\hline $\mathrm{pH}$ & $\begin{array}{l}\mathrm{pH} \\
\text { solution }\end{array}$ & $\begin{array}{l}\text { Cellulose/ } \\
\text { Polyester } \\
\text { blend fabric }\end{array}$ & Screen & $\begin{array}{l}\text { Graphite-PU } \\
\text { (Sensitive electrode) } \\
\text { and } \mathrm{Ag} / \mathrm{AgCl} \\
\text { (Reference } \\
\text { electrode) }\end{array}$ & Electrochemical & Potentiometric & [314] \\
\hline $\begin{array}{l}\mathrm{pH} \text { and } \\
\text { Lactate }\end{array}$ & Sweat & Cotton fabric & Screen & Indicator dye & Optical & Colorimetric & [309] \\
\hline $\mathrm{pH}$ & Sweat & $\begin{array}{l}\text { Knit fabric } \\
\text { T-shirt }\end{array}$ & Screen & Bioactive silk ink & Optical & Colorimetric & {$[301]$} \\
\hline Bacteria & Coli & Hand gloves & Inkjet & Bioactive silk ink & Optical & Colorimetric & [204] \\
\hline $\begin{array}{l}\text { Ferrocyanide/ } \\
\mathrm{H} 2 \mathrm{O} 2 / \\
\mathrm{NADH}\end{array}$ & Sweat & $\begin{array}{l}\text { Elastic } \\
\text { waistband of } \\
\text { underwear }\end{array}$ & Screen & Carbon & Electrochemical & $\begin{array}{l}\text { Volammetric/ } \\
\text { chronoamperometric }\end{array}$ & [315] \\
\hline Sweat rate & Sweat & UHF RFID tag & Screen & $\begin{array}{l}\text { Silver ink/ Polyester } \\
\text { resin }\end{array}$ & Electrochemical & - & [312] \\
\hline
\end{tabular}

screen printing PEDOT:PSS/PVA on knitted fabric [311]. The lactate sensor composed of three electrodes and was successful to sense lactate from sweat. Luo et al. (2018) printed $\mathrm{Ag} / \mathrm{AgCl}$ ink as a reference electrode and carbon graphite as a working and counter electrode on epoxy coated cotton fabric to sense lactate [300]. The sensor works by detecting $\mathrm{H}_{2} \mathrm{O}_{2}$ which generates by the enzymatic reaction of lactate. Though the studies discussed above outlined the great promise of detecting lactate, none of them demonstrated the possibility of remote monitoring lactate level which is the ultimate goal of the wearable biosensor. However, Merilampi et al. (2016) examined the possibility of using an ultra-high frequency (UHF) radio frequency identification (RFID) system to monitor sweat rate. Integrating silver printed tags with silver-plated antenna, they demonstrated that it is possible to remotely monitor the perspiration rate using RFID tag as the tag response showed a noticeable difference when exposed to the sweat. Upon utilization of the capability of communication through RFID tags, the device can perform as a multifunctional device [312].

Nomura et al. (2018) used an interdigitated silver ink conductive pattern to be printed on cotton fabric for continuous blood leakage monitoring (Fig. 10c) during hemodialysis, a renal replacement therapy [143]. The sensor showed the capability of detecting 


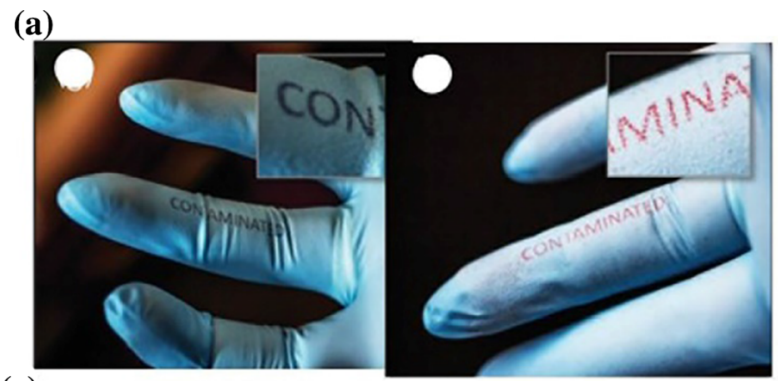

(c)

(b)
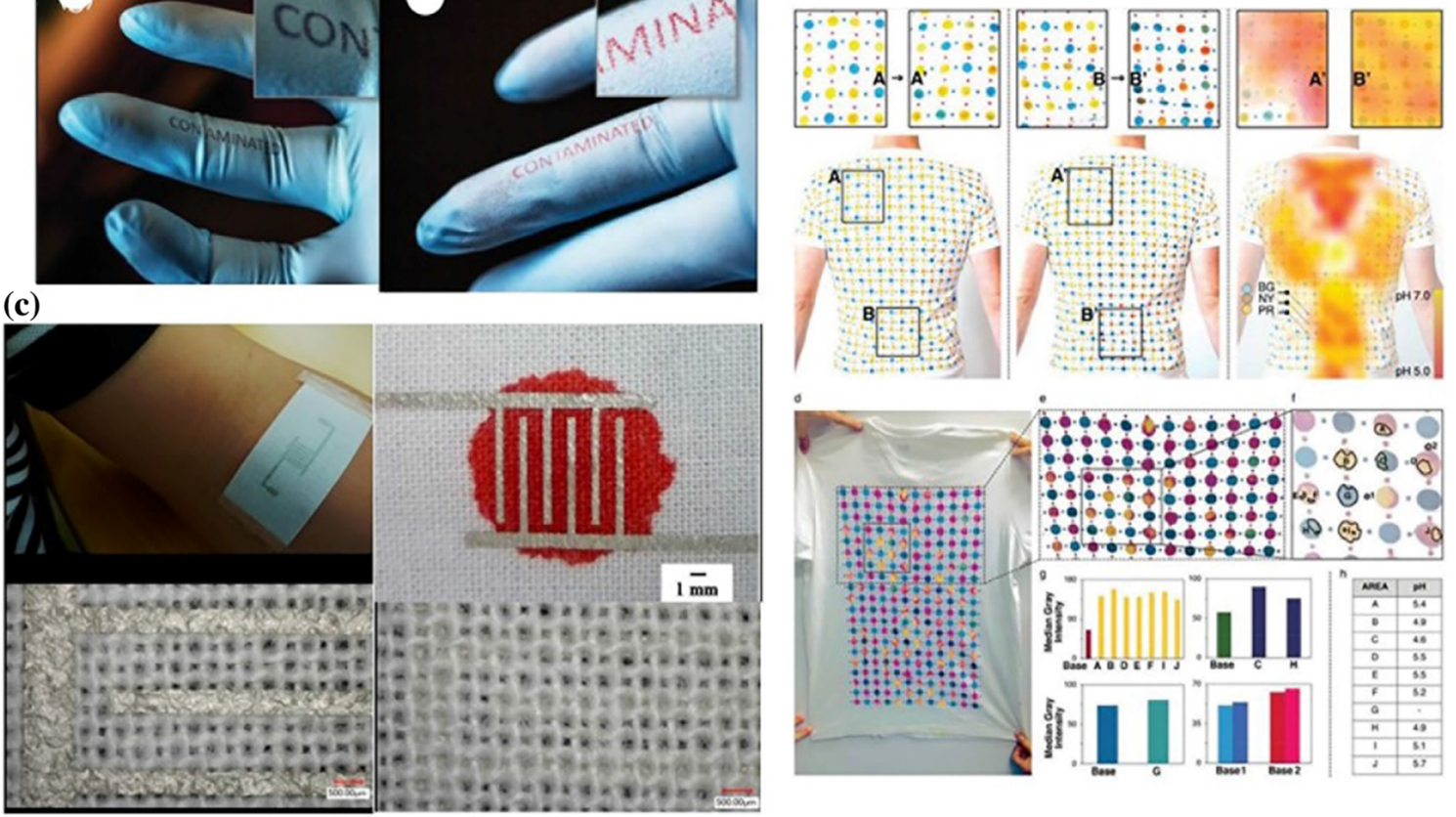

Figure 10 a A proof-of-concept textile glove with a printed pattern turns red from blue when exposed to E. coli bacteria. ( Reproduced with permission from ref. [204], Copyright (C) 2015 WILEY-VCH Verlag GmbH \& Co. KGaA, Weinheim) b pHsensitive ink printed T-shirt changes color according to the variation in $\mathrm{pH}$ at different parts of the body. (Reproduced with

blood volumes as low as $15 \mu \mathrm{L}$, which is significantly lower than those of commercially available products, and showed compatible performance with a reported value of approximately $10 \mu \mathrm{L}$ at the time of publication. Kinnamon et al. (2018) reported a biosensor developed by screen printing of silver electrodes as base and graphene oxide (GO) transduction film for detection of exposure to influenza A virus utilizing superior electrochemical properties [313]. Influenzaspecific affinity array was constructed upon GO layer, which introduces influenza-specific antibodies to the sensor surface. The sensor can detect exposure to the virus before symptom manifestation.

Printed textile-based electrodes have demonstrated high sensitivity to the biomarkers which shows the potential of continuous monitoring of anomaly in real-time and the detection of the onset of any disease. However, fresh sample collection is a challenge for sensor reliability as the sensor may provide erroneous data if continuous pumping of fresh biomarkers and effective removal of the biomarker is not ensured. Moreover, the sensors need to have high permission from ref. [301], Copyright (C) 2020 WILEY-VCH Verlag GmbH \& Co. KGaA, Weinheim) c Textile-based blood leakage sensor and microscopic image of the pattern. (Reproduced from ref. [143], Copyright (C) 2018 The Author. Published by MDPI).

sensitivity to specific biomarkers. The presence of multiple ions or biomarkers in the sample is expected and the failure of the sensor to provide signals with distinct differences may pose difficulty during data analysis.

\section{Temperature sensing}

Body temperature is a vital physiological parameter that can provide important information regarding both physical and mental health conditions. It is one of the four most important vital signs, i.e., temperature, heart rate, respiration rate, and blood pressure, which changes always with time [249, 316]. Ideal body temperature is around $37.2{ }^{\circ} \mathrm{C}$ and may fluctuate according to the state of health and response to physical and mental activities. Generally, body temperature increases due to fever or infection and decreases due to anemia or low blood flow rate [36, 249]. However, in recent days flexible, wearable temperature sensors are providing the opportunity for continuous, non-invasive, and remote monitoring 
as the temperature is being increasingly associated with various aspects of medicine and sports [46, 317-320]. Temperature can indicate health conditions like cardiovascular and pulmonological conditions, detect infections in wounds, and monitor the healing process [321-323]. Monitoring foot temperature continuously can become a game-changer for diabetic patients to prevent ulceration [324]. Temperature can also be an indicator of the extent of human activities and play a crucial role in monitoring the health of laborers working in harsh conditions [325]. Thermography is accepted as a valid index for emotions and can be linked to psychological aspects, for example, stress, which in turn causes various chronic diseases [316, 326]. Most of the wearable temperature sensors are resistive temperature sensors that operate by measuring changes in electrical resistance with temperature variation [36, 327]. Temperature sensors are generally mounted on the skin or kept in close contact with the body. The integration of temperature sensors into textiles may benefit patients, especially the older generation and infants. Though different research on temperature sensor integrated textiles has been reported [46, 328], the printed textile electrode for temperature sensing applications is extremely limited.

Kinkeldei et al. (2012) fabricated temperature sensors by printing silver nanoparticle-based ink on textiles and demonstrated similar performance of sensors fabricated by the lithography process [206]. Though the temperature coefficient of resistance was reported $0.0029^{\circ} \mathrm{C}$ with great bending stability, sensing performance was not stable. Jung et al. (2018) fabricated temperature sensors using combinations of PEDOT:PSS thermoelectric ink, silver nanoparticles (AgNPs), and graphene inks [171]. Three combinations were prepared: for the first two, PEDOT:PSS has been considered as p-type and AgNPs, graphene as n-type, and the last one were fabricated using AgNPs and graphene as p-type and n-type thermoelectric material, respectively. The first combination of p-type PEDOT:PSS and n-type AgNPs performed better in both low and high-temperature range with high durability of 800 cycles with $20 \%$ strain. The combination of PEDOT:PSS and AgNPs sensor printed on the polyester-cotton knit fabric utilized the Seebeck principle (Fig. 11a, b) and generated a thermoelectric voltage output of $1.1 \mathrm{mV}$ for a temperature difference of $100 \mathrm{~K}$. Zhao et al. (2018) used 3D printing to demonstrate a fiber-shaped temperature sensor
(Fig. 11c-f) based on reduced graphene oxide (rGO) [228]. The temperature sensitivity of the device was $1.95 \%{ }^{\circ} \mathrm{C}^{-1}$ which is much higher than CNT and platinum-based sensor and the sensor demonstrated quick response and recovery properties which is crucial for precise, real-time monitoring. The work in this area needs more attention as articles on the printed textile electrode for temperature sensing is limited. Moreover, the published results do not show comparable performance in terms of sensitivity or stability compared to the commercial sensors.

\section{Motion/activity monitoring and assisting}

Activity monitoring is an emerging field in the preventive, diagnostic, and rehabilitative health-care application sector [329]. While a wide range of activity monitoring devices is already available, most of them are rigid, bulky, and not suitable for comfortable and long-term use. Moreover, commercially available products can only provide information on basic and limited activity classification and thus fail to indicate and record any abnormal movement which is crucial for diagnosis [330-333]. Motion sensing has proved to be accurate in detecting and indicating the extent of neurological diseases [334-336], human gait studies, i.e., quality, smoothness, direction, frequency, and intensity of movement as well as posture detection [329, 337, 338]. Neurological rehabilitation involves repeated, personalized, home-based exercise programs under the supervision of professionals and require a frequent clinical visit. By utilizing motion sensors, every movement can be recorded, and it may assist the patient to self-monitor the current condition and gradual improvement by analyzing the daily performances. Additionally, medical professionals can evaluate their patients remotely and prescribe/instruct based on the performance of the subject [339]. Therefore, a lot of research endeavors utilizing highly flexible substrates including textiles to fabricate motion sensing devices for portable, wireless, real-time monitoring of large-scale human body locomotion efficiently without compromising comfort or limiting movement reported in recent time [338]. Wei and co-workers (2013) fabricated a free-standing cantilever structure for motion sensing applications [340]. The structure was developed on polyester/cotton fabric using sacrificial and structural layers by screen printing. The sacrificial layer was subsequently removed using 


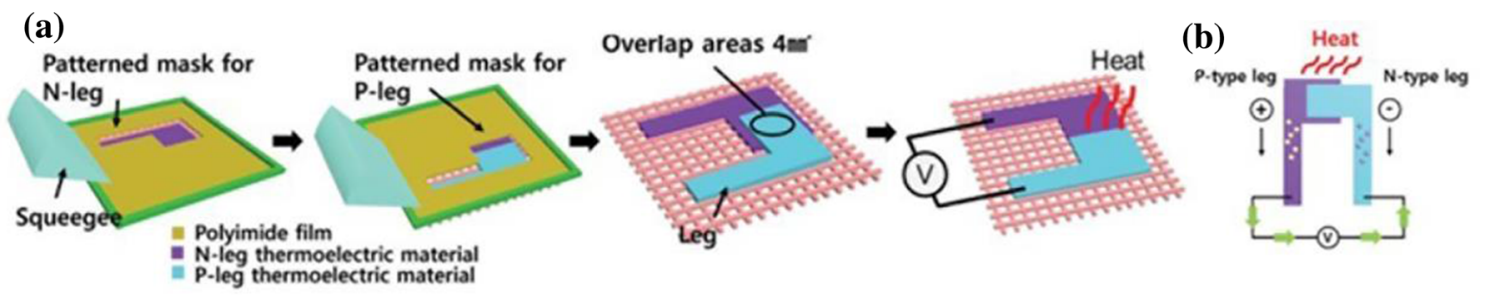

(c)
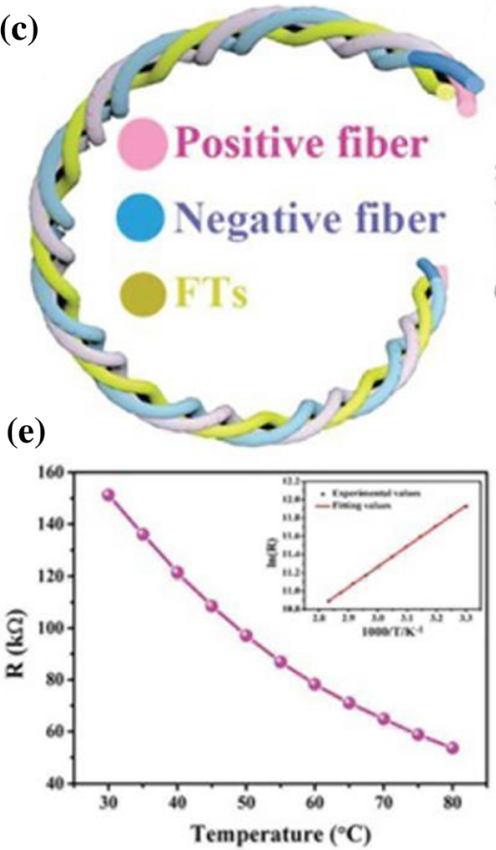

Figure 11 a Illustration of the thermoelectric fabric preparation process. $\mathbf{b}$ Principle of the thermoelectric temperature sensor. ([ab] reproduced from ref. [171], Copyright (C) 2018 The Authors. Published by The Royal Society of Chemistry) c Illustration of fiber asymmetric supercapacitor/fiber temperature sensor (FTs) assembly. $\mathrm{d}$ I-V curves of the device between 30 and $80{ }^{\circ} \mathrm{C}$. e The

heat and a freestanding structure was achieved. The group presented two different approaches, capacitive (Fig. 12a-i) [340] and piezoelectric (Fig. 12a-ii) [341], which operate by the principle of capacitance change and generating charge, respectively. The change in capacitance or charge that arises due to the deformation of the electrode along with the vibration during movement is recorded and analyzed. Åkerfeldt et al. (2015) presented a proof-of-concept glove that can detect human motion accurately [342]. The electrodes and interconnections were screen printed using PEDOT:PSS ink, whereas the sensor was based on bi-component fiber. A robot gripper was operated using the glove demonstrating the potential application in rehabilitation. Inkjet printed graphene/silver composite ink demonstrated similar results by responding to the movement of arms [142]. (d)
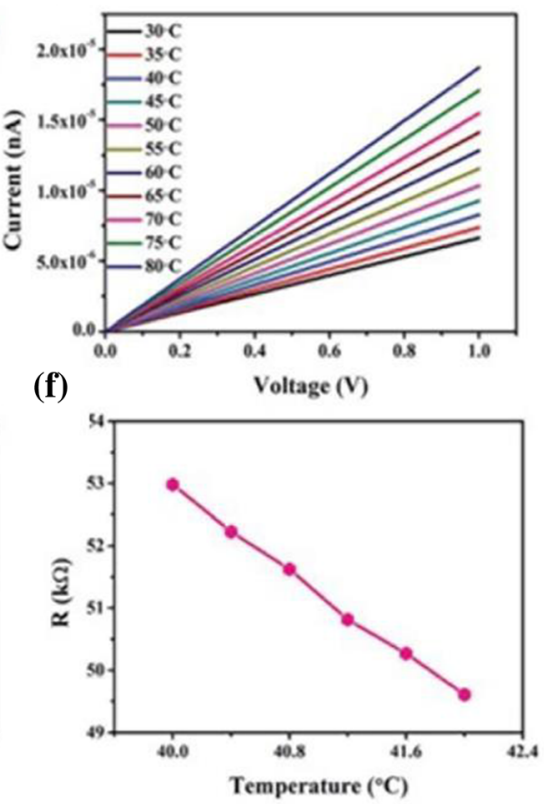

relation between resistance of the device and temperature. f Response resistance as a function of temperature. ([c-f] reproduced from ref. [228], Copyright (C) 2018 The Authors. Published by WILEY-VCH Verlag GmbH \& Co. KGaA, Weinheim).

Movement of human body can also be detected by applying pressure and recording the change in resistance or capacitance. Zhou et al. (2018) fabricated an all-fabric based piezoresistive pressure sensor by screen printing of silver paste and AgNWs on cotton fabric (Fig. 12b) [65]. The sensor demonstrated excellent sensitivity and able to detect wide range of pressure 0-30 kPa. The sensor has a detection limit of $0.76 \mathrm{~Pa}$ and response time of $6 \mathrm{~ms}$.

Apart from detecting and recording movements, textile electrodes have shown the capability of assisting in the exercise required for the rehabilitation process. Neural impairment often results in physical disability to an extent where patients cannot exercise by themselves and require continuous assistance [344]. Functional electrical stimulation (FES) activates nerves using electrical current and assists physically 


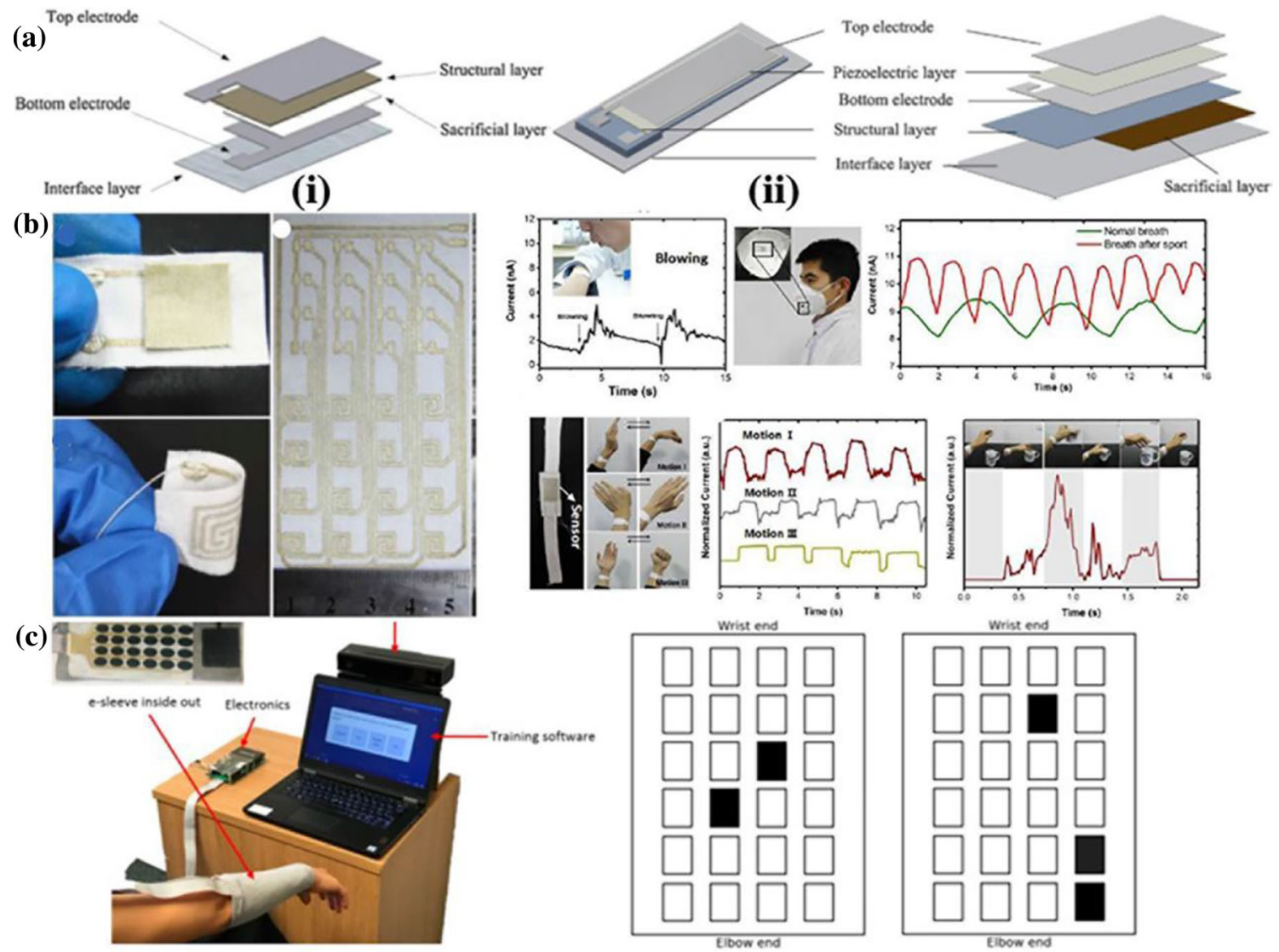

Figure 12 a Schematic diagram of the cantilever base (1) capacitive and (2) piezoelectric motion sensor. (Reproduced with permission from ref. [340, 341], Copyright (C) 2013 IOP Publishing, Copyright (C) 2013 Elsevier) b Photograph of textile pressure sensor with large-area circuits on cotton fabric and responses for blowing, respiration, and arms movement.

challenged people to practice the desired gesture (Fig. 12c). Yang and co-workers developed fabricbased electrode arrays for FES applications [343, 345]. Using motion sensors, the desired gesture is recorded, and the control algorithm calculates a combination of array elements and their stimulation level to reproduce the movement pattern.

The detection response, limit, and ranges of activity monitoring devices reported in the last decade using printed textile electrodes are very satisfactory for practical applications. Though an extremely elastic sensor surged in the past couple of years, the extensibility of the sensor depends on application requirements. The human body undergoes around 5-50\% extension due to different movements. While monitoring the movement of arms and legs requires large extensibility of the sensor, detecting the facial expression, finger movement, speech, etc. requires
(Reproduced with permission from ref. [65], Copyright (C) 2018 The Royal Society of Chemistry) c FES training system (Left), stimulation for hand opening gesture (Middle), and stimulation pattern for pointing gesture (Right). (Reproduced from ref. [343], Copyright (C) 2018. The Authors. Published by MDPI).

very small motion detection. The sensitivity requirement also depends on the user requirement whether the sensor being used to detect small or large motion. However, there are different issues yet to solve for the device to be used for remote monitoring in clinical settings. There is a possibility of noise introduction in the signal due to the unwanted movement of the body and a loose-fitting of the sensor may reduce signal quality. An ideal sensor requires multilevel integration of different systems like a functional unit, data conversion, and transfer, reliability, and reproducibility, robustness for long-term and continuous monitoring, etc. The rapid development of nanotechnology, artificial intelligence, and self-powered electronics might significantly assist activity monitoring sensors transitioning from consumer electronics to clinical diagnostics devices. 


\section{Challenges and future perspectives}

The human body is the storehouse of information related to health and a huge portion of that information cannot be detected or analyzed by naked eyes and thus require sophisticated equipment in healthcare settings. Unfortunately, continuous health monitoring of the large population in the traditional system requires regular visits to health-care professionals, which is not a feasible idea due to lack of infrastructure, and health experts. Additionally, frequent visit to the health-care center is time-consuming and expensive. Moreover, sophisticated equipment is rigid, mostly non-portable, and not suitable for usage at home as those require proper training to operate. The recent surge of consumer electronics and different activity trackers demonstrated the potential of wearable health monitoring. However, consumer electronics suffer from bulkiness, high cost, and unreliable data. The integration of sensing functionality into textiles is revolutionary because textiles are often annotated as the second skin and indispensable part of the human being after birth. Therefore, textile-based wearable health monitoring devices eliminate the requirements of additional electronic devices, and high flexibility and lightweight characteristics do not affect regular movement in daily life. Furthermore, textiles drape [346] well with the curvy body shape and can detect the movement precisely [347] and easier to expose to the body fluids [348, 349]. Implementing sensing properties for data acquisition, systems for storing, analyzing, and transmitting those data to warn and act while retaining properties of textiles, an integrated, continuous, remote, textile-based health-care facility providing system can be developed [350]. However, there still a lot of challenges with printed wearable health monitoring devices.

The first challenge posed by the textile-based electrode is seamless integration. Coating [351, 352] and printing [149] are the two commonly used methods with the potential of scalability. Coating fiber or yarn with active material and then weaving or knitting into fabric or direct coating on the fabric is widely popular. However, the coating method has a limitation of higher material usage and wastage while localized deposition of active material is also challenging [353]. Furthermore, this method often forms a film on the textile surface that does not comply with the characteristics of textile materials
[354]. Unlike the coating process, printing is performed mainly on two-dimensional fabric and has better control of active material deposition in almost any pattern on demand. This reduces material wastage and retains the characteristics of textile materials. However, one of the major drawbacks of the printing process compared to coating is limited material structures. It is extremely difficult to deposit conductive materials on low-dimensional or one-dimensional materials. Therefore, the traditional seamless integration process such as advanced weaving, knitting, and embroidery techniques is advantageous because these techniques do not affect the inherent characteristics of the substrates. Moreover, electrodes with complex structural geometry can be produced by these techniques.

The second challenge of developing printed electrodes on textile substrates is the surface roughness and porosity of textile fabric. Homogenous patterning of conductive ink in the desired place is critical for developing high-performance devices. The porosity and rough surface of textile fabric tend to localize and bleed the ink [355]. Therefore, earlier works demonstrated the use of an interface layer to smoothen the textile surface for better interconnection of inks [356]. This approach requires an additional protective layer to ensure that interconnects do not interfere with the signals acquired by the electrodes. However, the deposition of the interface and protective layer makes the process complicated and greatly affects the characteristics of textile fabric. To overcome this issue, isotropic nonwoven textile structures would be more suitable to decrease surface roughness. Further research on ink rheology and printing techniques is required to develop a fully compatible printing system for textiles substrates.

The third challenge of printed electrodes is a proper understanding of ink chemistry. The viscosity of conductive ink requires precise tuning for textile usage and often fails to comply with the stretchability of textile substrate, i.e., propagates crack and thus conduction network ruptures. The nanomaterialsbased active materials agglomerate in the nozzle and hamper proper printing procedure [80]. In this review, we have discussed several works that have addressed these problems of the printed textile electrode. By controlling ink chemistry and precise designing of the process parameters, i.e., pressure, temperature, the successful development of the textile electrode without any pre-treatment has been 
reported. Additionally, high-temperature post-treatment of deposited ink has been addressed [205]. Inkjet printing of particle-free ink could be an excellent solution to nozzle clogging during printing. Therefore, further research on particle-free inks would accelerate the development of highly efficient printed electrodes in future. Besides, elastomeric polymer-based nanocomposite ink and controlled permeation of ink into the fiber bulk would render textile electrodes with high elasticity for wearable and long-term monitoring applications.

The fourth challenge of textile-based dry electrodes is high impedance and this increases when exposed to sweat. Accurate data acquisition requires low skin impedance in the case of biopotential signal monitoring [357]. The addition of ionic liquid gel improved the performance and achieved better performance than commercial $\mathrm{Ag} / \mathrm{AgCl}$ electrodes [166]. Additionally, textile electrodes are prone to motion artifacts, i.e., higher noisy signal and baseline drift arises with the movement which is not desirable [262]. Therefore, textile electrodes printed on elastic substrates or compression garments can reduce the motion artifacts due to their high skin conformability. It is essential to explore different materials and designs (such as beads, needles, spheres, microarrays, wrinkled patterns, etc.) to produce highly sensitive biochemical printed electrodes for detecting subtle motion accurately.

The fifth challenge of the printed textile electrode is durability [358, 359]. The reported mechanical stability of printed textile electrodes is limited to a few thousand bending cycles, which in turn limits the possibility of long-term usage of the sensors. Additionally, metallic ink has a low binding affinity with a textile structure, and therefore, frequent bending, twisting, and stretching may severely damage the electrodes. The regular use of the printed electrodes requires laundering, and there is not enough report to evaluate the wash durability of the printed electrodes. Poor wash durability of printed textile electrodes could be a bottleneck for the long-term and continuous monitoring applications. However, carbonaceous materials such as graphene, MXenes (metal carbides/nitrides) emerged as promising materials for fabricating wearable electrodes. MXene contains functional groups on their surface which could be used to react/cross-link with textiles for developing durable electrodes. Besides, different encapsulation chemical treatments could be carried out to protect the active materials during laundering.

The sixth challenge of the printed electrode is powering them for continuous and long-term monitoring applications. While the functionality of the electrodes improved significantly in the last decade, designing self-powered electrodes still in the early stage. Connecting an external power source greatly reduces the wearability and portability of the devices. Therefore, low-power-consuming devices such as Bluetooth Low Energy (BLE) should be used. Moreover, transferring raw sensor data require higher energy, and therefore, a proper algorithm needs to develop and/or optimized to process the raw data before transferring it to the user. Recently, different nanogenerators such as piezoelectric, pyroelectric, and thermoelectric emerged as promising energy harvester which could be coupled with wearable sensors to provide sufficient powers. However, the efficiency of these nanogenerators should be considered before interfacing with wearable sensors.

These challenges and problems are required to be addressed in future works for the successful implementation of printing technology to develop electrodes for health-care applications on a large scale. The printing-based approach showed various prototype devices mostly on laboratory scale, and it is essential to develop fully functional commercial devices for practical applications. Most of the research reports are limited to silver inks, and other conductive materials and their composites need to be studied. We have discussed literature that has already focused on overcoming some of the challenges of printing textile electrodes and may pave the way for the development of chemically and mechanically stable, accurate, and reliable wearable health monitoring devices. Powering these devices is the major concern for remote and continuous monitoring applications. The self-powered wearable sensor is still under development and may require a couple of years to realize the feasibility of wearable health monitoring devices. Though a few research successfully demonstrated the use of bio-based ink, further investigation of biocompatible ink for biochemical sensing is required. By continuing this trend further, it is possible to achieve textile electrodes for health-care applications with low material consumption while printed patterns can enhance the aesthetic property along with functionality and reliability. 
Living amid a global pandemic, we are realizing the importance of continuous human health monitoring which is critical for the prediction and early detection of diseases. By monitoring subtle changes in health conditions, a forward-looking system can be developed. The successful development of low-cost and durable printed textile electrodes could save millions of lives during pandemic like coronavirus disease 2019 (COVID-19). To fight diseases like COVID-19, the most effective tool is diagnostics, and isolate infected individuals as soon as possible, preventing the spread. Shortness of breath and temperature variation is one of the two major symptoms of COVID-19 [360]. While it is impossible to continuously monitor the large population in the clinical setting, a point-of-care detection by using wearable health monitoring sensors could be an excellent preventive measure to trace the infected patients [361]. Using a printed temperature monitoring sensor, the body temperature over the weeks or months could be analyzed and any anomaly in the temperature pattern could signal the user a potential risk and may consult a physician at an early stage. Moreover, the patient could isolate themselves and avoid spreading the COVID-19 unknowingly. Similarly, the strain/pressure sensor could be used for continuous breath monitoring and analysis the respiratory behavior regularly $[362,363]$. While this might not be the clinical level and accurate detection, this could be used as preventive action by mass people to prevent the unwanted spreading of COVID-19. However, it is important to note that wearable sensors could be used to detect only a few symptoms related to COVID-19, but patients should always consult with health-care professionals.

\section{Conclusion}

The current contribution highlights the possibility of printed electrodes for wearable health monitoring applications. A large number of conductive materials have been printed on textile substrates, and their performance has been evaluated. However, improving the sensor performance depends on different parameters of printing, textile structures, and conductive materials being used. Sensitivity and linearity can be customized by innovative device design and using novel materials. However, printed textile electrodes have been extensively used for biopotential monitoring compared to biochemical sensing. While the functionality of printed wearable health monitoring is enhanced significantly, the reliability of data requires further improvement. Though electronic fabrication of electrodes has better data reliability, the printed electrode has the potential for bulk-scale fabrication and cost reduction to make the device reachable to mass people. A multidisciplinary approach can accelerate the transition of printed health monitoring devices for practical applications and facilitate a better health-care system.

\section{References}

[1] Rebovich ME, Vynias D, Frey MW (2010) Formation and functions of high-surface-area fabrics. Int J Fash Des, Technol Educ 3:129-134. https://doi.org/10.1080/1754326 6.2010 .511279

[2] Jakšić D, Jakšić N (2007) Assessment of porosity of flat textile fabrics. Text Res J 77:105-110. https://doi.org/10. 1177/0040517506065892

[3] Ozdemir H (2017) Permeability and wicking properties of modal and lyocell woven fabrics used for clothing. J Eng Fibers Fabr 12:155892501701200100. https://doi.org/10.1 $177 / 155892501701200102$

[4] Backer S (1951) The relationship between the structural geometry of a textile fabric and its physical properties: Part IV: interstice geometry and air permeability. Text Res J 21:703-714. https://doi.org/10.1177/004051755102101002

[5] Cho J, Moon J, Jeong K, Cho G (2007) Application of PUsealing into $\mathrm{Cu} / \mathrm{Ni}$ electroless plated polyester fabrics for e-textiles. Fibers Polym 8:330-334. https://doi.org/10.100 7/BF02877279

[6] Ling H, Liu S, Zheng Z, Yan F (2018) Organic flexible electronics. Small Methods 2:1800070. https://doi.org/10. 1002/smtd.201800070

[7] Acar G, Ozturk O, Golparvar AJ et al (2019) Wearable and flexible textile electrodes for biopotential signal monitoring: a review. Electronics 8:479. https://doi.org/10.3390/e lectronics 8050479

[8] Heo JS, Eom J, Kim Y-H, Park SK (2018) Recent progress of textile-based wearable electronics: a comprehensive review of materials, devices, and applications. Small 14:1703034. https://doi.org/10.1002/smll.201703034

[9] Zeng W, Shu L, Li Q et al (2014) Fiber-based wearable electronics: a review of materials, fabrication, devices, and applications. Adv Mater 26:5310-5336. https://doi.org/10. 1002/adma.201400633 
[10] Possanzini L, Tessarolo M, Mazzocchetti L et al (2019) Impact of fabric properties on textile pressure sensors performance. Sensors 19:4686. https://doi.org/10.3390/ s19214686

[11] Gonçalves C, Silva A, Gomes J, Simoes R (2018) Wearable E-textile technologies: a review on sensors. Actuators Control Elem Inven 3:14. https://doi.org/10.3390/inve ntions 3010014

[12] Islam GMN, Ali A, Collie S (2020) Textile sensors for wearable applications: a comprehensive review. Cellulose 27:6103-6131. https://doi.org/10.1007/s10570-020-032155

[13] Seyedin S, Zhang P, Naebe M et al (2019) Textile strain sensors: a review of the fabrication technologies, performance evaluation and applications. Mater Horiz 6:219-249. https://doi.org/10.1039/C8MH01062E

[14] Peng Y, Cui Y (2020) Advanced textiles for personal thermal management and energy. Joule 4:724-742. https://d oi.org/10.1016/j.joule.2020.02.011

[15] Hu R, Liu Y, Shin S et al (2020) Emerging materials and strategies for personal thermal management. Adv Energy Mater 10:1903921. https://doi.org/10.1002/aenm. 201903921

[16] Peng L, Su B, Yu A, Jiang X (2019) Review of clothing for thermal management with advanced materials. Cellulose. $\mathrm{h}$ ttps://doi.org/10.1007/s10570-019-02534-6

[17] Park J (2020) Functional fibers, composites and textiles utilizing photothermal and joule heating. Polymers 12:189. https://doi.org/10.3390/polym12010189

[18] Priya A, Kumar A, Chauhan B (2015) A review of textile and cloth fabric wearable antennas. Int $\mathrm{J}$ Comp App 116:975-8887. https://doi.org/10.5120/20425-2741

[19] Roh J-S, Chi Y-S, Kang TJ (2010) Wearable textile antennas. Ints J Fash Des, Technol Educ 3:135-153. http s://doi.org/10.1080/17543266.2010.521194

[20] Loss C, Gonçalves R, Pinho P, Salvado R (2020) A review of methods for the electromagnetic characterization of textile materials for the development of wearable antennas. In: Georgiadis A (ed) Carvalho NB. Wireless power transmission for sustainable electronics, Wiley, pp 27-56

[21] Shahariar H, Soewardiman H, Jur JS (2017) Fabrication and packaging of flexible and breathable patch antennas on textiles. SoutheastCon 2017:1-5

[22] Nilsson E, Mateu L, Spies P, Hagström B (2014) Energy harvesting from piezoelectric textile fibers. Procedia Eng 87:1569-1572. https://doi.org/10.1016/j.proeng.2014.11. 600

[23] Hu Y, Zheng Z (2019) Progress in textile-based triboelectric nanogenerators for smart fabrics. Nano Energy 56:16-24. h ttps://doi.org/10.1016/j.nanoen.2018.11.025
[24] Xu L, Fu X, Liu F et al (2020) A perovskite solar cell textile that works at -40 to $160{ }^{\circ} \mathrm{C}$. J Mater Chem A 8:5476-5483. https://doi.org/10.1039/C9TA13785H

[25] Ahmad K (2020) Textiles in solar cell applications. In: Ahmed S, Sheikh JN (eds) Shabbir M. Frontiers of textile materials, Wiley, pp 203-217

[26] Jost K, Dion G, Gogotsi Y (2014) Textile energy storage in perspective. J Mater Chem A. https://doi.org/10.1039/ C4TA00203B

[27] Huang Q, Wang D, Zheng Z (2016) Textile-based electrochemical energy storage devices. Adv Energy Mater 6:1600783. https://doi.org/10.1002/aenm.201600783

[28] Hui C, Kan C, Mak C, Chau K (2019) Flexible energy storage system - an introductory review of textile-based flexible supercapacitors. Processes 7:922. https://doi.org/1 0.3390/pr7120922

[29] Tebyetekerwa M, Marriam I, Xu Z et al (2019) Critical insight: challenges and requirements of fibre electrodes for wearable electrochemical energy storage. Energy Environ Sci 12:2148-2160. https://doi.org/10.1039/C8EE02607F

[30] Ghouri AS, Aslam R, Siddiqui MS, Sami SK (2020) recent progress in textile-based flexible supercapacitor. Front Mater. https://doi.org/10.3389/fmats.2020.00058

[31] Sundriyal P, Bhattacharya S (2020) Textile-based supercapacitors for flexible and wearable electronic applications. Sci Rep 10:13259. https://doi.org/10.1038/s41598-020-70 $182-\mathrm{z}$

[32] Gulzar U, Goriparti S, Miele E et al (2016) Next-generation textiles: from embedded supercapacitors to lithium ion batteries. J Mater Chem A 4:16771-16800. https://doi.org/ 10.1039/C6TA06437J

[33] Normann M, Grethe T, Schwarz-Pfeiffer A, Ehrmann A (2017) Development and characterization of textile batteries. IOP Conf Ser: Mater Sci Eng 175:012058. https://doi. org/10.1088/1757-899X/175/1/012058

[34] Lund A, Rundqvist K, Nilsson E et al (2018) Energy harvesting textiles for a rainy day: woven piezoelectrics based on melt-spun PVDF microfibres with a conducting core. Flex Electron 2(1):1-9

[35] Torah R, Lawrie-Ashton J, Li Y et al (2018) Energy-harvesting materials for smart fabrics and textiles. MRS Bull 43:214-219. https://doi.org/10.1557/mrs.2018.9

[36] Gu Y, Zhang T, Chen $\mathrm{H}$ et al (2019) Mini review on flexible and wearable electronics for monitoring human health information. Nanoscale Res Lett 14:263. https://oi.org/10. 1186/s11671-019-3084-x

[37] Lu Y, Lou Z, Jiang K et al (2019) Recent progress of selfpowered wearable monitoring systems integrated with microsupercapacitors. Materials Today Nano 8:100050. h ttps://doi.org/10.1016/j.mtnano.2019.100050 
[38] Shi Q, He T, Lee C (2019) More than energy harvesting Combining triboelectric nanogenerator and flexible electronics technology for enabling novel micro-/nano-systems. Nano Energy 57:851-871. https://doi.org/10.1016/j.nanoe n.2019.01.002

[39] Gualandi I, Marzocchi M, Achilli A et al (2016) Textile organic electrochemical transistors as a platform for wearable biosensors. Sci Rep 6:33637. https://doi.org/10.1038/ srep33637

[40] Gualandi I, Tessarolo M, Mariani F et al (2018) Nanoparticle gated semiconducting polymer for a new generation of electrochemical sensors. Sens Actuators, B Chem. https://d oi.org/10.1016/j.snb.2018.06.109

[41] Jia J, Xu C, Pan S et al (2018) Conductive thread-based textile sensor for continuous perspiration level monitoring. Sensors (Basel). https://doi.org/10.3390/s18113775

[42] Kim J, Imani S, de Araujo WR et al (2015) Wearable salivary uric acid mouthguard biosensor with integrated wireless electronics. Biosens Bioelectron 74:1061-1068. h ttps://doi.org/10.1016/j.bios.2015.07.039

[43] An X, Stylios GK (2018) A hybrid textile electrode for electrocardiogram (ECG) measurement and motion tracking. Materials (Basel). https://doi.org/10.3390/ma11101887

[44] Guo L, Sandsjö L, Ortiz-Catalan M, Skrifvars M (2020) Systematic review of textile-based electrodes for long-term and continuous surface electromyography recording. Text Res J 90:227-244. https://doi.org/10.1177/ 0040517519858768

[45] Fleury A, Alizadeh M, Stefan G, Chau T (2017) Toward fabric-based EEG access technologies: seamless knit electrodes for a portable brain-computer interface. In: 2017 IEEE Life Sciences Conference (LSC). pp 35-38

[46] Lugoda P, Costa JC, Oliveira C et al (2019) Flexible temperature sensor integration into E-textiles using different industrial yarn fabrication processes. Sensors 20:73. http s://doi.org/10.3390/s20010073

[47] Cho H-S, Koo S-M, Lee J et al (2011) Heart monitoring garments using textile electrodes for healthcare applications. J Med Syst 35:189-201. https://doi.org/10.1007/s10 916-009-9356-8

[48] Cho G, Jeong K, Paik MJ et al (2011) Performance evaluation of textile-based electrodes and motion sensors for smart clothing. IEEE Sens J 11:3183-3193. https://doi.org/ 10.1109/JSEN.2011.2167508

[49] Yu Y, Nyein HYY, Gao W, Javey A (2020) Flexible electrochemical bioelectronics: the rise of in situ bioanalysis. Adv Mater 32:1902083. https://doi.org/10.1002/adma. 201902083

[50] Agrawal DR, Tanabe Y, Weng D et al (2017) Conformal phased surfaces for wireless powering of bioelectronic microdevices. Nat Biomed Eng. https://doi.org/10.1038/s4 1551-017-0043

[51] Khan Y, Ostfeld AE, Lochner CM et al (2016) monitoring of vital signs with flexible and wearable medical devices. Adv Mater 28:4373-4395. https://doi.org/10.1002/adma. 201504366

[52] Chung D, Gray BL (2019) Editors' choice-development of screen-printed flexible multi-level microfluidic devices with integrated conductive nanocomposite polymer electrodes on textiles. J Electrochem Soc 166:B3116-B3124. h ttps://doi.org/10.1149/2.0191909jes

[53] Bhushan P, Umasankar Y, RoyChoudhury S et al (2019) Biosensor for monitoring uric acid in wound and its proximity: a potential wound diagnostic tool. J Electrochem Soc 166:B830-B836. https://doi.org/10.1149/2.1441910jes

[54] Zhou Y, Ding X, Zhang J et al (2014) Fabrication of conductive fabric as textile electrode for ECG monitoring. Fibers Polym 15:2260-2264. https://doi.org/10.1007/s122 21-014-2260-y

[55] Bansal M, Gandhi B (2019) CNT based electrodes (wearable \& textile-based) for cardiac monitoring in long term \& continuous fashion. AIP Conf Proc 2201:020023. https://d oi.org/10.1063/1.5141447

[56] Beach C, Karim N, Casson AJ (2018) Performance of graphene ECG electrodes under varying conditions. In: 2018 40th Annual International Conference of the IEEE Engineering in Medicine and Biology Society (EMBC). pp 3813-3816

[57] Noh Y, Bales JR, Reyes BA et al (2016) Novel conductive carbon black and polydimethlysiloxane ecg electrode: a comparison with commercial electrodes in fresh, chlorinated, and salt water. Ann Biomed Eng 44:2464-2479. h ttps://doi.org/10.1007/s10439-015-1528-8

[58] Lam DV, Jo K, Kim C-H et al (2016) Activated carbon textile via chemistry of metal extraction for supercapacitors. ACS Nano 10:11351-11359. https://doi.org/10.1021/ acsnano.6b06608

[59] Zhang L, Fairbanks M, Andrew TL (2017) Rugged textile electrodes for wearable devices obtained by vapor coating off-the-shelf. Plain-Woven Fabrics Adv Funct Mater 27:1700415. https://doi.org/10.1002/adfm.201700415

[60] Schwarz A, Hakuzimana J, Kaczynska A et al (2010) Gold coated para-aramid yarns through electroless deposition. Surf Coat Technol 204:1412-1418. https://doi.org/10.1016/ j.surfcoat.2009.09.038

[61] Foroughi J, Spinks GM, Wallace GG, Whitten PG (2008) Production of polypyrrole fibres by wet spinning. Synth Met 158:104-107. https://doi.org/10.1016/j.synthmet.2007. 12.008 
[62] Zhang J, Seyedin S, Qin S et al (2019) Fast and scalable wet-spinning of highly conductive PEDOT:PSS fibers enables versatile applications. J Mater Chem A 7:6401-6410. https://doi.org/10.1039/C9TA00022D

[63] Lima MD, Fang S, Lepro X et al (2011) Biscrolling nanotube sheets and functional guests into yarns. Science 331:51-55. https://doi.org/10.1126/science.1195912

[64] Paul G, Torah R, Beeby S, Tudor J (2015) Novel active electrodes for ECG monitoring on woven textiles fabricated by screen and stencil printing. Sens Actuators, A 221:60-66. https://doi.org/10.1016/j.sna.2014.10.030

[65] Zhou Z, Li Y, Cheng J et al (2018) Supersensitive all-fabric pressure sensors using printed textile electrode arrays for human motion monitoring and human-machine interaction. J Mater Chem C 6:13120-13127. https://doi.org/10.1039/ C8TC02716A

[66] Torah R, Wei Y, Li Y et al (2015) Printed textile-based electronic devices. In: Tao X (ed) Handbook of smart textiles. Springer Singapore, Singapore, pp 653-687

[67] Mather RR, Wardman RH (2015) The chemistry of textile fibres, 2nd edn. Royal Society of Chemistry, Cambridge

[68] Bunsell AR (2018) Introduction to the science of fibers. In: Bunsell AR (ed) Handbook of properties of textile and technical fibres. Woodhead Publishing, Netherlands, pp 1-20

[69] Cook JG (1984) Handbook of textile fibres: Natural Fibres. McGraw Hill Professional

[70] Denton MJ, Daniels PN (2002) Textile Terms and Definitions, 11th Revised, edition. The Textile Institute, Manchester, UK

[71] Chatterjee K, Ghosh TK (2020) 3D printing of textiles: potential roadmap to printing with fibers. Adv Mater 32:1902086. https://doi.org/10.1002/adma.201902086

[72] Russell SJ, Institute T (2007) Handbook of nonwovens. CRC Press, Boca Raton

[73] Adanur S (2019) Handbook of Weaving. CRC Press

[74] Au KF (2011) Advances in knitting technology. Woodhead Publ, Oxford

[75] Mestrovic MA, Helmer RJN, Kyratzis L, Kumar D (2007) Preliminary study of dry knitted fabric electrodes for physiological monitoring. In: 2007 3rd International Conference on Intelligent Sensors, Sensor Networks and Information. https://doi.org/10.1109/ISSNIP.2007.4496911

[76] Muhammad Sayem AS, Hon Teay S, Shahariar H et al (2020) Review on smart electro-clothing systems (SeCSs). Sensors 20:587. https://doi.org/10.3390/s20030587

[77] Xu PJ, Zhang H, Tao XM (2008) Textile-structured electrodes for electrocardiogram. Text Prog 40:183-213. http s://doi.org/10.1080/00405160802597479
[78] Takamatsu S, Itoh T (2016) Mechanical characterization of biomedical electrode on knit textile. In: 2016 Symposium on Design, Test, Integration and Packaging of MEMS/ MOEMS (DTIP). pp 1-4

[79] Karim N, Afroj S, Malandraki A et al (2017) All inkjetprinted graphene-based conductive patterns for wearable e-textile applications. J Mater Chem C 5:11640-11648. h ttps://doi.org/10.1039/C7TC03669H

[80] Shahariar H, Kim I, Soewardiman H, Jur JS (2019) Inkjet printing of reactive silver ink on textiles. ACS Appl Mater Interfac 11:6208-6216. https://doi.org/10.1021/acsami.8b 18231

[81] Ho DH, Cheon S, Hong P et al (2019) Multifunctional smart textronics with blow-spun nonwoven fabrics. Adv Func Mater 29:1900025. https://doi.org/10.1002/adfm. 201900025

[82] Sun M, Lv J, Xu H et al (2020) Smart cotton fabric screenprinted with viologen polymer: photochromic, thermochromic and ammonia sensing. Cellulose 27:2939-2952. https://doi.org/10.1007/s10570-020-029923

[83] Li BM, Kim I, Zhou Y et al (2019) Kirigami-Inspired Textile Electronics: K.I.T.E. Adv Mater Technol 4(11):1900511. https://doi.org/10.1002/admt.201900511

[84] Kang T-H, Merritt CR, Grant E et al (2008) Nonwoven fabric active electrodes for biopotential measurement during normal daily activity. IEEE Trans Biomed Eng 55:188-195. https://doi.org/10.1109/TBME.2007.910678

[85] Zhao S, Li J, Cao D et al (2017) Recent advancements in flexible and stretchable electrodes for electromechanical sensors: strategies, materials, and features. ACS Appl Mater Interfac 9:12147-12164. https://doi.org/10.1021/acsa mi.6b13800

[86] Heikenfeld J, Jajack A, Rogers J et al (2018) Wearable sensors: modalities, challenges, and prospects. Lab Chip 18:217-248. https://doi.org/10.1039/C7LC00914C

[87] Park SI, Brenner DS, Shin G et al (2015) Soft, stretchable, fully implantable miniaturized optoelectronic systems for wireless optogenetics. Nat Biotechnol 33:1280-1286. http s://oi.org/10.1038/nbt.3415

[88] Park J, Lee Y, Hong J et al (2014) Giant tunneling piezoresistance of composite elastomers with interlocked microdome arrays for ultrasensitive and multimodal electronic skins. ACS Nano 8:4689-4697. https://doi.org/10. 1021/nn500441k

[89] Kim J-O, Kwon SY, Kim Y et al (2019) Highly ordered 3D microstructure-based electronic skin capable of differentiating pressure, temperature, and proximity. ACS Appl Mater Interfac 11:1503-1511. https://doi.org/10.1021/acsa mi.8b19214 
[90] Liu S, Zheng R, Chen S et al (2018) A compliant, selfadhesive and self-healing wearable hydrogel as epidermal strain sensor. J Mater Chem C 6:4183-4190. https://doi.org/ 10.1039/C8TC00157J

[91] Benight SJ, Wang C, Tok JBH, Bao Z (2013) Stretchable and self-healing polymers and devices for electronic skin. Prog Polym Sci 38:1961-1977. https://doi.org/10.1016/j.p rogpolymsci.2013.08.001

[92] Tadakaluru S, Thongsuwan W, Singjai P (2014) Stretchable and flexible high-strain sensors made using carbon nanotubes and graphite films on natural rubber. Sensors 14:868-876. https://doi.org/10.3390/s140100868

[93] Economou A, Kokkinos C, Prodromidis M (2018) Flexible plastic, paper and textile lab-on-a chip platforms for electrochemical biosensing. Lab Chip 18:1812-1830. https://d oi.org/10.1039/C8LC00025E

[94] Tessarolo M, Gualandi I, Fraboni B (2018) recent progress in wearable fully textile chemical sensors. Adv Mater Technol 3:1700310. https://doi.org/10.1002/admt. 201700310

[95] Yuan L, Dai J, Fan X et al (2011) Self-cleaning flexible infrared nanosensor based on carbon nanoparticles. ACS Nano 5:4007-4013. https://doi.org/10.1021/nn200571q

[96] Lee S-M, Kim SH, Lee JH et al (2018) Hydrophobic and stretchable Ag nanowire network electrode passivated by a sputtered PTFE layer for self-cleaning transparent thin film heaters. RSC Adv 8:18508-18518. https://doi.org/10.1039/ C8RA00880A

[97] Koehler A (2013) Challenges for eco-design of emerging technologies: the case of electronic textiles. Mater Des 51:51-60. https://doi.org/10.1016/j.matdes.2013.04.012

[98] Paosangthong W, Torah R, Beeby S (2019) Recent progress on textile-based triboelectric nanogenerators. Nano Energy 55:401-423. https://doi.org/10.1016/j.nanoen.2018.10.036

[99] Wang L, Zhang K (2020) Textile-based thermoelectric generators and their applications. Energy Environ Mater 3:67-79. https://doi.org/10.1002/eem2.12045

[100] Ryu J, Gao Y, Cho JH, Choi S (2020) Horizontally structured microbial fuel cells in yarns and woven fabrics for wearable bioenergy harvesting. J Power Sources. https://d oi.org/10.1016/j.jpowsour.2020.229271

[101] Bandodkar AJ, Wang J (2016) Wearable biofuel cells: a review. Electroanalysis 28:1188-1200. https://doi.org/10.1 002/elan.201600019

[102] Wilson JIB, Mather RR (2019) Photovoltaic solar textiles. Proceedings 32:4. https://doi.org/10.3390/proceeding s2019032004

[103] Shrivas K, Ghosale A, Bajpai PK et al (2020) Advances in flexible electronics and electrochemical sensors using conducting nanomaterials: a review. Microchem J 156:104944. https://doi.org/10.1016/j.microc.2020.104944

[104] Yan T, Wang Z, Pan Z-J (2018) Flexible strain sensors fabricated using carbon-based nanomaterials: a review. Curr Opin Solid State Mater Sci 22:213-228. https://doi.org/10. 1016/j.cossms.2018.11.001

[105] Wang Y, Liu A, Han Y, Li T (2020) Sensors based on conductive polymers and their composites: a review. Polym Int 69:7-17. https://doi.org/10.1002/pi.5907

[106] Hasan MM, Hossain MdM, Chowdhury HK (2020) Twodimensional MXene-based flexible nanostructures for functional nanodevices: a review. J Mater Chem A. https://d oi.org/10.1039/D0TA11103A

[107] Post ER, Orth M, Russo PR, Gershenfeld N (2000) E-broidery: Design and fabrication of textile-based computing. IBM Syst J 39:840-860. https://doi.org/10.1147/sj. 393.0840

[108] Chou K-S, Huang K-C, Lee H-H (2005) Fabrication and sintering effect on the morphologies and conductivity of nano-Ag particle films by the spin coating method. Nanotechnology 16:779-784. https://doi.org/10.1088/0957-44 $84 / 16 / 6 / 027$

[109] Gomes P, Tama D, Carvalho H, Souto AP (2020) Resistance variation of conductive ink applied by the screen printing technique on different substrates. Coloration Technol cote. https://doi.org/10.1111/cote.12451

[110] Naghdi S, Rhee KY, Hui D, Park SJ (2018) A review of conductive metal nanomaterials as conductive, transparent, and flexible coatings, thin films, and conductive fillers: different deposition methods and applications. Coatings 8:278. https://doi.org/10.3390/coatings8080278

[111] Momtaz Islam Md, Reza MA, Ahmed DM et al (2019) Facile metallization technique of textiles for electronic textile applications. In: Majumdar A, Gupta D, Gupta S (eds) Functional textiles and clothing. Springer, Singapore, pp 91-99

[112] Sreeju N, Rufus A, Philip D (2016) Microwave-assisted rapid synthesis of copper nanoparticles with exceptional stability and their multifaceted applications. J Mol Liq 221:1008-1021. https://doi.org/10.1016/j.molliq.2016.06. 080

[113] Roshanghias A, Krivec M, Baumgart M (2017) Sintering strategies for inkjet printed metallic traces in $3 \mathrm{D}$ printed electronics. Flex Print Electron 2:045002. https://doi.org/ 10.1088/2058-8585/aa8ed8

[114] Zhang Z, Zhang X, Xin Z et al (2013) controlled inkjetting of a conductive pattern of silver nanoparticles based on the coffee-ring effect. Adv Mater 25:6714-6718. https://doi.or g/10.1002/adma.201303278 
[115] Siqueira JR, Oliveira ON (2017) 9 - Carbon-based nanomaterials. In: Da Róz AL, Ferreira M, de Lima LF, Oliveira ON (eds) Nanostructures. William Andrew Publishing, USA, pp 233-249

[116] Jang H, Park YJ, Chen X et al (2016) Graphene-based flexible and stretchable electronics. Adv Mater 28:4184-4202. https://doi.org/10.1002/adma.201504245

[117] Zhang S, Cheng Y, Xu W et al (2017) Dispersibility of different sized graphene oxide sheets and their reinforcement on polyamide 6 fibers. RSC Adv 7:56682-56690. h ttps://doi.org/10.1039/C7RA12261F

[118] Konkena B, Vasudevan S (2012) Understanding aqueous dispersibility of graphene oxide and reduced graphene oxide through pKa measurements. J Phys Chem Lett 3:867-872. https://doi.org/10.1021/jz300236w

[119] Rao S, Upadhyay J, Polychronopoulou K et al (2018) Reduced graphene oxide: effect of reduction on electrical conductivity. J Compos Sci 2:25. https://doi.org/10.3390/jc s2020025

[120] Cai L, Wang C (2015) Carbon nanotube flexible and stretchable electronics. Nanoscale Res Lett 10:320. https://d oi.org/10.1186/s11671-015-1013-1

[121] Nessim GD (2010) Properties, synthesis, and growth mechanisms of carbon nanotubes with special focus on thermal chemical vapor deposition. Nanoscale 2:1306-1323. https://doi.org/10.1039/B9NR00427K

[122] Li QW, Li Y, Zhang XF et al (2007) Structure-dependent electrical properties of carbon nanotube fibers. Adv Mater 19:3358-3363. https://doi.org/10.1002/adma.200602966

[123] Sadi MdS, Pan J, Xu A et al (2019) Direct dip-coating of carbon nanotubes onto polydopamine-templated cotton fabrics for wearable applications. Cellulose 26:7569-7579. https://doi.org/10.1007/s10570-019-02628-1

[124] Cummins G, Desmulliez MPY (2012) Inkjet printing of conductive materials: a review. Circuit World 38:193-213. https://doi.org/10.1108/03056121211280413

[125] Azoubel S, Magdassi S (2010) The formation of carbon nanotube dispersions by high pressure homogenization and their rapid characterization by analytical centrifuge. Carbon 48:3346-3352. https://doi.org/10.1016/j.carbon.2010.05. 024

[126] Guo X, Huang Y, Cai X et al (2016) Capacitive wearable tactile sensor based on smart textile substrate with carbon black \hspace0. 167em/silicone rubber composite dielectric. Meas Sci Technol 27(4):045105

[127] Jost K, Stenger D, R. Perez C, et al (2013) Knitted and screen printed carbon-fiber supercapacitors for applications in wearable electronics. Energy Environ Sci 6:2698-2705. https://doi.org/10.1039/C3EE40515J
[128] Pang AL, Arsad A, Ahmadipour M (2021) Synthesis and factor affecting on the conductivity of polypyrrole: a short review. Polym Adv Technol 32:1428-1454. https://doi.org/ 10.1002/pat.5201

[129] Tseghai GB, Mengistie DA, Malengier B et al (2020) PEDOT:PSS-based conductive textiles and their applications. Sensors 20:1881. https://doi.org/10.3390/s20071881

[130] K N, Rout CS, (2021) Conducting polymers: a comprehensive review on recent advances in synthesis, properties and applications. RSC Adv 11:5659-5697. https://doi.org/ 10.1039/D0RA07800J

[131] Liu J, Wang X, Li D et al (2015) Thermal conductivity and elastic constants of PEDOT:PSS with high electrical conductivity. Macromolecules 48:585-591. https://doi.org/10. 1021/ma502099t

[132] Kim YH, Sachse C, Machala ML et al (2011) Highly conductive PEDOT:PSS electrode with optimized solvent and thermal post-treatment for ITO-free organic solar cells. Adv Func Mater 21:1076-1081. https://doi.org/10.1002/adf m.201002290

[133] Miles LWC, Society of Dyers and Colourists (1994) Textile printing, 2nd edn. Society of Dyers and Colourists, Bradford

[134] Basiricò L, Cosseddu P, Fraboni B, Bonfiglio A (2011) Inkjet printing of transparent, flexible, organic transistors. Thin Solid Films 520:1291-1294. https://oi.org/10.1016/j. tsf.2011.04.188

[135] Cui Z (2016) Printed electronics: materials, technologies and applications. Wiley/Higher Education Press, Hoboken, NJ, Solaris South Tower, Singapore

[136] Suganuma K (2014) Introduction to Printed Electronics. Springer, New York, NY

[137] Kamyshny A, Magdassi S (2019) Conductive nanomaterials for $2 \mathrm{D}$ and $3 \mathrm{D}$ printed flexible electronics. Chem Soc Rev 48:1712-1740. https://doi.org/10.1039/C8CS00738A

[138] Leach RH (2007) The Printing ink manual. Springer, Dordrecht

[139] Flick EW (1999) Printing ink and overprint varnish formulations, 2nd edn. Noyes Publications/William Andrew Pub, Norwich, N.Y.

[140] Streitberger H-J, Goldschmidt A (2018) BASF Handbook Basics of Coating Technology, 3rd, revised. Vincentz, Hannover

[141] Sreenilayam SP, Ahad IU, Nicolosi V et al (2020) Advanced materials of printed wearables for physiological parameter monitoring. Mater Today 32:147-177. https://d oi.org/10.1016/j.mattod.2019.08.005

[142] Karim N, Afroj S, Tan S et al (2019) All inkjet-printed graphene-silver composite ink on textiles for highly 
conductive wearable electronics applications. Sci Rep 9:1-10. https://doi.org/10.1038/s41598-019-44420-y

[143] Nomura K, Horii Y, Kanazawa S et al (2018) Fabrication of a textile-based wearable blood leakage sensor using screenoffset printing. Sensors 18:240. https://doi.org/10.3390/ s18010240

[144] Pani D, Dessì A, Saenz-Cogollo JF et al (2016) Fully textile, PEDOT:PSS based electrodes for wearable ECG monitoring systems. IEEE Trans Biomed Eng 63:540-549. https://doi.org/10.1109/TBME.2015.2465936

[145] Kim I, Shahariar H, Ingram WF et al (2019) Inkjet process for conductive patterning on textiles: maintaining inherent stretchability and breathability in knit structures. Adv Func Mater 29:1807573. https://doi.org/10.1002/adfm. 201807573

[146] Xu X, Luo M, He P et al (2019) Screen printed graphene electrodes on textile for wearable electrocardiogram monitoring. Appl Phys A 125:714. https://doi.org/10.1007/s003 39-019-3006-x

[147] Sinha SK, Noh Y, Reljin N et al (2017) Screen-printed PEDOT:PSS electrodes on commercial finished textiles for electrocardiography. ACS Appl Mater Interfac 9:37524-37528. https://doi.org/10.1021/acsami.7b09954

[148] Cruz SMF, Rocha LA, Viana JC (2018) Printing technologies on flexible substrates for printed electronics. Flex Electron. https://doi.org/10.5772/intechopen.76161

[149] Huang Q, Zhu Y (2019) Printing conductive nanomaterials for flexible and stretchable electronics: a review of materials, processes, and applications. Adv Mater Technol 4:1800546. https://doi.org/10.1002/admt.201800546

[150] Blayo A, Pineaux B (2005) Printing processes and their potential for RFID printing. In: Proceedings of the 2005 joint conference on Smart objects and ambient intelligence innovative context-aware services: usages and technologies sOc-EUSAI '05. ACM Press, Grenoble, France, p 27

[151] Sung D, de la Fuente VA, Subramanian V (2010) Scaling and optimization of gravure-printed silver nanoparticle lines for printed electronics. IEEE Trans Comp Packag Technol 33:105-114. https://doi.org/10.1109/TCAPT.2009. 2021464

[152] Lee T-M, Lee S-H, Noh J-H et al (2010) The effect of shear force on ink transfer in gravure offset printing. $\mathrm{J} \mathrm{Mi-}$ cromech Microeng 20:125026. https://doi.org/10.1088/096 $0-1317 / 20 / 12 / 125026$

[153] Julin T (2012) Flexo-printed piezoelectric PVDF pressure sensors

[154] Qin D, Xia Y, Whitesides GM (2010) Soft lithography for micro- and nanoscale patterning. Nat Protoc 5:491-502. h ttps://doi.org/10.1038/nprot.2009.234
[155] Kamyshny A (2011) Metal-based Inkjet Inks for Printed Electronics. TOAPJ 4:19-36. https://doi.org/10.2174/ 1874183501104010019

[156] Fuller SB, Wilhelm EJ, Jacobson JM (2002) Ink-jet printed nanoparticle microelectromechanical systems. J Microelectromech Syst 11:54-60. https://doi.org/10.1109/84.982863

[157] Perelaer J, S. U (2010) Inkjet printing and alternative sintering of narrow conductive tracks on flexible substrates for plastic electronic applications. In: Turcu C (ed) Radio frequency identification fundamentals and applications design methods and solutions. InTech

[158] Arnold CB, Piqué A (2007) Laser direct-write processing. MRS Bull 32:9-15. https://doi.org/10.1557/mrs2007.9

[159] Christenson KK, Paulsen JA, Renn MJ, et al (2011) Direct printing of circuit boards using aerosol Jet\&reg, International conference; 27th, Digital printing technologies; Digital fabrication. In: Digital printing technologies; Digital fabrication, International Conference On Digital Printing Technologies, International conference; 27th, Digital printing technologies; Digital fabrication. IS\&T -the Society for Imaging Science and Technology;, Springfield, Va., pp 433-436

[160] Hannebauer H, Dullweber T, Falcon T, Brendel R (2013) Fineline printing options for high efficiencies and low ag paste consumption. Energy Procedia 38:725-731. https://d oi.org/10.1016/j.egypro.2013.07.339

[161] Novaković D, Kašiković N, Vladić G, Pál M (2016) 15 Screen Printing. In: Izdebska J, Thomas S (eds) Printing on Polymers. William Andrew Publishing, Netherlands, pp 247-261

[162] Kang B, Lee WH, Cho K (2013) Recent advances in organic transistor printing processes. ACS Appl Mater Interfac 5:2302-2315. https://doi.org/10.1021/am302796z

[163] Halonen E, Viiru T, Ostman K et al (2013) Oven sintering process optimization for inkjet-printed ag nanoparticle ink. IEEE Trans Compon, Packag Manufact Technol 3:350-356. https://doi.org/10.1109/TCPMT.2012.2226458

[164] Niittynen J, Abbel R, Mäntysalo M et al (2014) Alternative sintering methods compared to conventional thermal sintering for inkjet printed silver nanoparticle ink. Thin Solid Films 556:452-459. https://doi.org/10.1016/j.tsf.2014.02. 001

[165] Clark D (2010) Major trends in gravure printed electronics. Graphic Communication

[166] Takamatsu S, Lonjaret T, Crisp D et al (2015) Direct patterning of organic conductors on knitted textiles for longterm electrocardiography. Sci Rep 5:15003. https://doi.org/ $10.1038 /$ srep 15003 
[167] Paul GM, Cao F, Torah R et al (2014) A smart textile based facial EMG and EOG computer interface. IEEE Sens J 14:393-400. https://doi.org/10.1109/JSEN.2013.2283424

[168] Achilli A, Bonfiglio A, Pani D (2018) Design and characterization of screen-printed textile electrodes for ECG monitoring. IEEE Sens J 18:4097-4107. https://doi.org/10. 1109/JSEN.2018.2819202

[169] Pani D, Achilli A, Spanu A et al (2019) Validation of polymer-based screen-printed textile electrodes for surface EMG detection. IEEE Trans Neural Syst Rehabil Eng 27:1370-1377. https://doi.org/10.1109/TNSRE.2019. 2916397

[170] Achilli A, Pani D, Bonfiglio A (2017) Characterization of screen-printed textile electrodes based on conductive polymer for ECG acquisition. In: 2017 Computing in Cardiology (CinC). pp 1-4

[171] Jung M, Jeon S, Bae J (2018) Scalable and facile synthesis of stretchable thermoelectric fabric for wearable self-powered temperature sensors. RSC Adv 8:39992-39999. http s://doi.org/10.1039/C8RA06664G

[172] Jin H, Matsuhisa N, Lee S et al (2017) Enhancing the performance of stretchable conductors for E-textiles by controlled ink permeation. Adv Mater 29:1605848. https://d oi.org/10.1002/adma.201605848

[173] Lahti M, Leppävuori S, Lantto V (1999) Gravure-offsetprinting technique for the fabrication of solid films. Appl Surf Sci 142:367-370. https://doi.org/10.1016/S0169-433 2(98)00676-X

[174] Shin K-H, Nguyen HAD, Park J et al (2017) Roll-to-roll gravure printing of thick-film silver electrode micropatterns for flexible printed circuit board. J Coat Technol Res 14:95-106. https://doi.org/10.1007/s11998-016-9844-y

[175] Kopola P, Aernouts T, Guillerez S et al (2010) High efficient plastic solar cells fabricated with a high-throughput gravure printing method. Sol Energy Mater Sol Cells 94:1673-1680. https://doi.org/10.1016/j.solmat.2010.05. 027

[176] Wang G, Adil MA, Zhang J, Wei Z (2019) Large-area organic solar cells: material requirements, modular designs, and printing methods. Adv Mater 31:1805089. https://doi. org/10.1002/adma.201805089

[177] Merklein L, Daume D, Braig F et al (2019) Comparative study of printed multilayer OLED fabrication through slot die coating, gravure and inkjet printing, and their combination. Colloids Interfac 3:32. https://doi.org/10.3390/coll oids 3010032

[178] Park J, Nguyen HAD, Park S et al (2015) Roll-to-roll gravure printed silver patterns to guarantee printability and functionality for mass production. Curr Appl Phys 15:367-376. https://doi.org/10.1016/j.cap.2015.01.007
[179] Ohsawa M, Hashimoto N, Takeda N et al (2020) Bending reliability of transparent electrode of printed invisible silver-grid/PEDOT:PSS on flexible epoxy film substrate for powder electroluminescent device. Microelectron Reliab 109:113673. https://doi.org/10.1016/j.microrel.2020. 113673

[180] Honarvar MG, Latifi M (2017) Overview of wearable electronics and smart textiles. J Text Inst 108:631-652. h ttps://doi.org/10.1080/00405000.2016.1177870

[181] Zhong ZW, Ee JH, Chen SH, Shan XC (2020) Parametric investigation of flexographic printing processes for R2R printed electronics. Mater Manuf Processes 35:564-571. h ttps://doi.org/10.1080/10426914.2020.1732411

[182] Gajadhur M, Regulska M (2020) Mechanical and light resistance of flexographic conductive ink films intended for printed electronics. Dyes Pigm 178:108381. https://doi.org/ 10.1016/j.dyepig.2020.108381

[183] Morgan ML, Curtis DJ, Deganello D (2019) Control of morphological and electrical properties of flexographic printed electronics through tailored ink rheology. Org Electron 73:212-218. https://doi.org/10.1016/j.orgel.2019. 05.027

[184] Cano-Raya C, Denchev ZZ, Cruz SF, Viana JC (2019) Chemistry of solid metal-based inks and pastes for printed electronics - a review. Appl Mater Today 15:416-430. h ttps://doi.org/10.1016/j.apmt.2019.02.012

[185] Calvert P (2001) Inkjet printing for materials and devices. Chem Mater 13:3299-3305. https://doi.org/10.1021/c m0101632

[186] de Gans B-J, Duineveld PC, Schubert US (2004) Inkjet printing of polymers: state of the art and future developments. Adv Mater 16:203-213. https://doi.org/10.1002/ad ma.200300385

[187] Singh M, Haverinen HM, Dhagat P, Jabbour GE (2010) inkjet printing-process and its applications. Adv Mater 22:673-685. https://doi.org/10.1002/adma.200901141

[188] Wu J, Wang R, Yu H et al (2015) Inkjet-printed microelectrodes on PDMS as biosensors for functionalized microfluidic systems. Lab Chip 15:690-695. https://doi.or g/10.1039/C4LC01121J

[189] Hutchings IM, Martin GD (2014) Introduction to inkjet printing for manufacturing. In: Hutchings IM, Martin GD (eds) Inkjet Technology for Digital Fabrication. Wiley, Chichester, UK, pp 1-20

[190] Derby B (2010) Inkjet printing of functional and structural materials: fluid property requirements, feature stability, and resolution. Annu Rev Mater Res 40:395-414. https://doi. org/10.1146/annurev-matsci-070909-104502 
[191] Minemawari H, Yamada T, Matsui H et al (2011) Inkjet printing of single-crystal films. Nature 475:364-367. http s://doi.org/10.1038/nature10313

[192] Li D, Sutton D, Burgess A et al (2009) Conductive copper and nickel lines via reactive inkjet printing. J Mater Chem 19:3719-3724. https://doi.org/10.1039/B820459D

[193] Smith PJ, Morrin A (2012) Reactive inkjet printing. J Mater Chem 22:10965-10970. https://doi.org/10.1039/ C2JM30649B

[194] Derby B, Reis N (2003) Inkjet printing of highly loaded particulate suspensions. MRS Bull 28:815-818. https://doi. org $/ 10.1557 / \mathrm{mrs} 2003.230$

[195] Deegan RD, Bakajin O, Dupont TF et al (1997) Capillary flow as the cause of ring stains from dried liquid drops. Nature 389:827-829. https://doi.org/10.1038/39827

[196] Ahn BY, Duoss EB, Motala MJ et al (2009) Omnidirectional printing of flexible, stretchable, and spanning silver microelectrodes. Science 323:1590-1593. https://doi.org/1 $0.1126 /$ science. 1168375

[197] Friederich A, Binder JR, Bauer W (2013) Rheological control of the coffee stain effect for inkjet printing of ceramics. J Am Ceram Soc 96:2093-2099. https://doi.org/ $10.1111 /$ jace. 12385

[198] Arias AC, MacKenzie JD, McCulloch I et al (2010) Materials and applications for large area electronics: solution-based approaches. Chem Rev 110:3-24. https://doi.or g/10.1021/cr900150b

[199] Ruiz C, García-Frutos EM, Hennrich G, Gómez-Lor B (2012) Organic semiconductors toward electronic devices: high mobility and easy processability. J Phys Chem Lett 3:1428-1436. https://doi.org/10.1021/jz300251u

[200] Wang C, Takei K, Takahashi T, Javey A (2013) Carbon nanotube electronics - moving forward. Chem Soc Rev 42:2592-2609. https://doi.org/10.1039/C2CS35325C

[201] Arapov K, Abbel R, de With G, Friedrich H (2014) Inkjet printing of graphene. Faraday Discuss 173:323-336. http s://doi.org/10.1039/C4FD00067F

[202] Finn DJ, Lotya M, Cunningham G et al (2014) Inkjet deposition of liquid-exfoliated graphene and MoS2 nanosheets for printed device applications. J Mater Chem C 2:925-932. https://doi.org/10.1039/C3TC31993H

[203] Capasso A, Del Rio Castillo AE, Sun H et al (2015) Ink-jet printing of graphene for flexible electronics: an environmentally-friendly approach. Solid State Commun 224:53-63. https://doi.org/10.1016/j.ssc.2015.08.011

[204] Tao H, Marelli B, Yang M et al (2015) Inkjet printing of regenerated silk fibroin: from printable forms to printable functions. Adv Mater 27:4273-4279. https://doi.org/ 10.1002/adma.201501425
[205] Stempien Z, Rybicki E, Rybicki T, Kozanecki M (2016) Reactive inkjet printing of PEDOT electroconductive layers on textile surfaces. Synth Met 217:276-287. https://doi.org/ 10.1016/j.synthmet.2016.04.014

[206] Kinkeldei T, Mattana G, Leuenberger D, et al (2013) Feasibility of printing woven humidity and temperature sensors for the integration into electronic textiles. In: Advances in Science and Technology. /AST.80.77. Accessed 5 Jul 2020

[207] La T-G, Qiu S, Scott DK et al (2018) Two-layered and stretchable e-textile patches for wearable healthcare electronics. Adv Healthcare Mater 7:1801033. https://doi.org/ 10.1002/adhm.201801033

[208] Shahrubudin N, Lee TC, Ramlan R (2019) An overview on $3 \mathrm{D}$ printing technology: technological, materials, and applications. Procedia Manuf 35:1286-1296. https://doi.or g/10.1016/j.promfg.2019.06.089

[209] Lemu HG (2012) Study of capabilities and limitations of 3D printing technology. AIP Conf Proc 1431:857-865. h ttps://doi.org/10.1063/1.4707644

[210] Tofail SAM, Koumoulos EP, Bandyopadhyay A et al (2018) Additive manufacturing: scientific and technological challenges, market uptake and opportunities. Mater Today 21:22-37. https://doi.org/10.1016/j.mattod.2017.07.001

[211] Redwood B, Schöffer F, Garret B (2017) The 3D printing handbook: Technologies, design and applications. 3D HUBS, Amsterdam

[212] Sun Z, Velásquez-García LF (2017) Monolithic FFF-printed, biocompatible, biodegradable, dielectric-conductive microsystems. J Microelectromech Syst 26:1356-1370. h ttps://doi.org/10.1109/JMEMS.2017.2746627

[213] Hlavaty DG, Ashtiani-Zarandi M (1998) Method for making an electrode for electrical discharge machining by use of a stereolithography model

[214] Czelusniak T, Amorim FL, Higa CF, Lohrengel A (2014) Development and application of new composite materials as EDM electrodes manufactured via selective laser sintering. Int J Adv Manuf Technol 72:1503-1512. https://doi. org/10.1007/s00170-014-5765-Z

[215] Dilag J, Chen T, Li S, Bateman SA (2019) Design and direct additive manufacturing of three-dimensional surface micro-structures using material jetting technologies. Addit Manuf 27:167-174. https://doi.org/10.1016/j.addma.2019. 01.009

[216] Azhari A, Marzbanrad E, Yilman D et al (2017) Binder-jet powder-bed additive manufacturing (3D printing) of thick graphene-based electrodes. Carbon 119:257-266. https://d oi.org/10.1016/j.carbon.2017.04.028

[217] Justin DF, Stucker BE, Gabbita DJR, Britt DW (2011) Laser based metal deposition (LBMD) of antimicrobials to implant surfaces 
[218] Hahnlen R, Dapino MJ (2010) Active metal-matrix composites with embedded smart materials by ultrasonic additive manufacturing. In: Industrial and Commercial Applications of Smart Structures Technologies 2010. International Society for Optics and Photonics, $\mathrm{p} 764500$

[219] Chen C, Mehl BT, Munshi AS et al (2016) 3D-printed microfluidic devices: fabrication, advantages and limitations - a mini review. Anal Methods 8:6005-6012. https://d oi.org/10.1039/C6AY01671E

[220] Ni Y, Ji R, Long K et al (2017) A review of 3D-printed sensors. Appl Spectrosc Rev 52:623-652. https://doi.org/ 10.1080/05704928.2017.1287082

[221] Wang Y, Chen C, Xie H et al (2017) 3D-printed all-fiber liion battery toward wearable energy storage. Adv Func Mater 27:1703140. https://doi.org/10.1002/adfm. 201703140

[222] Liu Y, Hamid Q, Snyder J et al (2016) Evaluating fabrication feasibility and biomedical application potential of in situ 3D printing technology. Rapid Prototy J 22:947-955. https://doi.org/10.1108/RPJ-07-2015-0090

[223] Bogue R (2013) 3D printing: the dawn of a new era in manufacturing? Assem Autom 33:307-311. https://doi.org/ 10.1108/AA-06-2013-055

[224] Isharya launches India's first 3D printed jewellery collection. In: Elle India. https://elle.in/article/isharya-3d-printedjewellery-collection/. Accessed 9 Jul 2020

[225] Dilberoglu UM, Gharehpapagh B, Yaman U, Dolen M (2017) The role of additive manufacturing in the era of industry 4.0. Procedia Manuf 11:545-554. https://doi.org/ 10.1016/j.promfg.2017.07.148

[226] Vanderploeg A, Lee S-E, Mamp M (2017) The application of $3 \mathrm{D}$ printing technology in the fashion industry. Int $\mathrm{J}$ Fash Des, Technol Educ 10:170-179. https://doi.org/10.1080/1 7543266.2016.1223355

[227] Cao W, Ma C, Mao D et al (2019) MXene-reinforced cellulose nanofibril inks for 3D-printed smart fibres and textiles. Adv Funct Mater 29:1905898. https://doi.org/10. 1002/adfm.201905898

[228] Zhao J, Zhang Y, Huang Y et al (2018) 3D printing fiber electrodes for an all-fiber integrated electronic device via hybridization of an asymmetric supercapacitor and a temperature sensor. Adv Sci 5:1801114. https://doi.org/10.100 2/advs.201801114

[229] Tadesse MG, Dumitrescu D, Loghin C et al (2018) 3D printing of NinjaFlex filament onto PEDOT:PSS-coated textile fabrics for electroluminescence applications. J Elec Mater 47:2082-2092. https://doi.org/10.1007/s11664-0176015-6

[230] Shahariar H, Kim I, Bhakta R, Jur J (2020) Direct-write printing process of conductive paste on fiber bulks for wearable textile heaters. Smart Mater Struct. https://doi.org/ 10.1088/1361-665X/ab8c25

[231] Torah R, Wei Y, Li Y et al (2015) Fully direct write dispenser printed sound emitting smart fabrics. Electron Lett. https://doi.org/10.1049/el.2015.0235

[232] Bhakta RP Direct-write printed wearable textile electronics. Ph.D., North Carolina State University

[233] Lewis JA (2006) Direct ink writing of 3D functional materials. Adv Funct Mater 16:2193-2204. https://doi.org/ 10.1002/adfm.200600434

[234] Mwema FM, Akinlabi ET (2020) Basics of Fused Deposition Modelling (FDM). In: Mwema FM, Akinlabi ET (eds) Fused Deposition Modeling: Strategies for Quality Enhancement. Springer International Publishing, Cham, pp 1-15

[235] Melnikova R, Ehrmann A, Finsterbusch K (2014) 3D printing of textile-based structures by Fused Deposition Modelling (FDM) with different polymer materials. IOP Conf Ser: Mater Sci Eng 62:012018. https://doi.org/10.10 88/1757-899X/62/1/012018

[236] Hashemi Sanatgar R, Campagne C, Nierstrasz V (2017) Investigation of the adhesion properties of direct $3 \mathrm{D}$ printing of polymers and nanocomposites on textiles: Effect of FDM printing process parameters. Appl Surf Sci 403:551-563. https://doi.org/10.1016/j.apsusc.2017.01.112

[237] Richter C, Schmülling S, Ehrmann A, Finsterbusch K (2015) FDM printing of 3D forms with embedded fibrous materials. Design Manufacturing and Mechatronics. World Scientific, Singapore, pp 961-969

[238] Bártolo PJ (2011) Stereolithographic Processes. In: Bártolo PJ (ed) Stereolithography: Materials, Processes and Applications. Springer, US, Boston, MA, pp 1-36

[239] Appuhamillage GA, Chartrain N, Meenakshisundaram V et al (2019) 110th anniversary: vat photopolymerizationbased additive manufacturing: current trends and future directions in materials design. Ind Eng Chem Res 58:15109-15118. https://doi.org/10.1021/acs.iecr.9b02679

[240] Fouassier J-P (1995) Photoinitiation, photopolymerization, and photocuring: fundamentals and applications. Distributed by Hanser/Gardner Publications, Munich; New York; Cincinnati, Hanser

[241] Grothe T, Brockhagen B, Storck JL (2020) Three-dimensional printing resin on different textile substrates using stereolithography: a proof of concept. J Eng Fibers Fabr 15:1558925020933440. https://doi.org/10.1177/ 1558925020933440

[242] Chakraborty S, Biswas MC (2020) 3D printing technology of polymer-fiber composites in textile and fashion industry: a potential roadmap of concept to consumer. Compos Struct 
248:112562. https://doi.org/10.1016/j.compstruct.2020. 112562

[243] Sitotaw DB, Ahrendt D, Kyosev Y, Kabish AK (2020) Additive manufacturing and textiles-state-of-the-art. Appl Sci 10:5033. https://doi.org/10.3390/app10155033

[244] Ojuroye O, Torah R, Beeby S, Wilde A (2017) Smart Textiles for Smart Home Control and Enriching Future Wireless Sensor Network Data. In: Postolache OA, Mukhopadhyay SC, Jayasundera KP, Swain AK (eds) Sensors for Everyday Life: Healthcare Settings. Springer International Publishing, Cham, pp 159-183

[245] Lin X, Seet B-C, Joseph F (2017) Wireless Sensing Systems for Body Area Networks. In: Postolache OA, Mukhopadhyay SC, Jayasundera KP, Swain AK (eds) Sensors for Everyday Life: Healthcare Settings. Springer International Publishing, Cham, pp 221-239

[246] Ahmed IS, Kamardin K, Yamada Y, et al (2019) IoT Enabled Wireless Health Monitoring System Using Textile Antenna. In: 2019 IEEE Asia-Pacific Conference on Applied Electromagnetics (APACE). pp 1-6

[247] Cochrane C, Hertleer C, Schwarz-Pfeiffer A (2016) 2 Smart textiles in health: An overview. In: Koncar V (ed) Smart Textiles and their Applications. Woodhead Publishing, Oxford, pp 9-32

[248] Postolache G, Carvalho H, Catarino A, Postolache OA (2017) Smart Clothes for Rehabilitation Context: Technical and Technological Issues. In: Postolache OA, Mukhopadhyay SC, Jayasundera KP, Swain AK (eds) Sensors for Everyday Life: Healthcare Settings. Springer International Publishing, Cham, pp 185-219

[249] Hatamie A, Angizi S, Kumar S et al (2020) Reviewtextile based chemical and physical sensors for healthcare monitoring. J Electrochem Soc 167:037546. https://doi.org/ 10.1149/1945-7111/ab6827

[250] Naït-Ali A, Karasinski P (2009) Biosignals: Acquisition and General Properties. In: Naït-Ali A (ed) Advanced Biosignal Processing. Springer, Berlin, Heidelberg, pp 1-13

[251] Hoi-Jun Yoo, Yoo J, Long Yan (2010) Wireless fabric patch sensors for wearable healthcare. In: 2010 Annual International Conference of the IEEE Engineering in Medicine and Biology. IEEE, Buenos Aires, pp 5254-5257

[252] Paul G, Torah R, Beeby S, Tudor J (2014) The development of screen printed conductive networks on textiles for biopotential monitoring applications. Sens Actuators, A 206:35-41. https://doi.org/10.1016/j.sna.2013.11.026

[253] Yokus MA, Jur JS (2016) Fabric-based wearable dry electrodes for body surface biopotential recording. IEEE Trans Biomed Eng 63:423-430. https://doi.org/10.1109/T BME.2015.2462312
[254] Paul G, Torah R, Beeby S, Tudor J (2017) A printed, dry electrode Frank configuration vest for ambulatory vectorcardiographic monitoring. Smart Mater Struct 26:025029. h ttps://doi.org/10.1088/1361-665X/aa5436

[255] Ankhili A, Tao X, Cochrane C et al (2018) Comparative study on conductive knitted fabric electrodes for long-term electrocardiography monitoring: silver-plated and PEDOT:PSS coated fabrics. Sensors (Basel). https://doi.org/10. 3390/s 18113890

[256] Hsu P-C, Shen C-L, Chen F-L, et al (2018) A printed physiological monitoring module in e-textile. In: 2018 International Flexible Electronics Technology Conference (IFETC). pp 1-2

[257] Lidón-Roger JV, Prats-Boluda G, Ye-Lin Y et al (2018) Textile concentric ring electrodes for ECG recording based on screen-printing technology. Sensors 18:300. https://doi. org/10.3390/s18010300

[258] Paiva A, Vieira D, Cunha J et al (2019) Design of a Smart Garment for Cycling. In: Machado J, Soares F, Veiga G (eds) Innovation, Engineering and Entrepreneurship. Springer International Publishing, Cham, pp 229-235

[259] Seoane F, Soroudi A, Lu K et al (2019) Textile-friendly interconnection between wearable measurement instrumentation and sensorized garments - initial performance evaluation for electrocardiogram recordings. Sensors 19:4426. https://doi.org/10.3390/s19204426

[260] Xu X, Luo M, He P, Yang J (2020) Washable and flexible screen printed graphene electrode on textiles for wearable healthcare monitoring. J Phys D: Appl Phys 53:125402. h ttps://doi.org/10.1088/1361-6463/ab5f4a

[261] Pani D, Achilli A, Bassareo PP, et al (2016) Fully-textile polymer-based ECG electrodes: Overcoming the limits of metal-based textiles. In: 2016 Computing in Cardiology Conference (CinC). pp 373-376

[262] Bihar E, Roberts T, Ismailova E et al (2017) Fully printed electrodes on stretchable textiles for long-term electrophysiology. Adv Mater Technol 2:1600251. https://doi.org/ 10.1002/admt.201600251

[263] Wei Y, Wu Y, Tudor J (2017) A real-time wearable emotion detection headband based on EEG measurement. Sens Actuators, A 263:614-621. https://doi.org/10.1016/j.sna.2 017.07 .012

[264] Matiko JW, Wei Y, Torah R et al (2015) Wearable EEG headband using printed electrodes and powered by energy harvesting for emotion monitoring in ambient assisted living. Smart Mater Struct 24:125028. https://doi.org/10.1088/ 0964-1726/24/12/125028

[265] Ahmed A, Hossain MM, Adak B, Mukhopadhyay S (2020) Recent advances in 2D MXene integrated smart-textile 
interfaces for multifunctional applications. Chem Mater. $\mathrm{h}$ ttps://doi.org/10.1021/acs.chemmater.0c03392

[266] Souri H, Banerjee H, Jusufi A et al (2020) Wearable and stretchable strain sensors: materials, sensing mechanisms, and applications. Adv Intell Syst 2:2000039. https://doi. org/10.1002/aisy.202000039

[267] Amjadi M, Kyung K-U, Park I, Sitti M (2016) Stretchable, skin-mountable, and wearable strain sensors and their potential applications: a review. Adv Func Mater 26:1678-1698. https://doi.org/10.1002/adfm.201504755

[268] Cullinan MA, Panas RM, DiBiasio CM, Culpepper ML (2012) Scaling electromechanical sensors down to the nanoscale. Sens Actuators, A 187:162-173. https://doi.org/ 10.1016/j.sna.2012.08.035

[269] Li R, Zhou Q, Bi Y et al (2020) Research progress of flexible capacitive pressure sensor for sensitivity enhancement approaches. Sens Actuators, A. https://doi.org/10.10 16/j.sna.2020.112425

[270] Stern S (2006) Electrocardiogram: still the cardiologist's best friend. Circulation. https://doi.org/10.1161/CIRCULA TIONAHA.106.623934

[271] Yang G-Z (2014) Body sensor networks, 2nd edn. Springer, London

[272] Sornmo L, Laguna P (2005) Bioelectrical signal processing in cardiac and neurological applications. Elsevier/Academic Press, Boston, Mass

[273] Zarzoso V (2009) Extraction of ECG Characteristics Using Source Separation Techniques: Exploiting Statistical Independence and Beyond. In: Naït-Ali A (ed) Advanced Biosignal Processing. Springer, Berlin, Heidelberg, pp 15-47

[274] Palaniswami M (2016) Healthcare Sensor Networks: Challenges Toward Practical Implementation. CRC Press, Florida

[275] Pani D, Achilli A, Bonfiglio A (2018) Survey on textile electrode technologies for electrocardiographic (ECG) monitoring, from metal wires to polymers. Adv Mater Technol 3:1800008. https://doi.org/10.1002/admt. 201800008

[276] Searle A, Kirkup L (2000) A direct comparison of wet, dry and insulating bioelectric recording electrodes. Physiol Meas 21:271-283. https://doi.org/10.1088/0967-3334/21/2/ 307

[277] Webster JG, Clark JW (2010) Medical instrumentation: application and design, 4th edn. John Wiley \& Sons, Hoboken, NJ

[278] Crawford J, Doherty L (2012) Practical aspects of ECG recording. M \& K Pub., Keswick

[279] Cavalcanti Garcia MA, Vieira TMM (2011) Surface electromyography: Why, when and how to use it. Rev Andal Med Deporte 4:17-28
[280] Moritani T, Stegeman D, Merletti R (2005) Basic Physiology and Biophysics of EMG Signal Generation. In: Merletti R, Parker P (eds) Electromyography. John Wiley \& Sons Inc, Hoboken, NJ, USA, pp 1-25

[281] Farina D, Lorrain T, Negro F, Jiang N (2010) High-density EMG E-Textile systems for the control of active prostheses. In: 2010 Annual International Conference of the IEEE Engineering in Medicine and Biology. IEEE, Buenos Aires, pp 3591-3593

[282] Castellini C, van der Smagt P (2009) Surface EMG in advanced hand prosthetics. Biol Cybern 100:35-47. http s://doi.org/10.1007/s00422-008-0278-1

[283] G Li Y Geng D Tao P Zhou (2011) Performance of electromyography recorded using textile electrodes in classifying arm movements Conference proceedings : Annual International Conference of the IEEE Engineering in Medicine and Biology Society IEEE Engineering in Medicine and Biology Society Conference $201142434246 \mathrm{~h}$ ttps://doi.org/10.1109/IEMBS.2011.6091053

[284] Guo J, Yu S, Li Y, et al (2018) A soft robotic exo-sheath using fabric EMG sensing for hand rehabilitation and assistance. In: 2018 IEEE International Conference on Soft Robotics (RoboSoft). pp 497-503

[285] Turker H, Sze H (2013) Surface electromyography in sports and exercise. In: Turker DrH (ed) Electrodiagnosis in New Frontiers of Clinical Research. InTech

[286] Al-Mulla MR, Sepulveda F, Colley M (2011) A review of non-invasive techniques to detect and predict localised muscle fatigue. Sensors 11:3545-3594. https://doi.org/10. 3390/s110403545

[287] Sumner B, Mancuso C, Paradiso R (2013) Performances evaluation of textile electrodes for EMG remote measurements. In: 2013 35th Annual International Conference of the IEEE Engineering in Medicine and Biology Society (EMBC). IEEE, Osaka, pp 6510-6513

[288] Niijima A, Isezaki T, Aoki R, et al (2017) hitoeCap: wearable EMG sensor for monitoring masticatory muscles with PEDOT-PSS textile electrodes. pp 215-220

[289] Pino EJ, Arias Y, Aqueveque P (2018) Wearable EMG Shirt for Upper Limb Training. 2018 40th Annual International Conference of the IEEE Engineering in Medicine and Biology Society (EMBC). IEEE, Honolulu, HI, pp 4406-4409

[290] Hua H, Tang W, Xu X et al (2019) Flexible multi-layer semi-dry electrode for scalp eeg measurements at hairy sites. Micromachines 10:518. https://doi.org/10.3390/ mi10080518

[291] Khalaf A, Sejdic E, Akcakaya M (2019) EEG-fTCD hybrid brain-computer interface using template matching and wavelet decomposition. J Neural Eng 16:036014. https://d oi.org/10.1088/1741-2552/ab0b7f 
[292] Sun Y, Lo FPW, Lo B (2019) EEG-based user identification system using 1D-convolutional long short-term memory neural networks. Expert Syst Appl. https://doi.org/10.1016/ j.eswa.2019.01.080

[293] Radhakrishnan JK, Nithila S, Kartik SN et al (2018) a novel, needle-array dry-electrode with stainless steel microtips, for electroencephalography monitoring. J Med Devices 12:041001. https://doi.org/10.1115/1.4041227

[294] Guger C, Edlinger G, Harkam W et al (2003) How many people are able to operate an eeg-based brain-computer interface (bci)? IEEE Trans Neural Syst Rehabil Eng 11:145-147. https://doi.org/10.1109/TNSRE.2003.814481

[295] Senhadji L, Ansari-Asl K, Wendling F (2009) From EEG Signals to Brain Connectivity: Methods and Applications in Epilepsy. In: Naït-Ali A (ed) Advanced Biosignal Processing. Springer, Berlin, Heidelberg, pp 145-164

[296] Kim J, Campbell AS, de Ávila BE-F, Wang J (2019) Wearable biosensors for healthcare monitoring. Nat Biotechnol 37:389-406. https://doi.org/10.1038/s41587-01 9-0045-y

[297] (2020) Skin in the diagnostics game: wearable biosensor nano- and microsystems for medical diagnostics. Nano Today 30: 100828. https://doi.org/10.1016/j.nantod.2019. 100828

[298] Santos JL, Farahi F (2015) Handbook of optical sensors. CRC Press, Boca Raton London New York

[299] Janata J (2009) Principles of chemical sensors, 2nd edn. Springer, Dordrecht, New York

[300] Luo X, Yu H, Cui Y (2018) A wearable amperometric biosensor on a cotton fabric for lactate. IEEE Electron Device Lett 39:123-126. https://doi.org/10.1109/LED.201 7.2777474

[301] Matzeu G, Mogas-Soldevila L, Li W et al (2020) Largescale patterning of reactive surfaces for wearable and environmentally deployable sensors. Adv Mater. https://doi. org/10.1002/adma.202001258

[302] Mena-Bravo A, Luque de Castro MD (2014) Sweat: a sample with limited present applications and promising future in metabolomics. J Pharm Biomed Anal 90:139-147. https://doi.org/10.1016/j.jpba.2013.10.048

[303] Bandodkar AJ, Wang J (2014) Non-invasive wearable electrochemical sensors: a review. Trends Biotechnol 32:363-371. https://doi.org/10.1016/j.tibtech.2014.04.005

[304] Jadoon S, Karim S, Akram MR et al (2015) Recent developments in sweat analysis and its applications. Int J Anal Chem 2015:1-7. https://doi.org/10.1155/2015/164974

[305] Zhou Y, Han H, Naw HPP et al (2016) Real-time colorimetric hydration sensor for sport activities. Mater Des 90:1181-1185. https://doi.org/10.1016/j.matdes.2015.06. 078
[306] Toh HS, Batchelor-McAuley C, Tschulik K, Compton RG (2013) Electrochemical detection of chloride levels in sweat using silver nanoparticles: a basis for the preliminary screening for cystic fibrosis. Analyst 138:4292. https://doi. org/10.1039/c3an00843f

[307] Wujcik EK, Blasdel NJ, Trowbridge D, Monty CN (2013) Ion sensor for the quantification of sodium in sweat samples. IEEE Sensors J 13:3430-3436. https://doi.org/10.110 9/JSEN.2013.2257168

[308] Coyle S, Morris D, Lau K-T, et al (2009) Textile sensors to measure sweat $\mathrm{pH}$ and sweat-rate during exercise. In: 2009 3rd International Conference on Pervasive Computing Technologies for Healthcare. pp 1-6

[309] Promphet N, Rattanawaleedirojn P, Siralertmukul K et al (2019) Non-invasive textile based colorimetric sensor for the simultaneous detection of sweat $\mathrm{pH}$ and lactate. Talanta 192:424-430. https://doi.org/10.1016/j.talanta.2018.09.086

[310] Parrilla M, Cánovas R, Jeerapan I et al (2016) A textilebased stretchable multi-ion potentiometric sensor. Adv Healthcare Mater 5:996-1001. https://doi.org/10.1002/adh m.201600092

[311] Venkatraman PD, Velusamy V, Kharel R, Collins S (2016) Smart wearable biosensor for non-invasive real time detection of sweat lactate using compression garments. Textile Institute

[312] Merilampi S, Han He, Sydänheimo L, et al (2016) The possibilities of passive UHF RFID textile tags as comfortable wearable sweat rate sensors. In: 2016 Progress in Electromagnetic Research Symposium (PIERS). pp 3984-3987

[313] Kinnamon DS, Krishnan S, Brosler S et al (2018) Screen printed graphene oxide textile biosensor for applications in inexpensive and wearable point-of-exposure detection of influenza for at-risk populations. $\mathrm{J}$ Electrochem Soc 165:B3084. https://doi.org/10.1149/2.0131808jes

[314] Manjakkal L, Dang W, Yogeswaran N, Dahiya R (2019) Textile-based potentiometric electrochemical $\mathrm{pH}$ sensor for wearable applications. Biosensors 9:14. https://doi.org/10. 3390/bios9010014

[315] Yang Y-L, Chuang M-C, Lou S-L, Wang J (2010) Thickfilm textile-based amperometric sensors and biosensors. Analyst 135:1230. https://doi.org/10.1039/b926339j

[316] Li Q, Zhang L, Tao X, Ding X (2017) Review of flexible temperature sensing networks for wearable physiological monitoring. Adv Healthcare Mater 6:1601371. https://doi. org/10.1002/adhm.201601371

[317] Fuketa H, Hamamatsu M, Yokota T et al (2015) Energyautonomous fever alarm armband integrating fully flexible solar cells, piezoelectric speaker, temperature detector, and $12 \mathrm{~V}$ organic complementary FET circuits. 2015 IEEE 
International Solid-State Circuits Conference - (ISSCC) Digest of Technical Papers. IEEE, San Francisco, CA, USA, pp 1-3

[318] Hagberg K, Brånemark R (2001) Consequences of nonvascular trans-femoral amputation: a survey of quality of life, prosthetic use and problems. Prosthet Orthot Int 25:186-194. https://doi.org/10.1080/03093640108726601

[319] Wade AJ, Broadhead MW, Cady EB et al (2000) Influence of muscle temperature during fatiguing work with the first dorsal interosseous muscle in man: a $31 \mathrm{P}-\mathrm{NMR}$ spectroscopy study. Eur J Appl Physiol 81:203-209. https://doi. org/10.1007/s004210050031

[320] Smith CJ, Havenith G (2012) Body mapping of sweating patterns in athletes: a sex comparison. Med Sci Sports Exerc 44:2350-2361. https://doi.org/10.1249/MSS.0b013e $318267 \mathrm{~b} 0 \mathrm{c} 4$

[321] Trung TQ, Lee N-E (2017) Recent progress on stretchable electronic devices with intrinsically stretchable components. Adv Mater 29:1603167. https://doi.org/10.1002/ad ma.201603167

[322] Trung TQ, Lee N-E (2017) Materials and devices for transparent stretchable electronics. J Mater Chem C 5:2202-2222. https://doi.org/10.1039/C6TC05346G

[323] Nakagami G, Sanada H, Iizaka S et al (2010) Predicting delayed pressure ulcer healing using thermography: a prospective cohort study. J Wound Care 19(11):465-472

[324] Martín-Vaquero J, Hernández Encinas A, Queiruga-Dios A et al (2019) Review on wearables to monitor foot temperature in diabetic patients. Sensors (Basel). https://doi.org/ 10.3390/s19040776

[325] Khan S, Ali S, Bermak A (2019) Recent developments in printing flexible and wearable sensing electronics for healthcare applications. Sensors 19:1230. https://doi.org/10. 3390/s19051230

[326] Salazar-López E, Domínguez E, Ramos VJ et al (2015) The mental and subjective skin: emotion, empathy, feelings and thermography. Conscious Cogn: Int J 34:149-162. https://d oi.org/10.1016/j.concog.2015.04.003

[327] Khan S, Nguyen TP, Thiery L et al (2017) Aerosol jet printing of miniaturized. Low Power Flex Micro-Hotplates Proc 1:316. https://doi.org/10.3390/proceedings1040316

[328] Chen W, Dols S, Oetomo SB, Feijs L (2010) Monitoring body temperature of newborn infants at neonatal intensive care units using wearable sensors. In: Proceedings of the Fifth International Conference on Body Area Networks BodyNets '10. ACM Press, Corfu, Greece, p 188

[329] Wang Y, Ashktorab M, Chang H-I et al (2017) Wearable Motion Sensing Devices and Algorithms for Precise Healthcare Diagnostics and Guidance. In: Rehg JM, Murphy SA, Kumar S (eds) Mobile Health: Sensors, Analytic
Methods, and Applications. Springer International Publishing, Cham, pp 203-218

[330] Dobkin BH, Dorsch A (2011) The promise of mhealth: daily activity monitoring and outcome assessments by wearable sensors. Neurorehabil Neural Repair 25:788-798. https://doi.org/10.1177/1545968311425908

[331] Takacs J, Pollock C, Guenther J et al (2013) Validation of the Fitbit One activity monitor device during treadmill walking. J sci med sport / Sports Med Austr. https://doi.org/ 10.1016/j.jsams.2013.10.241

[332] Guo F, Li Y, Kankanhalli MS, Brown MS (2013) An evaluation of wearable activity monitoring devices. In: Proceedings of the 1st ACM international workshop on Personal data meets distributed multimedia - PDM '13. ACM Press, Barcelona, Spain, pp 31-34

[333] Fulk GD, Combs SA, Danks KA et al (2014) Accuracy of 2 activity monitors in detecting steps in people with stroke and traumatic brain injury. Phys Ther 94:222-229. https://d oi.org/10.2522/ptj.20120525

[334] Chung P-C, Hsu Y-L, Wang C-Y et al (2012) Gait analysis for patients with Alzheimer'S disease using a triaxial accelerometer. 2012 IEEE International Symposium on Circuits and Systems. IEEE, Seoul, Korea (South), pp 1323-1326

[335] Zampieri C, Salarian A, Carlson-Kuhta P et al (2011) Assessing mobility at home in people with early Parkinson's disease using an instrumented timed up and go test. Parkinsonism Relat Disord 17:277-280. https://doi.org/10. 1016/j.parkreldis.2010.08.001

[336] Morillo DS, Ojeda JLR, Foix LFC, Jimenez AL (2010) An accelerometer-based device for sleep apnea screening. IEEE Trans Inform Technol Biomed 14:491-499. https://d oi.org/10.1109/TITB.2009.2027231

[337] Geoff Appelboom BTB (2014) Motion sensors to assess and monitor medical and surgical management of parkinson's disease. Int J Phys Med Rehabil. https://doi.org/10. 4172/2329-9096.1000221

[338] Homayounfar SZ, Andrew TL (2020) Wearable sensors for monitoring human motion: a review on mechanisms, materials, and challenges. SLAS Technol: Trans Life Sci Innov 25:9-24. https://doi.org/10.1177/2472630319891128

[339] Lu T-H, Lin H-C, Chen R-R, Chen Y-L (2013) Motionsensing based management system for smart contextawareness rehabilitation healthcare. https://doi.org/10.423 6/ait.2013.32A001

[340] Wei Y, Torah R, Yang K et al (2013) Screen printing of a capacitive cantilever-based motion sensor on fabric using a novel sacrificial layer process for smart fabric applications. Meas Sci Technol 24:075104. https://doi.org/10.1088/095 7-0233/24/7/075104 
[341] Wei Y, Torah R, Yang K et al (2013) A screen printable sacrificial fabrication process to realise a cantilever on fabric using a piezoelectric layer to detect motion for wearable applications. Sens Actuators, A 203:241-248. h ttps://doi.org/10.1016/j.sna.2013.08.041

[342] Åkerfeldt M, Lund A, Walkenström P (2015) Textile sensing glove with piezoelectric PVDF fibers and printed electrodes of PEDOT:PSS. Text Res J 85:1789-1799. h ttps://doi.org/10.1177/0040517515578333

[343] Yang K, Meadmore K, Freeman C et al (2018) Development of user-friendly wearable electronic textiles for healthcare applications. Sensors 18:2410. https://doi.org/10. 3390/s 18082410

[344] McLaren R, Joseph F, Baguley C, Taylor D (2016) A review of e-textiles in neurological rehabilitation: How close are we? J NeuroEng Rehabil 13:59. https://doi.org/10. 1186/s12984-016-0167-0

[345] Yang K, Freeman C, Torah R et al (2014) Screen printed fabric electrode array for wearable functional electrical stimulation. Sens Actuators, A 213:108-115. https://doi.or g/10.1016/j.sna.2014.03.025

[346] Hunter L, Fan J, Chau D (2009) 5 - Fabric and garment drape. In: Fan J, Hunter L (eds) Engineering Apparel Fabrics and Garments. Woodhead Publishing, Netherlands, pp 102-130

[347] Wang J, Lu C, Zhang K (2020) Textile-based strain sensor for human motion detection. Energy Environ Mater 3:80-100. https://doi.org/10.1002/eem2.12041

[348] Coyle S, Lau K, Moyna N et al (2010) BIOTEXbiosensing textiles for personalised healthcare management. IEEE Trans Inf Technol Biomed 14:364-370. http s://doi.org/10.1109/TITB.2009.2038484

[349] Lisak G, Arnebrant T, Ruzgas T, Bobacka J (2015) Textilebased sampling for potentiometric determination of ions. Anal Chim Acta 877:71-79. https://doi.org/10.1016/j.aca. 2015.03.045

[350] He T, Wang H, Wang J et al (2019) Self-sustainable wearable textile nano-energy nano-system (NENS) for next-generation healthcare applications. Adv Sci 6:1901437. https://doi.org/10.1002/advs.201901437

[351] Huang S, Liu Y, Zhao Y et al (2019) Flexible electronics: stretchable electrodes and their future. Adv Func Mater 29:1805924. https://doi.org/10.1002/adfm.201805924

[352] Ahmed A, Jalil MA, Hossain MM et al (2020) A PEDOT:PSS and graphene-clad smart textile-based wearable electronic Joule heater with high thermal stability. J Mater Chem C 8:16204-16215. https://doi.org/10.1039/ D0TC03368E

[353] Khair N, Islam R, Shahariar H (2019) Carbon-based electronic textiles: materials, fabrication processes and applications. J Mater Sci 54:10079-10101. https://doi.org/ 10.1007/s10853-019-03464-1

[354] Liu L, Chen W, Zhang H et al (2019) Flexible and multifunctional silk textiles with biomimetic leaf-like MXene/ silver nanowire nanostructures for electromagnetic interference shielding, humidity monitoring, and self-derived hydrophobicity. Adv Funct Mater 29:1905197. https://doi. org/10.1002/adfm.201905197

[355] Mhetre S, Carr W, Radhakrishnaiah P (2010) On the relationship between ink-jet printing quality of pigment ink and the spreading behavior of ink drops. J Text Inst 101:423-430. https://doi.org/10.1080/00405000802449984

[356] Chauraya A, Whittow WG, Vardaxoglou JC et al (2013) Inkjet printed dipole antennas on textiles for wearable communications. IET Microwav Antennas Propag 7:760-767. https://doi.org/10.1049/iet-map.2013.0076

[357] Oliveira CC, Machado da Silva J, Trindade IG, Martins F (2014) Characterization of the electrode-skin impedance of textile electrodes. In: Design of Circuits and Integrated Systems. pp 1-6

[358] Lee WJ, Park JY, Nam HJ, Choa S (2018) Highly Stretchable, Durable, and Printable Textile Conductor. In: 2018 IEEE 20th Electronics Packaging Technology Conference (EPTC). pp 789-792

[359] Lee WJ, Park JY, Nam HJ, Choa S-H (2019) The development of a highly stretchable, durable, and printable textile electrode. Text Res J 89:4104-4113. https://doi.org/10. 1177/0040517519828992

[360] Menni C, Valdes AM, Freidin MB et al (2020) Real-time tracking of self-reported symptoms to predict potential COVID-19. Nat Med 26:1037-1040. https://doi.org/10.10 38/s41591-020-0916-2

[361] Demeke Teklemariam A, Samaddar M, Alharbi MG et al (2020) Biosensor and molecular-based methods for the detection of human coronaviruses: a review. Mol Cell Probes 54:101662. https://doi.org/10.1016/j.mcp.2020. 101662

[362] Roudjane M, Bellemare-Rousseau S, Drouin E et al (2020) Smart T-shirt based on wireless communication spiral fiber sensor array for real-time breath monitoring: validation of the technology. IEEE Sens J 20:10841-10850. https://doi. org/10.1109/JSEN.2020.2993286

[363] Roy K, Ghosh SK, Sultana A et al (2019) A self-powered wearable pressure sensor and pyroelectric breathing sensor based on GO interfaced PVDF nanofibers. ACS Appl Nano Mater 2:2013-2025. https://doi.org/10.1021/acsanm.9b00033

Publisher's Note Springer Nature remains neutral with regard to jurisdictional claims in published maps and institutional affiliations. 